\title{
Information technology, organizational design, and transfer pricing*
}

\author{
Shane S. Dikolli \\ The University of Texas at Austin \\ McCombs School of Business \\ CBA 4M.202 \\ Austin, TX 78712-0211 \\ USA
}

\author{
Igor Vaysman** \\ INSEAD \\ Accounting and Control \\ Boulevard de Constance, \\ 77305 Fontainebleau Cedex, \\ France
}

August, 2005

\begin{abstract}
We show how information technology affects transfer pricing. With constrained information technology, negotiated transfer pricing has an informational advantage: managers agree to prices that approximate the firm's cost of internal trade more precisely than cost-based transfer prices. With sufficiently rapid offers, this advantage outweighs opportunity costs of managers' bargaining time, and negotiated transfer pricing generates higher profits than the cost-based method. However, as information technology improves, the informational advantage diminishes; the opportunity costs of managers' bargaining eventually dominate, and cost-based methods generate higher profits. Our results explain why firms generally prefer cost-based methods, and when negotiated methods are preferable.
\end{abstract}

Keywords: Cost-based transfer pricing; Negotiated transfer pricing; Bargaining; Decentralization. JEL Classification: C72; D82; L23; M41.

\footnotetext{
*We thank Tim Baldenius, Robert Göx, Lynda Thoman, Donna Wei, Jerry Zimmerman, an anonymous referee and workshop participants at INSEAD, London Business School, and the AAA Management Accounting Section Conference for helpful comments.

** Corresponding author: Voice, +33 (0) 16469 4399; Fax, +33 (0) 16422 7731;Email, igor.vaysman@insead.edu
} 


\section{Introduction}

In the absence of competitive markets for internally traded products and services, why do some firms base transfer prices on internal costs and others allow managers to negotiate prices? ${ }^{1}$ Allowing managers to bargain over transfer prices has several drawbacks: the time that managers spend bargaining is lost to other productive activities; if negotiations take too long, the firm may miss some market opportunities; and if haggling leads to ill-will between managers, the firm may suffer from sub-optimal decisions and conflict (see Brickley, et al., 2004; Kaplan and Atkinson, 1998; Simons, 2000). Faced with these issues, why do firms ever let managers bargain over transfer prices? And what economic characteristics predict the preferred pricing method?

In any large firm, local managers have private information - superior knowledge of local conditions, business processes, and potential cash flows. Other parties in the firm rely on local managers' reports, but there are two important problems with this. First, a local manager may distort information; if truthful reports are desired, top management must provide appropriate incentives. Second, transferring local knowledge may be costly - it may be difficult or impossible for the local manager to fully describe the precise links between local information, the multitude of local decisions, all of the available alternatives, and the potential cash flows. And it may be difficult or impossible for other parties in the firm to quickly understand and act upon the local manager's reports. We show that it is the ability to communicate knowledge to top managers and others that is a key factor determining the preferred transfer-pricing method. Specifically, the more difficult it is to transfer the local knowledge of the supplying division, the more attractive is negotiated pricing.

The costs of transferring local knowledge to top managers and others vary widely across divisions, across firms, and over time. A number of factors influence these costs: the nature and complexity of local knowledge; the cultural, educational, and on-the-job training backgrounds of divisional and top managers; the necessity for rapid responses to changes in local conditions; the firm's size; the technology for communicating local information; and the geographic reach of the firm (Brickley, et al., 2004; Christie, et al., 2003; Demsetz, 1988; Jensen and Meckling, 1992).

\footnotetext{
${ }^{1}$ Practitioners and academics recognize the importance of transfer pricing. A survey reports $73 \%$ of managers think it important to price internal transfers to maximize operating performance (Ernst \& Young, 1999). Negotiated and cost-based methods are common in practice (Atkinson, 1987; Price Waterhouse, 1984; Tang, 1993). Hirshleifer (1956), Edlin and Reichelstein (1995), Baldenius, et al. (1999), and Vaysman (1996; 1998) analytically establish the contracting benefits of transfer pricing in various economic environments.
} 
We use the term "information-technology (IT) constraints" to describe the limitations of the firm's formal and informal information systems when transferring local divisional knowledge to top managers. ${ }^{2}$ This describes a continuum: in the extreme "IT-unconstrained" case, it is possible for the local manager to quickly and costlessly report on everything of local economic relevance (top managers must still provide truth-telling incentives if they desire truthful reports); at the other extreme, IT constraints are so severe that the local manager cannot provide any relevant reports whatsoever (reporting incentives are then not an issue). Of course, neither extreme is realistic: all firms rely on divisional reports, yet no reporting technology fully communicates everything about local conditions.

In the extreme "IT-unconstrained" case, cost-based transfer pricing works well. Divisional managers are given contracts that provide them incentives for truthful reporting (this, of course, costs the firm but cannot be avoided). Top management then receives all the relevant information about the supplying division, computes the relevant outlay and opportunity costs of internal trade, and sets the price equal to the total relevant cost. The buying division's internal-ordering decision is then optimal from the firm's point of view; but since top managers could simply impose this internal-ordering decision, it is not clear why the firm is organized into profit centers in the first place. Constrained IT provides an answer: if it is not possible to communicate all the relevant local information, two profit centers and cost-based transfer pricing guarantee superior decisions (Vaysman, 1996).

But, if IT constraints prevent local managers from fully and quickly reporting on everything of relevance to local cash flows, top management must rely on a concise but incomplete estimate of the supplying division's costs to optimally set the cost-based transfer price. Even with contractual incentives for truthful reporting, top management cannot get all the relevant information necessary to compute the relevant cost of internal trade. At best, the cost-based transfer price is set to equal top managers' estimate of the relevant cost (given their necessarily incomplete information). In Section 3 of the paper, we show that, since this cost estimate is by necessity sometimes too high and sometimes too low, the buying division's internal-ordering decision is suboptimal.

On the other hand, when divisional managers bargain over the transfer price (and thus, effectively,

\footnotetext{
${ }^{2}$ Low IT constraints characterize a local division with low costs of transferring knowledge to top management; high IT constraints - a division with high knowledge-transfer costs. Jensen and Meckling (1992) describe this continuum as "general" vs. "specific" knowledge. Demsetz (1988) and Christie, et al. (2003) use the terms "nonspecialized" and "specialized" knowledge.
} 
over whether to trade internally), top management can use divisional-profit-based compensation to ensure that the managers come to a price agreement only if it is in the firm's interest to transfer internally. The internal-trade decision thus incorporates the managers' local information better than under cost-based pricing. This is the informational advantage of the negotiated method. We compare this advantage with the organizational and opportunity costs the firm faces from managers' bargaining. ${ }^{3}$ To capture these costs, we use a multi-period offer-counteroffer bargaining model. We show that top management can use compensation schemes and bargaining rules to guarantee that divisional managers agree on a transfer price quickly. Negotiated transfer pricing is then superior to the cost-based method when offers and responses happen rapidly (this is formalized in Theorems 2 and 4).

We also consider the implications of improvements in a firm's knowledge-transfer systems. As IT improves, expected profits increase under both methods. But they increase faster with cost-based pricing: IT improvements enhance the supplying manager's ability to communicate local knowledge and, consequently, top management's ability to set transfer prices that approximate the relevant costs of internal trade. The informational advantage of the negotiated method decreases with IT improvements, and is eventually outweighed by the opportunity and organizational costs of managers' bargaining. Thus, with sufficiently unconstrained IT, the cost-based method generates higher profits than negotiated transfer pricing; we document this in Theorem 3.

An important caveat is that our study does not address two important practical issues. First, to simplify the analysis, we do not consider the effect of taxes on transfer-pricing method choice. Income taxes, tariffs, and domestic content laws influence a firm's transfer-price decisions, while national tax laws and international treaties constrain the firm's choices. ${ }^{4}$ Our results apply directly to situations where the tax effects are not an overriding consideration for internal trade, either because the trade does not cross tax

\footnotetext{
${ }^{3}$ Two papers compare negotiated with cost-based pricing schemes without explicitly considering opportunity costs of bargaining: Baldenius, et al. (1999) study the setting with symmetric information, and Baldenius (2000) with asymmetric information. They represent price negotiations by a static surplus-sharing rule and focus on specific investments and the hold-up problem as the key incentive issues under incomplete contracting. By contrast, we use dynamic bilateral bargaining to represent negotiations, allowing us to focus on bargaining time as an important organizational variable and to trade off the opportunity costs of the time spent bargaining against the informational advantage of the negotiated method.

${ }^{4}$ The taxation literature studies several related issues: (i) the impact of tax rates and regulations on production, location, and pricing decisions (Copithorne, 1971; Halperin and Srinidhi, 1987; Harris and Sansing, 1998; Horst, 1971; Samuelson, 1982); (ii) incentives to make investments in incomplete-contract settings (Sansing, 1999; Smith, 2002); (iii) computations of optimal transfer prices as functions of different tax rates (Baldenius, et al., 2003; Narayanan and Smith, 2000). In contrast, we focus on the incentive, coordination, and performance-evaluation objectives of transfer prices.
} 
jurisdictions, or because the firm maintains a system of transfer prices for performance evaluation separately from tax transfer prices (see Ernst \& Young, 1999; Springsteel, 1999). Where tax effects are important, our model can be extended to include these effects, along the lines of Baldenius et al. (2003).

Second, when a firm is implementing a cost-based pricing system, divisional managers may expend time and effort attempting to influence the system's design. But, as is typical in standard models of mechanism design with private information, it is optimal for the top management to disallow any influence activities by proposing the cost-based system to the managers in a "take-it-or-leave-it" fashion. Our analysis of optimal contracting under cost-based pricing thus does not admit the possibility that there are opportunity costs of managerial time from system-design-stage influence activities.

\section{The model}

\subsection{Basic model with unconstrained information technology}

The firm consists of headquarters (HQ) and two divisions: production and marketing. HQ represents the firm's risk-neutral owners. Manager 1's production division manufactures an intermediate product that serves as the input to Manager 2's marketing division; the product is not available in any outside market. The marketing division finishes and sells the product, earning revenues for the firm (net of any marketing division costs). For simplicity, the quantity $q$ of the intermediate product is either zero or one - the relationship between divisions is one of procurement. ${ }^{5}$

Each risk-neutral manager has a wealth of local knowledge relevant for the decisions that affect divisional cash flows. Much of each manager's relevant local knowledge is private. ${ }^{6}$ We use a standard technique for representing informational asymmetry in firms: we condense all of manager $i$ 's private knowledge into a single private-information variable $\theta_{i}$, for $i \in\{1,2\}$. The set of possible realizations of

\footnotetext{
${ }^{5}$ We use the procurement scenario, with $q$ equal to zero or one, for simplicity. The model can be extended to incorporate multiple quantity levels, with similar results about preferred transfer-pricing methods. The key differences are: (i) the optimal cost-based transfer price is a function of quantity (it is still a marginal-cost plus a markup price); and (ii) the bargaining procedure under negotiated pricing has two stages: the firm requires the managers to first bargain over the quantity, and then to bargain over the price (as suggested by Brickley, et al., 2004). Even in the procurement setting, unless divisional managers can communicate all of their local knowledge to the firm's HQ freely and instantaneously, divisional structure and delegation of decisions to managers provide the firm higher profits than a single HQ-managed responsibility center.

${ }^{6}$ Local decisions include scheduling, procurement, quality control, human-resource management, advertising, and distribution. Some examples of relevant local knowledge, for the production division, include input prices; wages; the tradeoffs inherent in product design; knowledge of current and replacement production technologies; employee-satisfaction levels; knowledge of product and process engineering; quality and reliability of local suppliers; and alternative uses of various constrained resources. For the marketing division, examples include knowledge of various markets, channels, and customers; current demand conditions; competitors' products and prices; and the competitive dynamics of the product market.
} 
this manager's private information is $\Theta_{i}=\left[\underline{\theta}_{i}, \bar{\theta}_{i}\right]$, with lower realizations of private information (e.g. low product-defect rates in the production division) representing "good news" about divisional environment.

The private-information variables are independent. The probability distribution function of $\theta_{i}-F_{i}\left(\theta_{i}\right)$ - is common knowledge and has a continuous density function $f_{i}\left(\theta_{i}\right)$. Analyses of contracting and organizational design with private information rely on a standard assumption about the distribution of private information: the risk ratio $\left[F_{i}\left(\theta_{i}\right) / f_{i}\left(\theta_{i}\right)\right]$ is increasing in $\theta_{i}$. This condition holds for most standard distribution functions (such as the uniform, normal, chi-squared, and exponential). It guarantees that the efficient divisional operations in (2) and (3) are monotone in the manager's private information; this, in turn, allows the replacement of the global incentive constraints by local incentive constraints in the HQ's profit maximization program.

After learning private information, each divisional manager makes decisions and takes actions affecting the firm's cash flows. Many of these decisions are potential sources of conflict with HQ (two examples are: a manager's choice of effort, valuable to the firm but costly to the manager; and consumption of perquisites, valued by a manager but costly to the firm). It is standard to convert incentive problems with unobservable actions and private information into economically equivalent pure-privateinformation representations by eliminating the action variables (see footnote 7 below for an illustration of this conversion; Demski and Sappington, 1984 and Guesnerie and Laffont, 1984 document the equivalence of the two representations).

With the pure-private-information representation, the productive parameter $z_{i} \in Z_{i} \subset \mathbb{R}^{+}$represents manager $i$ 's operating decisions that are valuable to the firm but costly to the manager, as follows: the firm's cost $C\left(q, z_{1}\right)$ is strictly decreasing in $z_{1}$; revenue $R\left(q, z_{2}\right)$ is strictly increasing in $z_{2}$; but manager $i$ 's personal cost function $V_{i}\left(z_{i}, \theta_{i}\right)$ is strictly increasing in $z_{i}$. Productive parameters thus capture the effects of both private information and unobservable actions on the firm's cash flows. ${ }^{7}$ For simplicity, we assume that

\footnotetext{
${ }^{7}$ This pure-private-information model with personal costs as functions of private information and productive parameters is a convenient representation of an economic setting where managers have private information and take unobservable actions (either must supply personally costly effort or consume slack). To illustrate, suppose the production manager can reduce the production division's cost with unobservable effort $a$ at a personal cost $a^{2}$. If the production division's cost - a function of private information and effort - equals $\left[\theta_{1} / a\right]^{n}$, this private-information-and-effort situation can be converted to the pureprivate-information one of this paper by eliminating the effort variable as follows. Set $z_{1}=\left[\theta_{1} / a\right]$ and treat $z_{1}$ as the variable of analysis, with $C\left(1, z_{1}\right)=\left[z_{1}\right]^{n}$ and $V_{1}\left(z_{1}, \theta_{1}\right)=\left[\theta_{1} / z_{1}\right]^{2}$. The two representations are economically equivalent; the pure-privateinformation one is more convenient to analyze.
} 
the personal-cost functions are multiplicatively separable in strictly increasing differentiable functions of the productive parameter and private information (this does not affect the main results):

$$
V_{i}\left(z_{i}, \theta_{i}\right)=b_{i}\left(z_{i}\right) v_{i}\left(\theta_{i}\right) \text { for } i \in\{1,2\} .
$$

We use $x_{i}$ to represent manager $i$ 's compensation. Each manager is free to quit after learning private information; compensation must then be high enough to assure that the manager's expected utility exceeds a reservation level, normalized to zero. We impose enough structure on the cost and revenue functions to assure that the firm's problem has a well-defined solution. ${ }^{8}$

We focus on the incremental impact of internal trade and thus, normalize to zero divisional cash flows when no internal trade takes place: $C\left(0, z_{1}\right)=R\left(0, z_{2}\right)=0$ for all $z_{1}, z_{2}$. The cost function captures all costs incremental with respect to the transfer decision. The issue of full-cost versus marginal-cost pricing thus does not arise in our model - full costs and marginal costs are the same.

So far, in this standard asymmetric-information model of the firm, there are no constraints on: (i) the managers' abilities to communicate all local knowledge to HQ costlessly and instantaneously, and (ii) HQ's ability to completely understand and act upon this knowledge costlessly and instantaneously. The Revelation Principle then implies that there is no value to decentralization, divisional structure, transfer pricing, or divisional performance evaluation. HQ maximizes the value of the firm by asking divisional managers for their local information, providing them contractual incentives to reveal that information truthfully, and then making all the decisions about the firm's operations. To convince each manager to reveal private information truthfully, HQ must pay a premium above the manager's reservation wage. This compensation premium is known as informational rent; it reduces the firm's profits relative to the first-best setting without private information.

In the second-best setting with private information but without IT constraints, HQ's expected payment to each manager equals $E_{\Theta_{i}}\left[b_{i}\left(z_{i}\right) h_{i}\left(\theta_{i}\right)\right]$, where $h_{i}\left(\theta_{i}\right) \equiv\left[v_{i}\left(\theta_{i}\right)+\frac{F_{i}\left(\theta_{i}\right)}{f_{i}\left(\theta_{i}\right)} v_{i}^{\prime}\left(\theta_{i}\right)\right]$; note that this exceeds the manager's expected personal cost $E_{\Theta_{i}}\left[b_{i}\left(z_{i}\right) v_{i}\left(\theta_{i}\right)\right] .{ }^{9}$ We use the term pre-transfer cost to

\footnotetext{
${ }^{8}$ For this, it is sufficient that (i) $\left[C\left(1, z_{1}\right)+V_{1}\left(z_{1}, \theta_{1}\right)\right]$ is strictly convex in $z_{1}$; and (ii) $\left[R\left(1, z_{2}\right)-V_{2}\left(z_{2}, \theta_{2}\right)\right]$ is strictly concave in $z_{2}$.

${ }^{9} E_{S}[\cdot]$ is the expectations operator over the set $S$. For details on computing informational rents and solving standard privateinformation contracting problems, see Fudenberg and Tirole (1991). Note that Fudenberg and Tirole (1991), among others, refer to $\left[b_{i}\left(z_{i}\right) h_{i}\left(\theta_{i}\right)\right.$ ] (capturing the manager's personal cost $b_{i}\left(z_{i}\right) v_{i}\left(\theta_{i}\right)$ and informational rent) as virtual cost. We refer to this as manager's compensation, to clearly distinguish this term from the production division's costs.
} 
refer to the firm's relevant costs in the production division: the sum of production costs $C\left(1, z_{1}\right)$ and the production manager's compensation $b_{1}\left(z_{1}\right) h_{1}\left(\theta_{1}\right)$. We use post-transfer net revenues to refer to the difference between the marketing division's revenues $R\left(1, z_{2}\right)$ and the marketing manager's compensation $b_{2}\left(z_{2}\right) h_{2}\left(\theta_{2}\right)$. To maximize the value of the firm, HQ maximizes the difference between the post-transfer net revenues and the pre-transfer production costs. When internal trade takes place, efficient productiondivision operations $\bar{z}_{1}\left(\theta_{1}\right)$ minimize the pre-transfer cost; this optimally trades off cost reductions in divisional cost $C\left(1, z_{1}\right)$ and increases in required compensation $b_{1}\left(z_{1}\right) h_{1}\left(\theta_{1}\right)$ :

$$
\bar{z}_{1}\left(\theta_{1}\right) \equiv \arg \min _{z_{1} \in Z_{1}}\left[C\left(1, z_{1}\right)+b_{1}\left(z_{1}\right) h_{1}\left(\theta_{1}\right)\right]
$$

Likewise, from the firm's perspective, efficient operations $\bar{z}_{2}\left(\theta_{2}\right)$ for the marketing division maximize the post-transfer net revenue; this optimally trades off increases in revenues $R\left(1, z_{2}\right)$ and increases in required compensation $b_{2}\left(z_{2}\right) h_{2}\left(\theta_{2}\right)$ :

$$
\bar{z}_{2}\left(\theta_{2}\right) \equiv \underset{z_{2} \in Z_{2}}{\arg \max }\left[R\left(1, z_{2}\right)-b_{2}\left(z_{2}\right) h_{2}\left(\theta_{2}\right)\right] .
$$

The firm's gains from internal trade when divisions operate efficiently are

$$
\left[R\left(1, \bar{z}_{2}\left(\theta_{2}\right)\right)-b_{2}\left(\bar{z}_{2}\left(\theta_{2}\right)\right) h_{2}\left(\theta_{2}\right)\right]-\left[C\left(1, \bar{z}_{1}\left(\theta_{1}\right)\right)+b_{1}\left(\bar{z}_{1}\left(\theta_{1}\right)\right) h_{1}\left(\theta_{1}\right)\right] \text {. }
$$

If the gains in (4) are positive, HQ mandates internal trade. Conversely, when the gains are negative, internal trade reduces the firm's profits, and HQ prohibits it. Figure 1 shows a typical efficient pre-transfer total cost function. The efficient net revenue function is constant with respect to changes in the production manager's private information. The gains from trade are thus strictly decreasing in the manager's private information.

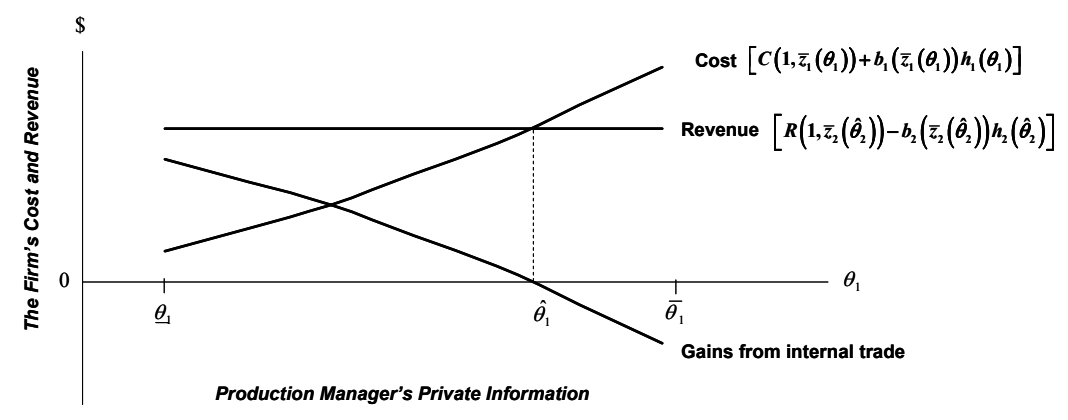

Figure 1. Efficient pre-transfer cost of the production division and the incremental impact of internal trade for any value $\hat{\theta}_{2}$ of the marketing manager's private information. The firm benefits from internal trade if and only if $\theta_{1} \leq \hat{\theta}_{1}$.

Figure 2 shows that the managers' private-information spaces are partitioned into two regions: 
internal trade when private-information realizations are good enough to yield non-negative gains from trade, and no internal trade otherwise. We assume that the internal-trade decision is non-trivial: the probability that the firm benefits from internal trade is positive but less than 1 .

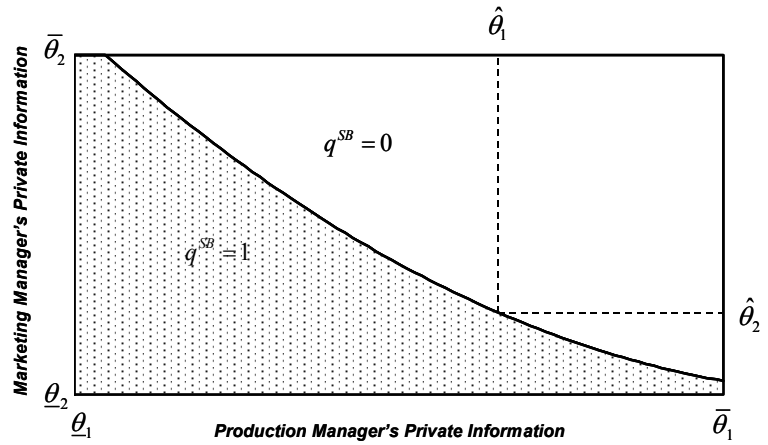

Figure 2. Optimal internal-trade decision rule $q^{S B}\left(\theta_{1}, \theta_{2}\right)$ in the absence of any IT constraints and transfer prices. The breakeven point $\left(\hat{\theta}_{1}, \hat{\theta}_{2}\right)$ from Figure 1 is on the boundary between the "trade" and the "no-trade" regions.

\subsection{Information technology constraints and profit-sharing contracts}

For the remainder of the paper, we discard the assumption that the managers can freely and instantaneously transfer all local information to HQ. Each manager's knowledge is rich, multidimensional, and specific to local operations. Transferring some local knowledge to HQ is almost free (examples are input prices and quantities). Other knowledge is specific and costly to transfer (examples include technological expertise, product-design tradeoffs, product and process engineering, market conditions, competitors' strategies, customer relationships, and alternative uses of constrained resources).

To develop transparent intuition and describe the implications of IT constraints for transfer pricing in a tractable setting, we initially limit only the production manager's ability to communicate with HQ (in Section 6 we show that the main results hold when neither manager can fully communicate all local knowledge to HQ). It is certainly too costly for the production manager to fully explain to HQ the precise links between local knowledge, the multitude of decisions the manager makes, and the resultant divisional cash flows. Instead, the manager provides HQ with a report, such as a divisional budget, which includes aggregated representations. The financial language of budgets captures the complexity of the production manager's local knowledge concisely but not completely. Further, there is a delay between the time the manager learns new information and the time HQ can internalize it and act upon it. HQ can then enhance the value of the firm by delegating decision rights to divisional managers and compensating them based on divisional profits.

While we do not explicitly model communication and processing costs, the technique introduced by 
Melumad et al. (1992) allows us to represent them. Formally, the manager's reports to HQ can take on at most $k$ distinct values. The restriction does not specify how the manager communicates with HQ, or what the manager reports. It simply forces the size of the reporting set $M_{1}$ to be smaller than the size of the manager's local-information set $\Theta_{1}$; this makes it impossible for the manager to explain everything of local relevance to HQ. But the following important result allows us to relate the reporting restriction to the common practice of divisional budgeting (the result also allows us to narrow the set of managerialcompensation contracts HQ needs to consider).

The technical result is that, with the reporting restriction, it is optimal for HQ to (i) partition the production manager's private-information space into $k$ intervals; and (ii) offer a contract that convinces the manager to truthfully report which of the intervals contains the manager's private information (see Step 2 of the proof of Theorem 1). ${ }^{10}$ We number these intervals in order of increasing $\theta_{1}$, use $\Theta_{1}^{u}$ to refer to the $u^{\text {th }}$ interval, and use $\bar{\theta}_{1}^{u}$ to refer to the upper bound of the $u^{\text {th }}$ interval, for $u \in\{1, \ldots, k\}$. The production manager's reporting set is then $M_{1}=\left\{\Theta_{1}^{1}, \Theta_{1}^{2}, \ldots, \Theta_{1}^{k}\right\}$; HQ requests that the manager report the interval $\Theta_{1}^{u}$ that contains the local information. The manager's report is strategic - the manager maximizes expected utility and reports truthfully only if given appropriate contractual incentives. But, since it is optimal for HQ to use contracts that give incentives for truthful reporting, for the remainder of the paper we focus on these truth-inducing contracts.

To illustrate the formal technique and the link to divisional budgeting, consider an extreme case of IT constraints: $k=2$. The production manager's private information space is divided into 2 intervals: divisional conditions are "favorable" when the manager's private information is in the interval $\Theta_{1}^{1}$; "unfavorable" when private information is in $\Theta_{1}^{2}$ :

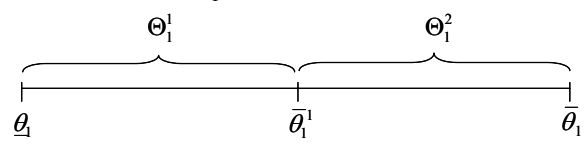

The production manager's reports have two economically equivalent interpretations: (i) reports about local private information (e.g. "favorable" or "unfavorable"), and (ii) budgets, or cost estimates (e.g. low or high). For example, when the manager reports that local conditions are "favorable", HQ cannot precisely

\footnotetext{
${ }^{10}$ The intuition is similar to (but, because of IT constraints, not identical to) the Revelation Principle. Any contracting outcome where the manager's reporting strategy is to distort his information can be replicated by a contract where HQ commits to apply the same distortion to the manager's report. In the replicating contract, the manager thus has the incentive to report truthfully. Note that since we do not limit the marketing manager's ability to communicate with HQ until Section 6, the Revelation Principle implies that this manager's reporting set $M_{2}$ is the same as the private-information set $\Theta_{2}$.
} 
forecast either how the manager will operate the division or what the pre-transfer costs will be. But the "favorable" report corresponds to a unique cost budget. Consider any contract that pays the production manager a share $\alpha_{1}$ of divisional profit, with divisional profit computed by $\left[T-C\left(1, z_{1}\right)\right]-$ some internal transfer price minus divisional cash flows (we use profit-sharing contracts in the analysis below). The manager will operate the division to maximize the difference between divisional-profit-based compensation and personal cost; from the manager's point of view, optimal divisional operations $z_{1}^{*}()$ will depend on local information $\theta_{1}$ and the manager's profit share $\alpha_{1}: z_{1}^{*}\left(\alpha_{1}, \theta_{1}\right) \in \arg \max _{z_{1}}\left[\alpha_{1}\left(T-C\left(1, z_{1}\right)\right)-b_{1}\left(z_{1}\right) v_{1}\left(\theta_{1}\right)\right]$. Lacking full knowledge about the division, HQ cannot predict exactly what the divisional costs $C\left(1, z_{1}^{*}\left(\alpha_{1}, \theta_{1}\right)\right)$ will be. But HQ can compute (i) the expected divisional cost $E_{\Theta_{1}^{1}}\left[C\left(1, z_{1}^{*}\left(\alpha_{1}, \theta_{1}\right)\right)\right]$; and (ii) the production manager's expected divisional-profit-based compensation.

The manager's report that local conditions are "favorable" is thus equivalent to the manager budgeting divisional costs at $E_{\Theta_{1}^{1}}\left[C\left(1, z_{1}^{*}\left(\alpha_{1}, \theta_{1}\right)\right)\right]$. HQ can request that the manager provide either (i) direct reports about private information, or (ii) budgets; the two reporting systems are identical. For exposition, we will call the production manager's reports "budgets," with the understanding that "a budget report $\Theta_{1}^{u}$ " refers to the budget $E_{\Theta_{1}^{u}}\left[C\left(1, z_{1}^{*}\left(\alpha_{1}\left(\Theta_{1}^{u}\right), \theta_{1}\right)\right)\right]$. It is useful for the analysis below to define the "typical" private-information realization $\theta_{1}^{u}$ in the interval $\Theta_{1}^{u}$, which can be derived from $h_{1}\left(\theta_{1}^{u}\right)=E_{\Theta_{1}^{u}}\left[h_{1}\left(\theta_{1}\right)\right]$.

In summary, the production manager sends HQ budgets (i.e. cost estimates), but these budgets cannot fully describe the production division's economic environment. HQ can neither perfectly predict what the production manager's operating decisions will be nor exactly what production costs will be. Since it is optimal for HQ to provide incentives for "truthful" budgeting, HQ can forecast that production costs will be in a certain range, but there will be variances from the budget. ${ }^{11}$

With IT constraints on the production side, there is a benefit to delegating local decisions to divisional managers and guiding internal trade via a system of internal prices and divisional-profit-based compensation. We now turn to the analysis of cost-based and then negotiated transfer pricing.

\footnotetext{
${ }^{11}$ This technique also allows us to capture variations in IT constraints. As $k$ gets larger, HQ's understanding of the production division becomes more accurate; expected variances between the manager's budget and realized costs decrease. We use this in Section 5 to analyze the implications of changes in IT constraints for the firm's transfer-pricing method choices.
} 


\section{Cost-based transfer pricing with information technology constraints}

With cost-based pricing, HQ sets the transfer price using the production manager's cost budget. If the managers trade at some price $T$ and divisional cash flows are $C\left(1, z_{1}\right)$ and $R\left(1, z_{2}\right)$, divisional profits equal $\left[T-C\left(1, z_{1}\right)\right]$ for production and $\left[R\left(1, z_{2}\right)-T\right]$ for marketing. Each manager's compensation consists of a fixed salary and a share of divisional profit. HQ uses budget-based compensation plans: manager $i$ 's budget $m_{i}$ determines that manager's fixed salary $\beta_{i}\left(m_{i}\right)$ and the profit share $\alpha_{i}\left(m_{i}\right) .{ }^{12}$ The marketing manager decides whether or not to place an order; we use $q^{C B}(\cdot)$ to represent this decision. It is optimal for HQ to make take-it-or-leave-it contractual offers to each divisional manager; the managers are thus not allowed to attempt to negotiate contractual terms or to otherwise attempt to influence the design of the cost-based transfer-pricing system. The sequence of events is in the timeline below.

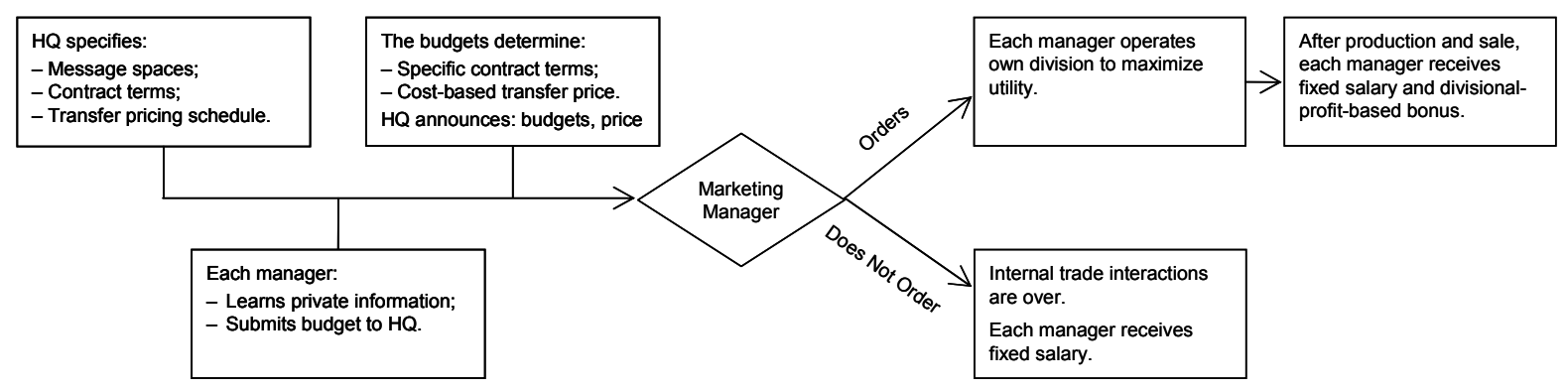

When designing the cost-based pricing system, HQ has three contracting variables - divisional-profit shares, fixed salaries, and the transfer price - to tackle three related incentive questions:

1. Will the managers truthfully budget costs and revenues?

2. Will the managers trade internally if and only if it is in the firm's interest?

3. When the managers trade internally, will they operate their divisions optimally?

We answer these questions using backward induction, starting at the right-hand-side of the timeline. First, we examine the managers' operating decisions following marketing's internal order (and how HQ influences these decisions). Armed with predictions about operating decisions, we next consider the marketing manager's internal-ordering decision (and how HQ influences this decision). Last, we describe how HQ convinces the managers to produce truthful budgets.

\footnotetext{
${ }^{12}$ Note the following key ingredients of our model of cost-based transfer pricing: the transfer price is based solely on the report of the production manager; the production manager can not refuse to fill an order placed by marketing; and each manager's compensation contract is independent of the other manager's report. We comment on these modeling choices below, in the discussion following Theorem 1 .
} 
Divisional operations. If the marketing manager orders the product, each manager operates his division to maximize personal utility, and, following production and sale, receives both a fixed salary and a share of his division's profit. We use $z_{i}^{C B}\left(m_{i}, \theta_{i}\right)$ to represent manager $i$ 's divisional operating decision (to make the decision, each manager trades off increases in personal costs and in compensation). ${ }^{13}$ By now, each manager has sent divisional budgets to HQ, and HQ has announced the cost-budget-based transfer price $T$.

Conjecturing for the moment that HQ can provide incentives for truthful reporting, the marketing manager's operating decision maximizes the difference between divisional-profit-based compensation

$$
\begin{aligned}
& {\left[\alpha_{2}\left(\theta_{2}\right)\left(R\left(1, z_{2}\right)-T\right)\right] \text { and personal cost }\left[b_{2}\left(z_{2}\right) v_{2}\left(\theta_{2}\right)\right]:} \\
& z_{2}^{C B}\left(\theta_{2}, \theta_{2}\right)=\arg \max _{z_{2} \in Z_{2}}\left[\alpha_{2}\left(\theta_{2}\right) R\left(1, z_{2}\right)-b_{2}\left(z_{2}\right) v_{2}\left(\theta_{2}\right)\right] .
\end{aligned}
$$

The production manager's operating decision maximizes the difference between profit-sharing payment $\left[\alpha_{1}\left(\Theta_{1}^{u}\right)\left(T-C\left(1, z_{1}\right)\right)\right]$ and personal cost $\left[b_{1}\left(z_{1}\right) v_{1}\left(\theta_{1}\right)\right]$ :

$$
z_{1}^{C B}\left(\Theta_{1}^{u}, \theta_{1}\right)=\arg \min _{z_{1} \in Z_{1}}\left[\alpha_{1}\left(\Theta_{1}^{u}\right) C\left(1, z_{1}\right)+b_{1}\left(z_{1}\right) v_{1}\left(\theta_{1}\right)\right] .
$$

Divisional-profit shares are HQ's only means of guiding the managers' divisional operating decisions; the cost-based transfer price does not affect them, because the price is set before the managers make these decisions. Further, divisional operations do not depend on how the firm prices transfers: based on cost or on managers' negotiations. Different prices, and different pricing methods, determine only whether there is internal trade. This simplifies the later comparison of the two methods. Divisional operating decisions $z_{1}^{C B}\left(\Theta_{1}^{u}, \theta_{1}\right)$ and $z_{2}^{C B}\left(\theta_{2}, \theta_{2}\right)$ that are optimal under the cost-based method are available with negotiated pricing - HQ simply uses the same divisional-profit shares. The profit shares that convince the managers to operate their divisions efficiently are ${ }^{14}$

\footnotetext{
${ }^{13}$ After HQ and manager $i$ agree on the manager's compensation contract $\alpha_{i}(\bullet), \beta_{i}(\bullet)$, the key variables that influence the manager's operating decisions are (i) local information $\theta_{i}$ and (ii) the manager's report $m_{i}$. To simplify the notation, we can then write the manager's operating decision $z_{i}^{C B}\left(m_{i}, \theta_{i}\right)$ as just a function of these two variables. Below, we further simplify the notation: since it is optimal for HQ to provide the managers contractual incentives for truthful reporting, under efficient costbased transfer pricing the marketing manager reports truthfully, i.e. $m_{2}=\theta_{2}$.

${ }^{14}$ The optimal profit shares are not central to the analysis below; we state them here to describe the optimal transfer price. For the marketing manager, comparison of the operating decision in (5) with the second-best decision in (3) points to the optimal profit share in (7); the production manager's profit share takes a similar form, but subject to IT constraints. The derivations of the optimal operating decisions (and thus the optimal profit shares) are in steps 1 and 3 of the proof of Theorem 1. Note that each manager's profit share can be written as the ratio of personal cost $b_{i}\left(z_{i}\right) v_{i}\left(\theta_{i}\right)$ and expected compensation $b_{i}\left(z_{i}\right) h_{i}\left(\theta_{i}\right)$, which are both strictly positive terms. Accordingly, the profit shares $\alpha_{i}\left(\theta_{i}\right)$ are strictly positive. In fact, because compensation exceeds personal cost, the profit shares are in the interval $(0,1]$.
} 


$$
\alpha_{1}\left(\Theta_{1}^{u}\right)=\frac{v_{1}\left(\theta_{1}^{u}\right)}{h_{1}\left(\theta_{1}^{u}\right)} \text { and } \alpha_{2}\left(\theta_{2}\right)=\frac{v_{2}\left(\theta_{2}\right)}{h_{2}\left(\theta_{2}\right)}
$$

Internal trade. Having set the profit shares to guarantee efficient divisional operations, HQ guides internal trade using the cost-based transfer price. ${ }^{15}$ The marketing manager orders the product if and only if, given the transfer price, his divisional profit share exceeds his personal cost:

$$
\alpha_{2}\left(\theta_{2}\right)\left[R\left(1, z_{2}^{C B}\left(\theta_{2}, \theta_{2}\right)\right)-T\left(\Theta_{1}^{u}\right)\right] \geq b_{2}\left(z_{2}^{C B}\left(\theta_{2}, \theta_{2}\right)\right) v_{2}\left(\theta_{2}\right)
$$

Dividing both sides of this inequality by the profit-sharing parameter $\alpha_{2}\left(\theta_{2}\right)$ from (7) and rearranging, from the marketing manager's point of view, internal trade is attractive if and only if

$$
R\left(1, z_{2}^{C B}\left(\theta_{2}, \theta_{2}\right)\right)-b_{2}\left(z_{2}^{C B}\left(\theta_{2}, \theta_{2}\right)\right) h_{2}\left(\theta_{2}\right) \geq T\left(\Theta_{1}^{u}\right) .
$$

The firm, on the other hand, benefits from internal trade as long as the marketing division's posttransfer net revenues (with efficient marketing operations) exceed the production division's pre-transfer costs (with efficient production operations). The left-hand-side of the marketing manager's internal-order decision rule (8) equals the marketing division's post-transfer net revenues. Can HQ use the cost-based transfer price on the right-hand-side of (8) to convince the manager to internalize the production division's pre-transfer costs? Because of IT constraints, the answer is no - the production manager's budget cannot reveal everything about the production division; and lacking complete knowledge about the production division, HQ cannot design a cost-based pricing rule that communicates the relevant outlay and opportunity costs of internal trade to the marketing manager. At best, HQ uses the cost-based transfer price to communicate HQ's estimate of the total relevant cost, given HQ's necessarily incomplete information. This estimate equals the production manager's budget $E_{\Theta_{1}^{u}}\left[C\left(1, z_{1}^{C B}\left(\Theta_{1}^{u}, \theta_{1}\right)\right)\right]$ plus a mark-up for the manager's expected compensation:

$$
T\left(\Theta_{1}^{u}\right)=E_{\Theta_{1}^{u}}\left[C\left(1, z_{1}^{C B}\left(\Theta_{1}^{u}, \theta_{1}\right)\right)+b_{1}\left(z_{1}^{C B}\left(\Theta_{1}^{u}, \theta_{1}\right)\right) \frac{v_{1}\left(\theta_{1}\right)}{v_{1}\left(\theta_{1}^{u}\right)} h_{1}\left(\theta_{1}^{u}\right)\right] .
$$

Then, using (8), the marketing manager orders if and only if there are expected gains from trade in the reporting interval $\Theta_{1}^{u}$. The formal result is in Theorem 1 below; we illustrate it in Figures 3 and 4 for extreme

\footnotetext{
${ }^{15}$ A common criticism of cost-based transfer prices is that they allow producers to export cost inefficiencies. Here, however, the profit shares prevent cost inefficiencies from being passed on to marketing because (i) the profit shares induce efficient divisional operations, and (ii) the transfer price is based on a cost budget, with any inefficiencies borne by production (although our oneperiod model does not address the possibility of production overestimating the current period's budget to "pad" future budgets).
} 
$(k=2)$ IT constraints. Here the production manager's budget can take on only two values: "low" or "high." The transfer price is based on this budget. Thus, HQ can set at most two different transfer prices: one when the manager's local information is "unfavorable" $\left(\theta_{1} \in \Theta_{1}^{2}\right)$, and a lower price when the information is "favorable" $\left(\theta_{1} \in \Theta_{1}^{1}\right)$. This triggers two types of inefficiencies for the firm: the "no-trade inefficiency" when the marketing manager does not order, even though the firm would benefit from internal trade; and the "trade" inefficiency when the marketing manager does order, even though internal trade destroys profits.

We illustrate the "no-trade" inefficiency in Figure 3 for a given value of the marketing manager's private information. The firm benefits from internal trade as long as the production manager's local information is below the breakeven value $\hat{\theta}_{1}$; but since the single transfer price in the reporting interval $\Theta_{1}^{2}$ is higher than the post-transfer revenue (left-hand side of inequality (8)), the marketing manager does not order when the production manager's private information is anywhere in $\Theta_{1}^{2}$. The shaded area in Figure 3 shows the extent of the firm's loss; in Figure 4, in the unshaded triangles between the cost-based trading boundary and the gainsfrom-trade boundary the marketing manager does not order even though the firm would benefit.

Conversely, for a subset of private-information realizations the marketing manager orders the product even though internal trade reduces the firm's profits. This takes place when the post-transfer net revenues are greater then the transfer price but less than the production division's pre-transfer cost. The "trade" inefficiencies are in the shaded triangles between the two boundaries in Figure 4.

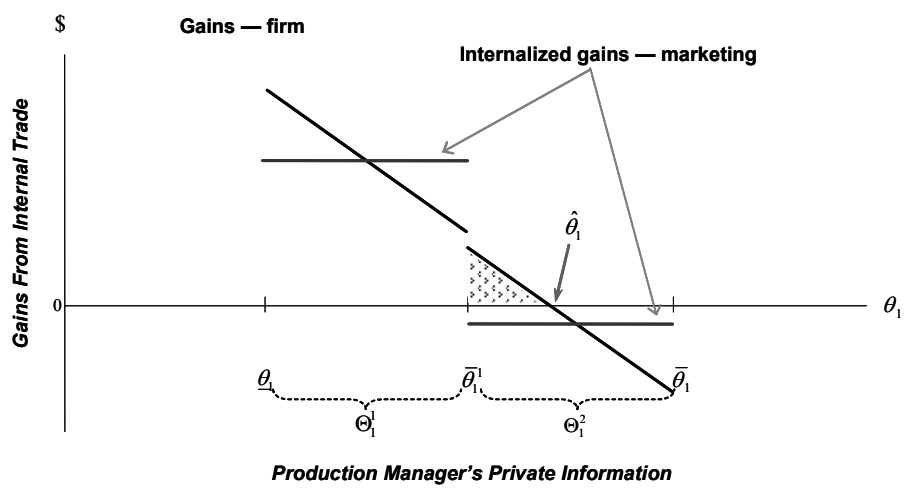

Figure 3. Cost-based transfer pricing and IT constraints for a fixed value $\hat{\theta}_{2}$ of the marketing manager's information. The firm benefits from internal trade as long as $\theta_{1} \leq \hat{\theta}_{1}$, but marketing does not order the product when $\theta_{1}>\bar{\theta}_{1}^{1}$. 


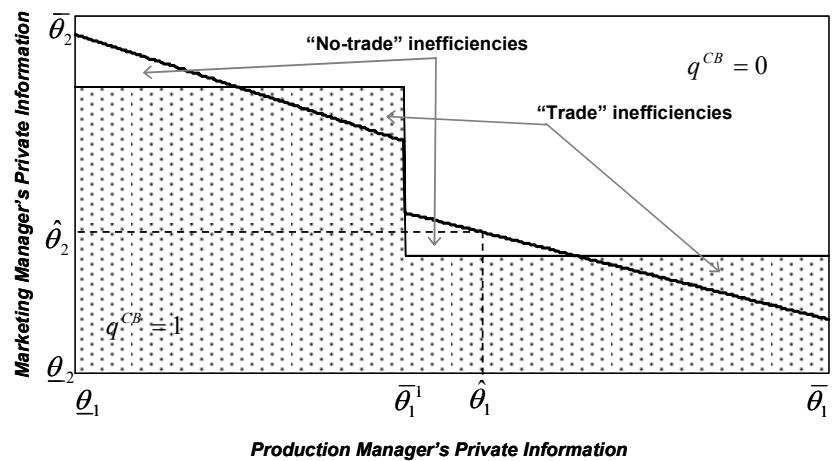

Figure 4. The optimal internal-trade decision rule $q^{C B}(\cdot)$ with cost-based transfer pricing and IT constraints; the managers trade in the shaded region. The downward sloping step line is the boundary between the regions where the firm's gains from internal trade are positive (below the line) and negative (above the line).

Truthful budgeting. HQ uses the managers' profit shares to guarantee efficient divisional operations and the cost-based transfer price to manage internal trade. That leaves one contracting variable for each manager - the fixed salary - to convince the manager to truthfully budget divisional cash flows. This is enough. HQ sets each fixed salary so that the manager faces a forecasting trade-off: a less ambitious budget allows the manager to exert less effort (or to consume slack), at the expense of lower total compensation; a more ambitious budget requires harder work, at a higher total compensation. It is then possible to judiciously set the fixed-salary component of compensation to guarantee that each manager, when making this trade-off, issues an unbiased budget. ${ }^{16}$

We formalize these results in Theorem 1 (see Appendix B for all proofs).

Theorem 1. Under cost-based transfer pricing, the firm maximizes its expected profit with the take-it or leave-it offer of the transfer-pricing rule in (9) and divisional profit-sharing contracts in (7). The managers operate their divisions efficiently. The marketing manager orders the intermediate product if and only if post-transfer net revenues $\left[R\left(1, z_{2}^{C B}\left(\theta_{2}, \theta_{2}\right)\right)-b_{2}\left(z_{2}^{C B}\left(\theta_{2}, \theta_{2}\right)\right) h_{2}\left(\theta_{2}\right)\right]$ exceed the transfer price in (9).

At this point, three key modeling ingredients leading to Theorem 1 deserve additional attention: the transfer price is based solely on the production manager's report; each manager's compensation contract is independent of the other manager's report; and the production manager cannot refuse to fill an order.

The first ingredient - the transfer price is a function only of the production manager's report reflects that a cost-based transfer price is typically based on the actual or estimated costs incurred by the

\footnotetext{
${ }^{16}$ Truth-inducing budgets allow us to compute the upper bound on the firm's profit under cost-based pricing (Gonik, 1979 and Kirby, et al., 1991 provide examples of incentives needed to elicit truthful forecasts). In practice, truth-inducing budgeting systems are rare, for several reasons. First, when future targets are adjusted based on current forecasts and performance, managers have incentives to reduce current performance (this is known as the ratchet effect). Second, the vast majority of firms use budgets both to communicate local knowledge and to evaluate performance; practical trade-offs between the two objectives may necessitate allowing local managers some budgetary slack. Finally, implementing truth-inducing systems may be too expensive.
} 
firm up to the point of internal transfer (we discuss the consequences of setting the transfer price based on both managers' messages below, in the last paragraph of this section). In our model, the production manager's report communicates the cost budget, and the marketing manager takes the budget-based price as a given when making the internal-ordering decision. With this representation of cost-based pricing, the second key modeling ingredient - divisional profit sharing - is optimal, because the incentive problem that HQ faces can be separated into three objectives: (i) guide operations in each division toward efficient ones; (ii) manage internal trade given efficient divisional operations; and (iii) guarantee truthful reporting. HQ uses divisional profit shares to achieve (i), the cost-based transfer price to achieve (ii), and the fixed-salary compensation to achieve (iii). Neither allowing one manager's compensation to depend on the other manager's report nor including the firm's profit in compensation plans affects the results.

With cost-based transfer pricing, allowing the production manager the right to refuse marketing's order is generally detrimental. Given that right and the profit shares in (7) needed for optimal divisional operations, the production manager will reject orders whenever the manager's pre-transfer cost exceeds the transfer price, no matter how positive the marketing manager's information $\theta_{2}$. This will eliminate the "trade" inefficiency of cost-based pricing but create additional losses (using the $k=2$ example of Figure 4, there will be no internal trade in the regions immediately below each "trade" inefficiency triangle). This could be beneficial for the firm when the range of marketing's post-transfer net revenues is narrow. ${ }^{17}$ The "no-trade" inefficiencies, however, would still remain and, with the foresight of Theorems 2 and 4, our main results ranking the two pricing methods would be unchanged.

As we note below at the beginning of Section 6, unless the marketing manager's ability to communicate is also restricted, the firm's profits are the highest under a revenue-based transfer-pricing system where HQ: (i) sets the transfer price based on the marketing manager's report, and (ii) allows the production manager to "push" the product to the marketing division. This higher level of profits can also be attained with the marketing manager placing the order, the transfer price set by HQ based on both managers' reports, and the production manager having the right to refuse any order. However, when neither manager can fully communicate all local knowledge to HQ, negotiated transfer pricing is superior to both cost-based and revenue-based pricing methods (see Section 6 below).

\footnotetext{
${ }^{17}$ To see this, note that if the marketing manager's private information set is a singleton, giving the production manager the right of refusal eliminates the "trade" inefficiency without creating additional losses (but the "no-trade" inefficiency still remains).
} 


\section{Negotiated transfer pricing with information technology constraints}

With negotiated pricing, divisional managers bargain over whether there is internal trade and, if so, at what price. Compared with cost-based pricing, this method offers the firm a number of benefits: (i) the firm's central management does not have to be involved in setting the price, allowing divisional managers to operate under greater autonomy (Vaysman, 1998); (ii) the managers may better exploit specific knowledge about local opportunities, which HQ may otherwise be unable to access (Kaplan and Atkinson, 1998); and (iii) the agreed transfer price may better approximate the relevant cost of the internal product (Brickley, et al., 2004).

However, bargaining is time-consuming and can lead to conflict and ill-will (Brickley, et al., 2004; Kaplan and Atkinson, 1998; Simons, 2000). The time spent negotiating prices or dealing with organizational conflict is lost to other value-generating activities. The firm thus incurs opportunity and organizational costs increasing in bargaining delays. We formally represent managerial negotiations and capture these costs using the following multi-stage bargaining structure. One of the managers makes a price offer at the beginning of a bargaining time period $n \in\{1,2, \ldots\}$, and the other manager accepts or rejects this offer at the end of the time period. The length of a time period (thus the length of time between offers) is $\Delta>0$. The time the managers spend bargaining is not spent on other value-generating activities; there are thus opportunity costs for the firm and for the managers. Price bargaining for one period displaces the "next-best" activity. If each manager has many possible value-generating activities, it is then natural to capture these opportunity costs with a per-period discount factor $\delta \in(0,1)$ (decreasing in $\Delta$ ), in the spirit of opportunity-cost-of-capital techniques. ${ }^{18}$

We now answer the following key questions:

1. How should the top management set up the negotiated pricing system?

2. What prices do managers reach in their negotiations? Do the prices approximate the relevant costs of internal trade better or worse than the dictated price under the cost-based method?

3. How long will managerial negotiations generally last? How can HQ encourage divisional managers to reach agreement quickly (and thus to minimize the bargaining-time disadvantages)?

4. When can we rank the two transfer-pricing methods?

\footnotetext{
${ }^{18}$ All results are similar as long as there are some opportunity and organizational bargaining costs. The discount factor representation has a second natural economic interpretation: there is some positive probability $r$ that the managers' opportunity to generate gains disappears when they continue bargaining for another period (because of competitor responses, market changes, a manager's unexpected separation from the firm, or random factors). Our analysis captures this setting with $\delta=[1-r]$.
} 
There are two important design issues for HQ to resolve when setting up the negotiated pricing system: (i) which bargaining procedure should the managers use; and (ii) how to compensate the managers. Initially, we consider the bargaining procedure where the production manager makes all price offers, and the marketing manager accepts or rejects them. We comment on the alternative procedure, with the marketing manager making offers, in the paragraph following Theorem 2 and use the alternative procedure in Section 6.

The second design issue - managerial compensation - is significant for two reasons. First, as under costbased pricing, divisional profit shares directly affect local decisions. Second, compensation contracts influence the range of transfer prices acceptable to each manager. As under cost-based transfer pricing, HQ uses budgetbased compensation plans: HQ specifies these compensation plans; requests a budget from each manager; and each manager's budget determines that manager's fixed salary and profit share. To guide the managers' transfer-price bargaining, HQ makes the budgets available to both managers. ${ }^{19}$ The precise sequence of events is depicted in the following timeline and described further below.

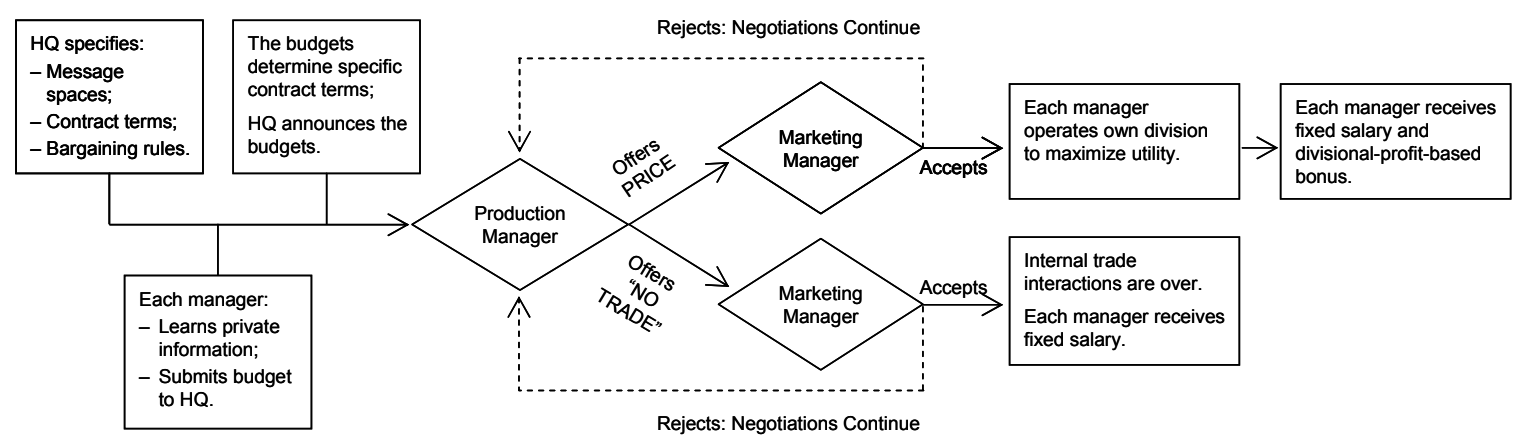

Not depicted in the timeline is HQ's threat to intervene if the managers fail to reach agreement by some time $\bar{n}$ - chosen to make irresolvable disputes unattractive. The managers, at time periods $n \in\{1,2, \ldots, \bar{n}-1\}$, simultaneously negotiate the price and whether or not the product is produced and transferred. The production manager either (i) offers a transfer price, or (ii) proposes that internal trade not take place. The marketing manager accepts or rejects the offer. If the managers agree not to engage in internal trade (we use $q^{N E G}(\cdot)=0$ to represent this), each manager is paid a fixed salary. If the managers agree to produce and transfer in period $n$ at transfer price $p^{n}$, manager $i$ operates his own division; we use $q^{N E G}(\cdot)=1$ to represent the manager's agreement to trade, and $z_{i}^{N E G}\left(m_{i}, \theta_{i}\right)$ to represent manager $i$ 's divisional operations.

\footnotetext{
${ }^{19}$ Without budget-based compensation, negotiated transfer pricing performs poorly compared with the optimal cost-based pricing of Section 3: divisional decisions are strictly worse, and managerial bargaining leads to inferior internal-trade decisions.
} 
We analyze perfect Bayesian equilibria of managerial interactions. A formal definition and additional notation describing managers' actions, strategies and beliefs are in Appendix A. As under cost-based pricing, HQ uses each manager's fixed-salary compensation component to provide incentives for truthful reporting (note that here inducing truth-telling may not be without loss of generality, because the production manager cannot commit to how he will use the marketing manager's message; however, with the foresight of Theorems 2 and 4, truth-telling contracts are sufficient for the firm to enjoy the advantages of negotiated pricing). Our discussion below relies on HQ's ability to elicit accurate reports.

When managers negotiate the transfer price, the firm and the managers incur costs because of bargaining time and internal conflicts. Why then should HQ ever use negotiated transfer prices for internal trade? Efficiency losses under cost-based transfer pricing in Figures 3 and 4 suggest a possibility: because of IT constraints, HQ imposes a single transfer price that applies when the production manager's local information is, for example, "unfavorable" (i.e. $\theta_{1} \in \Theta_{1}^{2}$ ); the transfer price cannot be tailored to just how unfavorable the local information is. The cost-based transfer price is the HQ's expectation of the pre-transfer cost consistent with an "unfavorable" budget; the price cannot fully communicate the production division's local knowledge and the relevant outlay and opportunity costs of internal trade. But with negotiated pricing the production manager, who understands the local knowledge, makes the price offers; HQ provides incentives to convince him to use this knowledge in the firm's interest - to make price offers that, compared with the cost-based transfer price, are more closely tailored to just how unfavorable the local information is.

Despite the production manager's superior knowledge when making transfer-price offers, the firm does not necessarily benefit from negotiated pricing - the production manager makes the offers to maximize individual utility and not overall firm profits; and the marketing manager responds to the offers also to maximize individual utility. To evaluate the performance of the two pricing methods, we next consider the range of prices negotiated by the managers, the duration of negotiations, and, most importantly, the performance ranking of the two pricing methods.

Negotiated prices. If HQ uses the same divisional profit-sharing rules as under cost-based transfer pricing

$$
\alpha_{1}\left(\Theta_{1}^{u}\right)=\frac{v_{1}\left(\theta_{1}^{u}\right)}{h_{1}\left(\theta_{1}^{u}\right)} ; \quad \alpha_{2}\left(\theta_{2}\right)=\frac{v_{2}\left(\theta_{2}\right)}{h_{2}\left(\theta_{2}\right)},
$$

and the managers agree to internal trade after $n$ bargaining periods at some price $p^{n}$, the managers will 
operate their divisions exactly as under optimal cost-based transfer pricing: $z_{1}^{N E G}\left(\Theta_{1}^{u}, \theta_{1}\right)=z_{1}^{C B}\left(\Theta_{1}^{u}, \theta_{1}\right)$, and $z_{2}^{N E G}\left(\theta_{2}, \theta_{2}\right)=z_{2}^{C B}\left(\theta_{2}, \theta_{2}\right){ }^{20}$

Consider the production manager's price-offer strategy. The manager, when making a price offer $p^{n}$, uses marketing's budget $\theta_{2}$ to predict the change in the marketing manager's utility from accepting the offer. This incremental utility is the difference between marketing's profit share and personal cost:

$$
\frac{v_{2}\left(\theta_{2}\right)}{h_{2}\left(\theta_{2}\right)}\left[R\left(1, z_{2}^{N E G}\left(\theta_{2}, \theta_{2}\right)\right)-p^{n}\right]-b_{2}\left(z_{2}^{N E G}\left(\theta_{2}, \theta_{2}\right)\right) v_{2}\left(\theta_{2}\right) \text {. }
$$

The marketing manager will definitely not accept a price offer that decreases his utility; rearranging (11), the maximum acceptable transfer price equals marketing's budgeted post-transfer revenue net of compensation costs (for notational clarity, we suppress the dependence of $p^{M A X}$ on $\theta_{2}$ )

$$
p^{M A X}=R\left(1, z_{2}^{N E G}\left(\theta_{2}, \theta_{2}\right)\right)-b_{2}\left(z_{2}^{N E G}\left(\theta_{2}, \theta_{2}\right)\right) h_{2}\left(\theta_{2}\right) .
$$

Fully aware of this, what offers will the production manager make? The specific bargaining procedure required by HQ - price offers by the production manager, and acceptance or rejection by the marketing manager - allows us to answer this question. The marketing manager's bargaining power is limited to accepting or rejecting offers. If internal trade improves the production manager's utility, the best price-offer strategy is then simply to make a "take-it-or-leave-it" proposal: offer the maximum price that the marketing manager would ever accept. That price is $p^{M A X}$.

What is the marketing manager's best response to this price offer? The manager can either accept the price or reject it in expectation of a better price offer in a future bargaining period. Under what conditions could the marketing manager "reasonably" expect a better offer? This could happen only if the marketing manager, by rejecting a price offer, changed the production manager's beliefs (in all other elements, all the bargaining periods are identical). But this cannot happen in equilibrium, since (i) the production manager only forms beliefs about the marketing manager's private information; and (ii) HQ's contract with the managers assures that all equilibria involve the marketing manager issuing truthful budgets (and, thus, effectively revealing local private information).

Thus, the production manager will never make a better price offer, and the marketing manager's best response is to quickly (after one bargaining period) accept production's price offer $p^{M A X}$. To summarize,

\footnotetext{
${ }^{20}$ This is not surprising, since divisional operations are independent of the agreed transfer price and the bargaining period; the operations only depend on each manager's information and the profit-sharing rules.
} 
if the managers ever agree on a transfer price, this agreement takes place after one bargaining period; the price equals marketing's budgeted post-transfer net revenues.

Internal trade. Predictable negotiated transfer prices allow precise forecasts of the conditions leading to internal trade. The production manager only initiates price negotiations if trade at $p^{M A X}$ increases his utility: production's profit-sharing payment must exceed the manager's personal cost:

$$
\frac{v_{1}\left(\theta_{1}^{u}\right)}{h_{1}\left(\theta_{1}^{u}\right)}\left[p^{M A X}-C\left(1, z_{1}^{N E G}\left(\Theta_{1}^{u}, \theta_{1}\right)\right)\right] \geq b_{1}\left(z_{1}^{N E G}\left(\Theta_{1}^{u}, \theta_{1}\right)\right) v_{1}\left(\theta_{1}\right)
$$

Substituting the maximum acceptable transfer price from (12) and rearranging, internal trade takes place if and only if

$$
\left[R\left(1, z_{2}^{N E G}\left(\theta_{2}, \theta_{2}\right)\right)-b_{2}\left(z_{2}^{N E G}\left(\theta_{2}, \theta_{2}\right)\right) h_{2}\left(\theta_{2}\right)\right] \geq\left[C\left(1, z_{1}^{N E G}\left(\Theta_{1}^{u}, \theta_{1}\right)\right)+b_{1}\left(z_{1}^{N E G}\left(\Theta_{1}^{u}, \theta_{1}\right)\right) \frac{v_{1}\left(\theta_{1}\right)}{v_{1}\left(\theta_{1}^{u}\right)} h_{1}\left(\theta_{1}^{u}\right)\right] .
$$

The left-hand side of this inequality is the firm's post-transfer net revenue; the right-hand side is the firm's pre-transfer cost. Thus, the managers agree to internal trade if and only if there are gains from this trade from the firm 's point of view. Negotiated transfer pricing eliminates inefficient trade under costbased pricing (in the region $\left(\hat{\theta}_{1}, \bar{\theta}_{1}\right]$ of Figure 3 ).

This happens because production's transfer-price offer is the marketing division's post-transfer efficient revenue. Because of the bargaining power granted by HQ, the production manager captures, and thus internalizes, the entire gains from internal trade. We illustrate this in Figure 5.

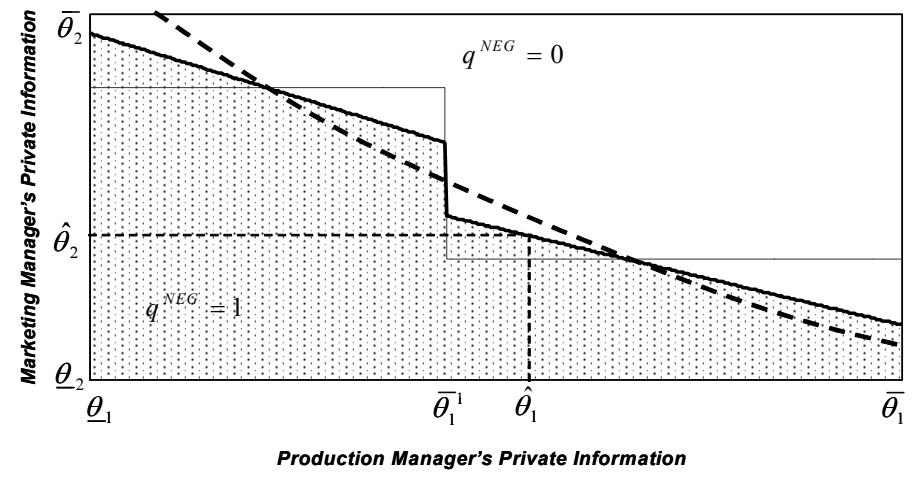

Figure 5. The internal-trade decision rule $q^{N E G}($ ) with negotiated transfer pricing and IT constraints.

In Figure 5, the heavy solid line is the boundary between the shaded trade region and the unshaded no-trade region under negotiated transfer pricing. The thin step-function line is the trade/no-trade boundary under optimal cost-based pricing (see Figure 4 ). Note the breakeven point $\left(\hat{\theta}_{1}, \hat{\theta}_{2}\right)$ from Figures 
3 and 4. Under optimal cost-based transfer pricing, the marketing manager made his internal-ordering decision based on the transfer price imposed by HQ; the cost-based price could not fully communicate all of the production manager's relevant knowledge; and, thus, some inefficient trade was inevitable (here illustrated by the shaded region below and to the left of $\left(\hat{\theta}_{1}, \hat{\theta}_{2}\right)$ and above the thin step-function trade/notrade boundary under cost-based pricing).

With negotiated pricing, the production manager, privately aware of local knowledge, captures all the gains from trade and, with proper incentives, only makes reasonable price offers when the firm benefits from trade. The breakeven point $\left(\hat{\theta}_{1}, \hat{\theta}_{2}\right)$ is thus on the trading boundary; internal trade under negotiated pricing is efficient. And, when compared with cost-based transfer pricing, the trading boundary under negotiated pricing is uniformly closer to the IT-unconstrained efficient trading boundary (smooth dashed curve in Figure 5).

We can now rank the firm's profits under the two methods, by comparing the informational advantage of the negotiated method with the opportunity and organizational costs of managers' bargaining. Since price negotiations conclude after one period, the key determinant of the bargaining costs is the length of each bargaining period. If the managers can be convinced to provide price offers and responses quickly, the informational advantage of negotiated transfer pricing exceeds the bargaining costs. We formalize the preceding discussion in Theorem 2.

Theorem 2. With production-side IT constraints and production-manager-offer negotiated transfer pricing, the firm can provide divisional-profit-based incentive contracts that guarantee:

1. Truthful reporting by divisional managers;

2. Efficient divisional operations;

3. Transfer-price agreement after one bargaining period;

4. Internal trade if and only if the firm gains from this trade;

If the length of each bargaining period $\Delta$ is below a threshold value, the firm's expected profit under negotiated transfer pricing is strictly higher than under cost-based transfer pricing.

The rapid conclusion and the efficiency of transfer-price negotiations hinge on the production manager making the first price offer based on the marketing manager's unrestricted report (we consider reporting restrictions for both managers in Section 6). If, instead, HQ requires that marketing makes offers and production accepts or rejects them, there will be delays prior to price agreement: the marketing 
manager will initially offer a low price and then increase prices over time. With the foresight of Theorem 4, the firm can still enjoy higher profits with marketing-manager-offer bargaining than with cost-based pricing (though with production-side-only IT constraints, production-manager-offer bargaining is the preferred bargaining procedure).

We next examine the effect of improvements in information technology on our analysis.

\section{Negotiated versus cost-based transfer pricing with improving information technology}

Firms continuously upgrade the quantity and quality of information available to managers. IT improves because of decreasing IT costs, the proliferation of enterprise-resource-planning systems, and improved communication technologies (Sircar, et al., 2000). The key implications of IT improvements for our analysis are the enhanced abilities of improved databases and communication technologies to capture, analyze, and communicate throughout the organization the production manager's local knowledge and the links between this knowledge, business processes, decisions, and resultant cash flows. As IT improves, ceteris paribus, HQ can expect increased profitability under either transfer-pricing method (see, for counterexamples, Arya, et al., 2000; Mishra and Vaysman, 2001; Sappington, 1986).

But what are the implications of improved IT for the ranking of the two pricing methods? To formally answer this question, we represent the "IT-improvement" idea with an increase in the number of reporting intervals. Specifically, given an existing information system that partitions the production division's private-information set into $k$ intervals $\Theta_{1}^{1}, \Theta_{1}^{2}, \ldots, \Theta_{1}^{k}$, we represent an IT improvement by dividing each of the $k$ intervals into two new ones. The improved information system splits the production manager's information set into $2 k$ intervals: ${ }^{21}$

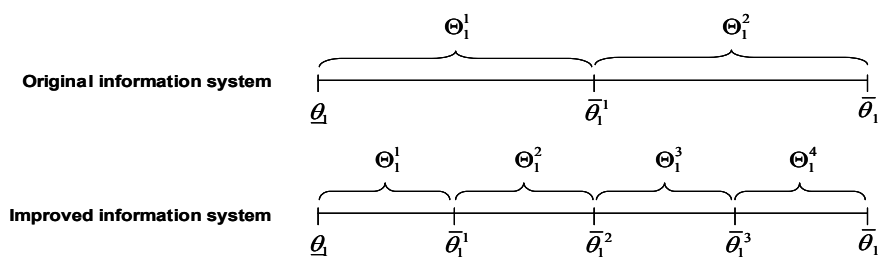

Further IT improvements in turn subdivide each of the reporting intervals. Each improvement increases the number of reporting intervals and reduces the size of each of the production manager's reporting intervals. Consequently, the manager's budget report representing that the private information is

\footnotetext{
${ }^{21}$ Other representations of IT system improvements provide identical results. For example, an improved system can be one with a greater number of reporting intervals than the original one, as long as either: (i) HQ decides how to partition the production division's private information space, or (ii) IT improvements happen in a regular fashion, over the entire range of the manager's private information. Our representation of IT improvements is the simplest, yet sufficient to obtain and illustrate the results.
} 
in some interval involves less and less uncertainty for HQ and for the marketing manager; and the variances between the cost budget and realized costs decrease.

For example, an IT improvement from two reporting intervals $(k=2)$ to four intervals $(k=4)$ means that the production manager can report conditions as "highly favorable", "moderately favorable", "moderately unfavorable" and "highly unfavorable", rather than simply "favorable" or "unfavorable".

There are four possible budget reports with the improved system, compared with two possible reports with the original system; the production manager's cost estimates are thus more precise. ${ }^{22}$

Cost-based transfer pricing with IT constraints does not achieve goal congruence. However, IT improvements diminish this problem. As a reporting interval shrinks, relying on average pre-transfer cost in each of the smaller-sized intervals to set the price triggers correspondingly smaller distortions in internal trade decisions and thus increases the gains from trades. In Figures 3 and 4, the goal-congruence problem is the profit-destroying internal trade in the $\left(\hat{\theta}_{1}, \bar{\theta}_{1}\right]$ region; as the interval surrounding $\hat{\theta}_{1}$ shrinks, the impact of the goal-congruence problem with cost-based pricing decreases.

The two panels of Figure 6 illustrate how IT improvements diminish the goal-congruence problem. Panel A shows the negotiated method's informational advantage with severe IT constraints: the production manager's budget can take on at most two values. The firm improves its IT in Panel B: the manager's budget can now take on four values. As IT improves, the area where the cost-based method's goalcongruence problem causes trading inefficiencies shrinks.

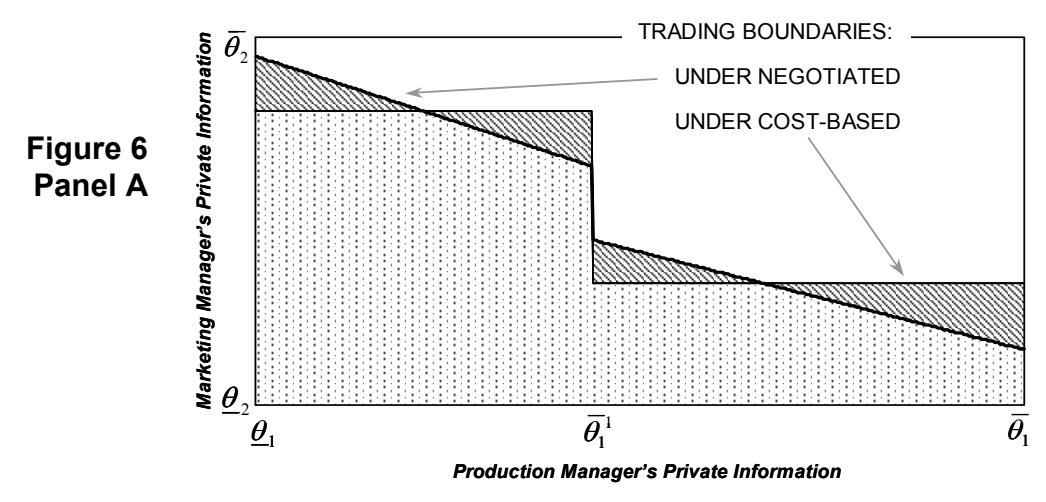

\footnotetext{
${ }^{22}$ Alternatively, IT improvements can represent an IT system's enhanced abilities to capture, categorize, and report relevant information not previously contained in divisional budgets. For example, an IT improvement can allow the production manager to explicitly incorporate different quality levels into divisional reports; instead of creating a budget without specifically considering product quality, following this improvement, the manager can provide different budgets for different quality levels. A specific example from practice is Hershey's recent information system improvement that allows managers to access information sorted on the basis of brand type rather than on the basis of manufacturing data (PR-Newswire, 2002). This illustrates a finer partitioning of the information set that we represent with improved IT, i.e. instead of creating a budget for specific manufacturing activities, in the improved system managers can create budgets by each brand type.
} 


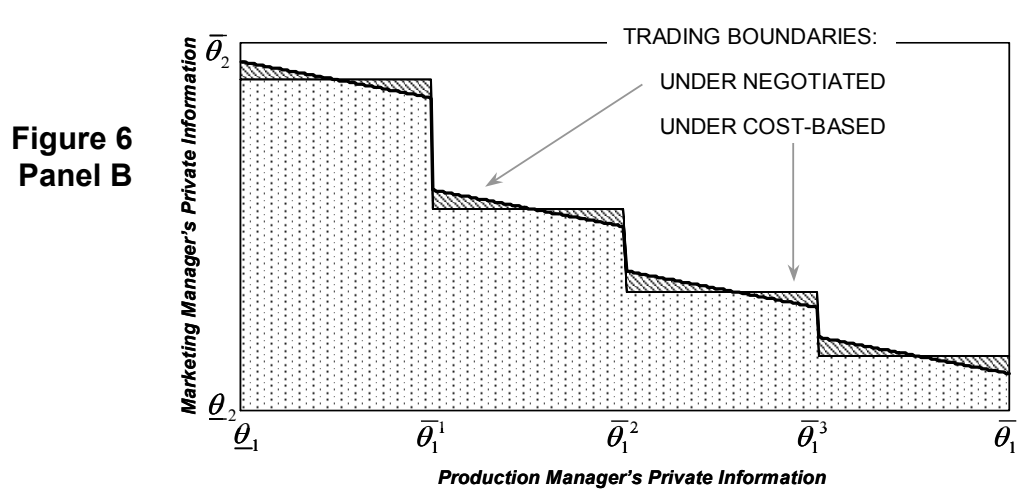

Figure 6. In both panels, the thick line is the boundary between the trade and no-trade regions under the negotiated pricing method. The thin step-function line is the boundary under the cost-based method. The hatched areas between the two boundaries are the areas with inefficient trade under the cost-based method. Note that the IT improvement from 2 to 4 reporting intervals decreases the size of the inefficient-trade areas.

While the negotiated method's informational advantage decreases with each IT improvement, bargaining necessarily generates opportunity and organizational costs for the firm. Thus, for sufficiently unconstrained IT, the cost-based method generates higher profits. We formalize this in Theorem 3 .

Theorem 3. As the information system improves, the firm's expected profit increases strictly faster under cost-based transfer pricing than under negotiated pricing. With a sufficiently unconstrained information system, the firm's expected profit under cost-based pricing strictly exceeds expected profit under negotiated pricing.

Note that Theorem 3 relies on partial-equilibrium analysis: we hold fixed the opportunity cost of delay per unit of time. If competitors also experience lower IT costs and start to react faster, the opportunity cost per unit of time may go up. The disadvantages of delays under negotiated pricing are then even greater, favoring cost-based pricing systems.

\section{Marketing and production IT constraints}

The analysis of sections 3-5 described the implications of IT constraints for transfer pricing in a setting with only production-side IT constraints. This allowed us to describe the economic intuition underlying the advantage of negotiated pricing when communication between a division and HQ is restricted. However, because of one-sided IT constraints, the preceding analysis suffers along two dimensions. ${ }^{23}$ First, HQ's delegation of the internal-trade decision under cost-based transfer pricing is superficial (HQ could make the decision itself, relying on the managers' reports). Second, cost-based and

\footnotetext{
${ }^{23} \mathrm{We}$ are grateful to the anonymous referee for identifying these caveats and encouraging us to study the setting where IT constraints affect both managers' ability to communicate their private information.
} 
negotiated pricing are both dominated by a revenue-based system, where HQ: (i) sets the transfer price based on the marketing manager's report, and (ii) allows the production manager to "push" the product to the marketing division. Under the revenue-based system, the production manager, whose communication is restricted, makes the resource allocation decision in possession of all the information relevant for managing internal trade. We now extend our analysis to incorporate IT constraints for both divisions.

The formal analysis is in the proof of Theorem 4 in the appendix. The intuition is as follows. As in the analysis of Sections 3 and 4, HQ uses identical profit shares under cost-based and negotiated pricing to convince the managers to operate their divisions efficiently. Marketing-side IT constraints do not change the optimal cost-based transfer price; HQ still sets the price as in (9), at the expected cost in the production division plus a markup for the production manager's expected compensation. Consequently, the marketing manager internalizes the average gains from trade in each reporting interval of the production manager. The cost-based method thus suffers the inefficiencies identified in Section 3 (see Figures 3 and 4): the "notrade" inefficiency when there are gains from trade but the transfer price exceeds the marketing manager's incremental utility from trade; and the "trade" inefficiency where the marketing manager orders the product even though internal trade reduces the firm's profits.

Negotiated transfer pricing allows the firm to diminish these inefficiencies. In Theorem 4, we show that the "no-trade" inefficiency is reduced with the negotiated pricing system where the firm grants the marketing manager the right to make price offers (the production manager accepts or rejects the offers). The equilibrium analysis is simplified by the fact that the production manager's acceptance strategy takes the following simple form: accept a transfer-price offer as long as the manager's private information is below a cut-off value (the cut-off is a function of the offered price). The marketing manager's strategy is to start with low transfer-price offers and increase the price every bargaining period.

HQ threatens to impose the optimal cost-based transfer price if the managers fail to agree by the terminal bargaining period $\bar{n}$. In the region with the "no-trade" inefficiency under cost-based pricing, the production manager is then willing to accept price offers lower than the cost-based transfer price because if the threatened cost-based-price intervention is imposed, the marketing manager will not place the order, and the production manager will forego any available gains from trade. This assures that internal trade in this region takes place with strictly positive probability under negotiated pricing, increasing the firm's profit beyond that available under cost-based pricing. 
Of course, with IT constraints on the marketing side, neither manager knows the other manager's private information, even if HQ is able to induce truthful reporting. Thus, the earlier result about immediate resolution of managers' bargaining does not apply here - the marketing manager cannot guarantee that production will accept the first transfer-price offer. In general, managers' negotiations conclude in a given bargaining period with some positive probability; and with positive probability the managers' negotiations last for multiple periods, as late as the penultimate bargaining period $\bar{n}-1$. However, the specification of maximum bargaining time $\bar{n}$ is up to HQ. Thus, to show that the firm's profit is higher under negotiated transfer pricing than the under the cost-based system, it is sufficient to show that the negotiated system is the preferred one for some $\bar{n}$ (HQ will use any other maximumbargaining-period policy only if it offers still higher profit). We do this below, in Theorem 4 , for $\bar{n}=2$. In this case, the delay under negotiated pricing is at most two periods. And, as in Theorem 2, if the managers can be convinced to provide offers and responses quickly, the advantage of negotiated pricing exceeds the bargaining cost.

Theorem 4. With IT constraints limiting communication between both managers and HQ, the upper bound on the firm's expected profit under negotiated transfer pricing is strictly higher than under costbased pricing when the length of each bargaining period $\Delta$ is below a threshold value.

To conclude the analysis, we note that by symmetry, negotiated transfer pricing also allows the firm to earn higher expected profit than a revenue-based transfer-pricing system. Also note that the Theorem 3 result concerning information improvements applies to the analysis of this section as well: holding the length of a bargaining period constant, with a sufficiently unconstrained IT, cost-based transfer pricing allows the firm to earn higher expected profit than does negotiated pricing.

\section{Conclusion}

A challenge for multi-divisional, vertically-integrated firms is to delegate operating decisions in a way that encourages divisional managers to use their private information in the best interests of the firm as a whole. This is complicated by constraints on the flow and availability of information within the firm. That better and cheaper information leads to improved profits is recognized; less obvious are the implications of IT improvements for organizational design. Our results show that a firm's informational environment is a key factor determining its transfer-pricing method. 
When IT constraints prevent divisional managers from transferring local knowledge about the firm's production process, we show that properly structured negotiated transfer pricing has an informational advantage over the cost-based method: with the right incentives, managers agree on transfer prices that approximate the costs of internal transfer more accurately. Consequently, when opportunity and organizational costs of bargaining are sufficiently small, the informational advantage of the negotiated method generates higher firm profits. Conversely, improvements in IT lead to faster increases in profit under cost-based transfer pricing than under the negotiated method, because the value-destroying internal trade under cost-based pricing diminishes. With sufficiently unconstrained IT, the cost-based method provides higher profits than negotiated transfer pricing because, all else equal, the remaining opportunity and organizational costs of managerial bargaining outweigh the profit destroyed by inefficient internal trade under IT-constrained cost-based transfer pricing.

Our results have several empirical implications. First, the results help explain survey evidence in Vancil (1978) who found that: (i) firms comprising unrelated businesses use negotiated transfer-pricing significantly more than cost-based transfer pricing (34\% versus $15 \%$ ) and (ii) vertically-integrated firms operating within a single product market use cost-based transfer pricing significantly more than negotiated transfer pricing (49\% versus 12\%). Managers in firms comprising unrelated businesses are more likely to have diverse educational, functional, and training backgrounds; the cost of transferring divisional knowledge to top managers is thus higher (i.e. higher IT constraints) than in vertically-integrated firms in a single product market. Vancil's evidence is thus consistent with Theorems 2 and $4 .^{24}$

Second, our results imply that firms with the following characteristics are more likely to prefer negotiated transfer pricing: (i) understanding divisional operations requires specialized education or training; (ii) divisional operations are physically located far from the headquarters; (iii) divisional operations are in quickly-changing environments requiring rapid responses; (iv) lack of sophisticated enterprise-resource-planning (ERP) systems; and (v) large firm size. ${ }^{25}$

\footnotetext{
${ }^{24}$ Our discussion of empirical implications, consistent with the modeling in the paper, addresses firms where the tax effect of transfer pricing is not an overriding consideration, primarily because the trade does not cross tax jurisdictions. Even when it does cross tax jurisdictions, empirical evidence suggests that at least some firms maintain two transfer-pricing systems: one to manage internal trade, and a separate one for taxes (Ernst and Young 1999). However, maintaining separate systems can be extremely costly because the taxation authorities can argue that the tax-based transfer pricing system has no legitimate business purpose and take legal action to use the internal system for taxation purposes (Springsteel, 1999).

${ }^{25}$ The firm-size factor may explain why in 152 Canadian firms, Atkinson (1987) finds $60 \%$ use cost-based methods, and $7 \%$ use
} 
Third, Theorem 3 offers a number of testable predictions. The most direct prediction is that the ratio of firms with cost-based transfer pricing to those with negotiated pricing is higher after the 1990s IT boom than before. ${ }^{26}$ During the 1990 s, many firms invested heavily in internal information systems and benefited from increased computing power per manager (Sircar, et al., 2000). Further, ERP systems streamlined communications between different functional lines in large organizations, improving firms' abilities to plan and to coordinate decisions that previously had to be made with incomplete information about internal processes (Cairncross, 2000). The investments in communication and reporting systems lowered the barriers to internal communication. Theorem 3 predicts that this reduction in knowledge-transfer costs increases the attractiveness of cost-based transfer pricing.

Fourth, the results can predict preferred pricing methods in modern business-to-business retail alliances. ${ }^{27}$ Any links between two companies' information systems are likely to be constrained because the benefits of unconstrained sharing of information will be outweighed by associated proprietary costs. If so, a testable prediction of Theorems 2 and 4 is that the transfer prices in these alliances are more likely to be negotiated than to be based on the supplier's cost.

Finally, our results have practical implications. All else being equal, firms with low costs of transferring divisional knowledge earn higher profits with cost-based than with negotiated transfer pricing. Firms with high knowledge-transfer costs earn higher profits with the negotiated method, but must strive to minimize organizational conflict and the opportunity cost of managers' time devoted to bargaining; these important implications for job design must be explored in future research.

Given the widespread use of transfer pricing in practice, surprisingly little evidence exists that identifies preferred methods. Moreover, no empirical work on transfer pricing has been guided by hypotheses generated from the results and economic intuition of theoretical modeling. Our results, as well as those of Baldenius et al. (1999) and Baldenius (2000), can form a framework of testable hypotheses that can be used to guide empirical tests of the theory.

negotiated ones - statistics that differ significantly from the Tang (1993) and Vancil (1978) surveys that document significantly higher use of negotiated pricing. If the Canadian firms are smaller than the U.S. firms in the latter surveys, transferring local knowledge is less costly, and our results predict greater use of cost-based transfer pricing for the Atkinson firms.

${ }^{26}$ As a pre-IT-boom benchmark, Tang (1993) identifies a 2.7:1 ratio of cost-based to negotiated transfer-price usage.

${ }^{27}$ For example, Circuit City has an agreement with Amazon.com to supply pickup services to Amazon customers. 


\section{Appendix A. Managers' beliefs and reporting and bargaining strategies.}

In each period $n \in\{0,1, \ldots, \bar{n}-1\}$ manager $i \in\{1,2\}$ takes an observable action $a_{i}^{n} \in A_{i}^{n}$. Period- 0 actions are managerial reports: $A_{i}^{0}=M_{i}$. With production-manager-offer extensive form, in periods $n \in\{1,2, \ldots, \bar{n}-1\}$, the production manager either (i) offers a transfer price $p^{n}$, or (ii) offers that production and transfer not take place. At the end of each time period, the marketing manager either (i) accepts the offer, or (ii) rejects the offer. Then $A_{1}^{n}=\mathbb{R} \cup$ "No Production" and $A_{2}^{n}=\{$ "Accept","Reject" $\}$ for $n \in\{1,2, \ldots, \bar{n}-1\}$. With marketing-manager-offer extensive form, $A_{1}^{n}=\{$ "Accept","Reject" $\}$ and $A_{2}^{n}=\mathbb{R} \cup$ "No Production" for $n \in\{1,2, \ldots, \bar{n}-1\}$. Let $a^{n} \equiv\left(a_{1}^{n}, a_{2}^{n}\right)$.

If the game continues through any period $n, \Upsilon^{n} \equiv\left(a^{0}, a^{1}, \ldots, a^{n-1}\right)$ is the history for all prior periods, with $\Upsilon^{0} \equiv \varnothing$. If $n=0$, or if the managers continue price negotiations in period $n$, the bargaining history $\Upsilon^{n}$ is non-terminal. Otherwise, the history is terminal. Following a non-terminal history $\Upsilon^{n}$, manager $i$ 's strategy is a probability distribution $\sigma_{i}^{n}(\cdot)$ over the set $A_{i}^{n}$. For every $a_{i}^{n} \in A_{i}^{n}, \sigma_{i}^{n}\left(a_{i}^{n} \mid \Upsilon^{n}, \theta_{i}\right)$ is the probability that manager $i$ with information $\theta_{i}$ takes the action $a_{i}^{n}$ following the history $\Upsilon^{n}$. Let $\sigma_{i} \equiv\left(\sigma_{i}^{0}, \sigma_{i}^{1}, \ldots, \sigma_{i}^{\bar{n}}\right), i \in\{1,2\}$ and $\sigma \equiv\left(\sigma_{1}, \sigma_{2}\right)$. Manager $i$ 's beliefs about the private information of manager $j \neq i$ are described by the probability density function $\mu_{i}\left(\theta_{j} \mid \theta_{i}, \Upsilon^{n}\right)$ after any game history $\Upsilon^{n}$. Let $\mu \equiv\left(\mu_{1}, \mu_{2}\right)$. A perfect Bayesian equilibrium is then a set of strategies and beliefs $(\sigma, \mu)$ such that:

1. Following every game history $\Upsilon^{n}$, the continuation strategies form a Bayesian-Nash equilibrium for the continuation game given the beliefs $\mu_{i}\left(\theta_{j} \mid \theta_{i}, \Upsilon^{n}\right)$.

2. Bayes' rule is used to update beliefs whenever possible.

3. Manager $i$ 's beliefs about manager $j$ 's private information are independent of manager $i$ 's private information and manager $i$ 's actions $-\forall \theta_{i}, \theta^{\prime}, \theta_{j}, \Upsilon^{n}: \mu_{i}\left(\theta_{j} \mid \theta_{i}, \Upsilon^{n}\right)=\mu_{i}\left(\theta_{j} \mid \theta_{i}^{\prime}, \Upsilon^{n}\right)$ and $\mu_{i}\left(\theta_{j} \mid \theta_{i},\left(\Upsilon^{n-1}, a^{n}\right)\right)=\mu_{i}\left(\theta_{j} \mid \theta_{i},\left(\Upsilon^{n-1}, \hat{a}^{n}\right)\right)$ if $a_{j}^{n}=\hat{a}_{j}^{n}$.

\section{Appendix B. Proofs.}

Theorem 1. We prove this result in four steps. First, we show that the marketing manager's operations and compensation equal the optimal second-best ones. Second, we show that the performance of any contract with the production manager can be replicated by one where HQ provides him incentives for truthfully 
reporting the interval containing private information. Third, we derive (i) the optimal divisional operations and compensation of the production manager; and (ii) the internal-ordering decision optimal for the firm. Fourth, we show that the production manager does in fact operate his division optimally, and that the marketing manager orders the product if and only if it is beneficial for the firm.

Step 1 - The marketing manager. Given the transfer-pricing rule in (9) and profit shares in (7), we show that HQ induces the manager to operate the marketing division optimally at the lowest possible compensation. The firm's gains from trade are then $\Gamma\left(\Theta_{1}^{u}, \theta_{1}, \theta_{2}\right) \equiv\left[R\left(1, \bar{z}_{2}\left(\theta_{2}\right)\right)-b_{2}\left(\bar{z}_{2}\left(\theta_{2}\right)\right) h_{2}\left(\theta_{2}\right)\right]-\left[C\left(1, z_{1}^{C B}\left(\Theta_{1}^{u}, \theta_{1}\right)\right)+b_{1}\left(z_{1}^{C B}\left(\Theta_{1}^{u}, \theta_{1}\right)\right) \frac{v_{1}\left(\theta_{1}\right)}{v_{1}\left(\theta_{1}^{u}\right)} h_{1}\left(\theta_{1}^{u}\right)\right] .(\mathrm{A}-1)$

If the managers report truthfully: (i) with internal trade, marketing division's operations are identical to the second-best ones in (3): $z_{2}^{C B}\left(\theta_{2}, \theta_{2}\right)=\bar{z}_{2}\left(\theta_{2}\right)$ for all $\theta_{2} \in \Theta_{2}$; and (ii) the manager orders the product if and only if $E_{\Theta_{1}^{u}}\left[\Gamma\left(\Theta_{1}^{u}, \theta_{1}, \theta_{2}\right)\right] \geq 0$. Let $\hat{\Gamma}\left(\Theta_{1}^{u}, \theta_{1}, \theta_{2}\right) \equiv \max \left\{0, \Gamma\left(\Theta_{1}^{u}, \theta_{1}, \theta_{2}\right)\right\}$. HQ sets the manager's fixed-salary as follows:

$$
\beta_{2}\left(m_{2}\right)=\sum_{u=1}^{k}\left\{\int_{\bar{\theta}_{1}^{u-1}}^{\bar{\theta}_{1}^{u}}\left(b_{2}\left(z_{2}^{S B}\left(\theta_{1}, m_{2}\right)\right) v_{2}\left(m_{2}\right)-\alpha_{2}\left(m_{2}\right) \hat{\Gamma}\left(\Theta_{1}^{u}, \theta_{1}, m_{2}\right)+\int_{m_{2}}^{\bar{\theta}_{2}} b_{2}\left(z_{2}^{S B}\left(\theta_{1}, t\right)\right) v_{2}^{\prime}(t) d t\right) f_{1}\left(\theta_{1}\right) d \theta_{1}\right\} .
$$

The marketing manager's expected compensation is then

$$
E_{\Theta_{1}}\left[b_{2}\left(z_{2}^{S B}\left(\left(\theta_{1}, \theta_{2}\right)\right)\right) v_{2}\left(\theta_{2}\right)+\int_{\theta_{2}}^{\bar{\theta}_{2}} b_{2}\left(z_{2}^{S B}\left(\theta_{1}, t\right)\right) v_{2}^{\prime}(t) d t\right]
$$

which is the minimum second-best compensation (Fudenberg and Tirole, 1991). The marketing division's efficient revenue (net of compensation) is $\bar{R}\left(\theta_{2}\right) \equiv\left[R\left(1, \bar{z}_{2}\left(\theta_{2}\right)\right)-b_{2}\left(\bar{z}_{2}\left(\theta_{2}\right)\right) h_{2}\left(\theta_{2}\right)\right]$.

We next show that the manager reports truthfully using the following from Mirrlees (1986) - for any positive-valued function $W_{i}: \Theta_{i} \times \Theta_{i} \rightarrow \mathbb{R}, W_{i}\left(\theta_{i}, \theta_{i}\right) \geq W_{i}\left(\theta_{i}, m_{i}\right)$ for all $\theta_{i}, m_{i} \in \Theta_{i}$ if:

(i) $W_{i}\left(\theta_{i}, \theta_{i}\right)=W_{i}\left(\bar{\theta}_{i}, \bar{\theta}_{i}\right)-\int_{\theta_{i}}^{\bar{\theta}_{i}} \frac{\partial}{\partial \theta_{i}} W_{i}(t, t) d t \quad \forall \theta_{i} \in \Theta_{i}$; and (ii) $\frac{\partial}{\partial \theta_{i}} W_{i}\left(\theta_{i}, m_{i}\right)$ is weakly increasing in $m_{i}$ for all $\theta_{i}, m_{i} \in \Theta_{i}$. To use these sufficient conditions, let $W_{2}\left(\theta_{2}, m_{2}\right)$ represent the expected utility, under cost-based transfer pricing, of the manager with private information $\theta_{2}$ who reports $m_{2}$. We then have $W_{2}\left(\bar{\theta}_{2}, \bar{\theta}_{2}\right)=0$ and, using (A-2), sufficient condition (i) holds. Using the envelope theorem, 
$\frac{\partial}{\partial \theta_{2}} W_{2}\left(\theta_{2}, m_{2}\right)=-E_{\Theta_{2}}\left[b_{2}\left(z_{2}^{C B}\left(m_{2}, \theta_{2}\right)\right) v_{2}^{\prime}\left(\theta_{2}\right)\right]$. Since $\alpha_{2}\left(m_{2}\right)$ is decreasing in $m_{2}, z_{2}^{C B}\left(m_{2}, \theta_{2}\right)$ is

likewise decreasing in $m_{2}$. Thus, since $b_{2}(\cdot)$ is increasing in $z_{2}$ and $v_{2}^{\prime}\left(\theta_{2}\right)>0, \frac{\partial}{\partial \theta_{2}}\left[W_{2}\left(\theta_{2}, m_{2}\right)\right]$ is increasing in $m_{2}$, and sufficient condition (ii) holds.

Step 2 - Using truth-inducing contracts with production manager is without loss of generality. Consider any finite message set of size $\hat{k}$ for the production manager: $\hat{M}_{1}=\left\{m_{1}^{1}, \ldots, m_{1}^{\hat{k}}\right\}$. Any implementable divisional-operations rule $z_{1}: \hat{M}_{1} \times \Theta_{1} \rightarrow \mathbb{R}$ used by this manager must satisfy sequential rationality: it must maximize his utility at the stage of the game where the manager decides on divisional operations:

$$
z_{1}\left(m_{1}, \theta_{1}\right) \in \arg \min _{z_{1} \in Z_{1}}\left[\alpha_{1}\left(m_{1}\right) C\left(1, z_{1}\right)+b_{1}\left(z_{1}\right) v_{1}\left(\theta_{1}\right)\right] .
$$

The Revelation Principle does not apply here, but we now prove that an argument along the lines of the Principle applies to the following relaxed contract-design problem for the HQ - abstract for now from the marketing manager's internal-trade decision, and maximize the firm's profits with following instruments: the transfer-pricing rule $T\left(m_{1}\right)$; compensation plan $\left\langle\alpha_{1}\left(m_{1}\right), \beta_{1}\left(m_{1}\right)\right\rangle$; and HQ's internal-trade decision $q\left(m_{1}, \theta_{2}\right)$. This modified program is a relaxed one, since the real problem includes an additional constraint: the marketing manager's internal-trade decision must be sequentially rational. When the production manager's private information is $\theta_{1}$, expected utility from reporting $m_{1}$ is

$$
W\left(\theta_{1}, m_{1}\right) \equiv E_{\Theta_{2}}\left[\left\{\alpha_{1}\left(m_{1}\right)\left[T\left(m_{1}\right)-C\left(1, z_{1}\left(m_{1}, \theta_{1}\right)\right)\right]-b_{1}\left(z_{1}\left(m_{1}, \theta_{1}\right)\right) v_{1}\left(\theta_{1}\right)\right\} q\left(m_{1}, \theta_{2}\right)+\beta_{1}\left(m_{1}\right)\right] .
$$

$\left(\partial W / \partial z_{1}\right)$ - the partial derivative of the manager's expected utility in (A-4) with respect to $z_{1}\left(m_{1}, \theta_{1}\right)$ - equals $E_{\Theta_{2}}\left[\left\{-\alpha_{1}\left(m_{1}\right) C_{z_{1}}\left(1, z_{1}\left(m_{1}, \theta_{1}\right)\right)-b_{1}^{\prime}\left(z_{1}\left(m_{1}, \theta_{1}\right)\right) v_{1}\left(\theta_{1}\right)\right\} q\left(m_{1}, \theta_{2}\right)\right]$, and

$$
\frac{\partial}{\partial \theta_{1}}\left(\frac{\partial W}{\partial z_{1}}\right)=-E_{\Theta_{2}}\left[-b_{1}^{\prime}\left(z_{1}\left(m_{1}, \theta_{1}\right)\right) v_{1}^{\prime}\left(\theta_{1}\right) q\left(m_{1}, \theta_{2}\right)\right]<0 .
$$

Note that (A-5) is the standard Spence-Mirrlees single-crossing condition (Fudenberg and Tirole, 1991: 259). The condition means that, when viewed as functions of $\theta_{1}$, any two expected utilities $W\left(\theta_{1}, m_{1}\right)$ and $W\left(\theta_{1}, \hat{m}_{1}\right)$ either (i) are equal for all $\theta_{1} \in\left[\underline{\theta}_{1}, \bar{\theta}_{1}\right]$; or (ii) cross at most once on $\left[\underline{\theta}_{1}, \bar{\theta}_{1}\right]$.

Now consider any perfect Bayesian equilibrium (PBE) of the modified problem; the production manager's equilibrium reporting strategy $\lambda: \Theta_{1} \rightarrow \hat{M}_{1}$ must maximize the manager's expected utility: 
$\lambda\left(\theta_{1}\right) \in \underset{m_{1} \in \hat{M}_{1}}{\arg \max }\left[W\left(\theta_{1}, m_{1}\right)\right]$ (for simplicity, we consider pure strategies; identical analysis applies to mixed strategies). Since $\left|\hat{M}_{1}\right|<\left|\Theta_{1}\right|$, the production manager's reporting strategy must use identical reports for different realizations of private information: for some $\theta_{1}^{\prime}<\theta_{1}^{\prime \prime}, \lambda\left(\theta_{1}^{\prime}\right)=\lambda\left(\theta_{1}^{\prime \prime}\right)$. This means either that the manager's reporting strategy is constant (i.e., $\left.\lambda\left(\theta_{1}\right)=\lambda\left(\theta_{1}^{\prime}\right) \forall \theta_{1}, \theta_{1}^{\prime} \in\left[\underline{\theta}_{1}, \bar{\theta}_{1}\right]\right)$ or the reporting strategy has a number of discontinuities. We next show that if $\lambda\left(\theta_{1}\right)$ has more than $\hat{k}$ discontinuities, then there is a PBE of the modified problem in all respects identical to the PBE with $\lambda\left(\theta_{1}\right)$, with one exception: the production manager's reporting strategy $\hat{\lambda}\left(\theta_{1}\right)$ has at most $\hat{k}$ discontinuities.

Consider any pair $\theta_{1}^{\prime}<\theta_{1}^{\prime \prime}$, with $\lambda\left(\theta_{1}^{\prime}\right)=\lambda\left(\theta_{1}^{\prime \prime}\right)$. Suppose that $\lambda()$ is not constant on the interval $\left[\theta_{1}^{\prime}, \theta_{1}^{\prime \prime}\right]$, i.e. that for some $\hat{\theta}_{1} \in\left[\theta_{1}^{\prime}, \theta_{1}^{\prime \prime}\right], \lambda\left(\hat{\theta}_{1}\right) \neq \lambda\left(\theta_{1}^{\prime}\right)$. This means that $W\left(\hat{\theta}_{1}, \lambda\left(\hat{\theta}_{1}\right)\right) \geq W\left(\hat{\theta}_{1}, \lambda\left(\theta_{1}^{\prime}\right)\right)$. But it is not possible that $W\left(\hat{\theta}_{1}, \lambda\left(\hat{\theta}_{1}\right)\right)>W\left(\hat{\theta}_{1}, \lambda\left(\theta_{1}^{\prime}\right)\right)$, as we now show by contradiction. Suppose $W\left(\hat{\theta}_{1}, \lambda\left(\hat{\theta}_{1}\right)\right)>W\left(\hat{\theta}_{1}, \lambda\left(\theta_{1}^{\prime}\right)\right) . W\left(\hat{\theta}_{1}, \lambda\left(\hat{\theta}_{1}\right)\right)$ and $W\left(\hat{\theta}_{1}, \lambda\left(\theta_{1}^{\prime}\right)\right)$ are both continuous in $\theta_{1}$. Thus, there exists some open interval $\left(\dot{\theta}_{1}, \ddot{\theta}_{1}\right)$ that contains $\hat{\theta}_{1}$ and is itself a subset of $\left(\theta_{1}^{\prime}, \theta_{1}^{\prime \prime}\right)$ such that

$$
W\left(\dot{\theta}_{1}, \lambda\left(\theta_{1}\right)\right)>W\left(\dot{\theta}_{1}, \lambda\left(\theta_{1}^{\prime}\right)\right) \text { and } W\left(\ddot{\theta}_{1}, \lambda\left(\theta_{1}\right)\right)>W\left(\ddot{\theta}_{1}, \lambda\left(\theta_{1}^{\prime}\right)\right)
$$

(and, in fact, for every $\theta_{1} \in\left(\dot{\theta}_{1}, \ddot{\theta}_{1}\right)$, the manager strictly prefers reporting $\lambda\left(\hat{\theta}_{1}\right)$ over $\lambda\left(\theta_{1}^{\prime}\right)$ ). Recall that that the manager at least weakly prefers $\lambda\left(\theta_{1}^{\prime}\right)$ at the boundaries of $\left[\theta_{1}^{\prime}, \theta_{1}^{\prime \prime}\right]: W\left(\theta_{1}^{\prime}, \lambda\left(\theta_{1}^{\prime}\right)\right) \geq W\left(\theta_{1}^{\prime}, \lambda\left(\hat{\theta}_{1}\right)\right)$ and $W\left(\theta_{1}^{\prime \prime}, \lambda\left(\theta_{1}^{\prime}\right)\right) \geq W\left(\theta_{1}^{\prime \prime}, \lambda\left(\hat{\theta}_{1}\right)\right)$. Together with (A-6) this implies that $W\left(\theta_{1}, \lambda\left(\theta_{1}^{\prime}\right)\right)$ and $W\left(\theta_{1}, \lambda\left(\hat{\theta}_{1}\right)\right) \operatorname{cross}$ twice on $\left(\theta_{1}^{\prime}, \theta_{1}^{\prime \prime}\right)$ - a contradiction of single crossing. Thus, the manager with private information $\hat{\theta}_{1}$ is indifferent between reporting $\lambda\left(\hat{\theta}_{1}\right)$ and $\lambda\left(\theta_{1}^{\prime}\right): W\left(\hat{\theta}_{1}, \lambda\left(\hat{\theta}_{1}\right)\right)=W\left(\hat{\theta}_{1}, \lambda\left(\theta_{1}^{\prime}\right)\right)$. Also, since expected utility in (A-4) is continuous in $E_{\Theta_{2}}[q()]$ and in $z_{1}()$, if the manager is indifferent between reporting $\lambda\left(\hat{\theta}_{1}\right)$ and $\lambda\left(\theta_{1}^{\prime}\right)$ for $\theta_{1}$ in some open interval containing $\hat{\theta}_{1}$, then $E_{\Theta_{2}}\left[q\left(\lambda\left(\hat{\theta}_{1}\right), \theta_{2}\right)\right]=E_{\Theta_{2}}\left[q\left(\lambda\left(\theta_{1}^{\prime}\right), \theta_{2}\right)\right]$, and $z_{1}\left(\lambda\left(\hat{\theta}_{1}\right), \theta_{1}\right)=z_{1}\left(\lambda\left(\theta_{1}^{\prime}\right), \theta_{1}\right)$ for $\theta_{1}$ in that interval. 
We are now ready to construct the equivalent reporting strategy $\hat{\lambda}: \Theta_{1} \rightarrow \hat{M}_{1}$ that has at most $\hat{k}$ discontinuities. Begin with $\underline{\theta}_{1}$. It is possible that that multiple messages $m_{1} \in \hat{M}_{1}=\left\{m_{1}^{1}, \ldots, m_{1}^{\hat{k}}\right\}$ maximize the production manager's expected utility when the manager's private information is $\underline{\theta}_{1}$. We find the message $m_{1}\left(\underline{\theta}_{1}\right)$ that also maximizes the manager's expected utility for the "furthest" $\theta_{1} \in\left[\underline{\theta}_{1}, \bar{\theta}_{1}\right]$. Define $\hat{M}_{1}\left(\underline{\theta}_{1}\right) \subseteq \hat{M}_{1}$ as the set of messages among these that also maximize the manager's expected utility in some open set $\left(\underline{\theta}_{1}, \theta_{1}\right) \subseteq\left[\underline{\theta}_{1}, \bar{\theta}_{1}\right]$. For each $m_{1} \in \hat{M}_{1}\left(\underline{\theta}_{1}\right)$, find the maximum private information realization $\theta_{1}^{*}\left(m_{1}\right)$ for which $m_{1}$ maximizes the expected utility of the manager with this private information: $\theta_{1}^{*}\left(m_{1}\right) \equiv \sup \left\{\theta_{1} \in\left[\underline{\theta}_{1}, \bar{\theta}_{1}\right] \mid m_{1} \in \arg \max _{\hat{m}_{1} \in \hat{M}_{1}}\left[W\left(\theta_{1}, \hat{m}_{1}\right)\right]\right\}$. Find the largest $\theta_{1}^{*}\left(m_{1}\right)$ : $\hat{\theta}_{1}\left(\underline{\theta}_{1}\right) \equiv \max _{m_{1} \in \hat{M}_{1}\left(\underline{\theta}_{1}\right)}\left[\theta_{1}^{*}\left(m_{1}\right)\right]$. If there is a unique message $m_{1} \in \hat{M}_{1}\left(\underline{\theta}_{1}\right)$ that maximizes the expected utility of the manager with private information $\hat{\theta}_{1}\left(\underline{\theta}_{1}\right)$, define $m_{1}\left(\underline{\theta}_{1}\right)$ as that unique message; if there are several messages, define $m_{1}\left(\underline{\theta}_{1}\right)$ as the one among these with the lowest superscript index (just to impose a selection rule). Note that, since the message $m_{1}\left(\underline{\theta}_{1}\right)$ maximizes the manager's expected utility at $\underline{\theta}_{1}$ and at $\hat{\theta}_{1}\left(\underline{\theta}_{1}\right)$, it is also a best-response message for all $\theta_{1} \in\left[\underline{\theta}_{1}, \hat{\theta}_{1}\left(\underline{\theta}_{1}\right)\right)$. Define $\hat{\lambda}\left(\theta_{1}\right)=m_{1}\left(\underline{\theta}_{1}\right)$ for all $\theta_{1} \in\left[\underline{\theta}_{1}, \hat{\theta}_{1}\left(\underline{\theta}_{1}\right)\right)$. Note that $m_{1}\left(\underline{\theta}_{1}\right)$ cannot maximize the manager's expected utility for any $\theta_{1}>\hat{\theta}_{1}\left(\underline{\theta}_{1}\right)$.

Next, proceed to $\theta_{1}^{1} \equiv \hat{\theta}_{1}\left(\underline{\theta}_{1}\right)$. In the same manner, find the message $m_{1}\left(\theta_{1}^{1}\right)$ that maximizes the manager's expected utility at $\theta_{1}^{1}$ and at the "furthest" $\theta_{1} \in\left[\theta_{1}^{1}, \bar{\theta}_{1}\right]$ (use $\hat{\theta}_{1}\left(\theta_{1}^{1}\right)$ to represent this "furthest" point). Define $\hat{\lambda}\left(\theta_{1}\right)=m_{1}\left(\theta_{1}^{1}\right)$ for all $\theta_{1} \in\left[\theta_{1}^{1}, \hat{\theta}_{1}\left(\theta_{1}^{1}\right)\right)$. Proceed to $\theta_{1}^{2} \equiv \hat{\theta}_{1}\left(\theta_{1}^{1}\right)$. Continue this iterative process until finding a message $m_{1}\left(\theta_{1}^{u}\right)$ that maximizes the manager's utility at some $\theta_{1}^{u} \in\left[\underline{\theta}_{1}, \bar{\theta}_{1}\right)$ and also at $\bar{\theta}_{1}$. Define $\hat{\lambda}\left(\theta_{1}\right)=m_{1}\left(\theta_{1}^{u}\right)$ for all $\theta_{1} \in\left[\theta_{1}^{u}, \bar{\theta}_{1}\right]$.

By construction, $\hat{\lambda}\left(\theta_{1}\right)$ is an optimal reporting strategy; it is almost everywhere continuous in $\theta_{1}$, with at most $\hat{k}$ discontinuities, and where $\hat{\lambda}\left(\theta_{1}\right)$ is continuous, it is constant. Further, $\hat{\lambda}\left(\theta_{1}\right)$ partitions $\Theta_{1}$ into 
$k \leq \hat{k}$ intervals. Number these intervals in order of increasing $\theta_{1}: \Theta_{1}^{1}, \Theta_{1}^{2}, \ldots, \Theta_{1}^{k} ;$ let $M_{1} \equiv\left\{\Theta_{1}^{1}, \Theta_{1}^{2}, \ldots, \Theta_{1}^{k}\right\}$

We now construct a truth-inducing contract that replicates the performance of the PBE equilibrium (this follows the spirit of the proof of the Revelation Principle - for example, see Fudenberg and Tirole, 1991: 255-256). Define $\bar{\lambda}: M_{1} \rightarrow \hat{M}_{1}$ by $\bar{\lambda}\left(\Theta_{1}^{u}\right)=\hat{\lambda}\left(E_{\Theta_{1}^{u}}\left[\theta_{1}\right]\right)$. Consider $\left\langle\bar{\alpha}_{1}(), \bar{\beta}_{1}(), \bar{T}()\right\rangle, \bar{q}()$, with $\bar{\alpha}_{1} \equiv \alpha_{1} \circ \bar{\lambda} ; \bar{\beta}_{1} \equiv \beta_{1} \circ \bar{\lambda} ; \bar{T} \equiv T \circ \bar{\lambda} ;$ and $\bar{q}\left(m_{1}, \theta_{2}\right) \equiv q\left(\bar{\lambda}\left(m_{1}\right), \theta_{2}\right)$ for all $\theta_{2} \in \Theta_{2}$. If $\lambda\left(\theta_{1}\right)$ is the manager's reporting strategy in the original PBE, then truthful reporting is the manager's reporting strategy under $\left\langle\bar{\alpha}_{1}(), \bar{\beta}_{1}(), \bar{T}()\right\rangle, \bar{q}()$. The equilibrium outcomes are identical. Thus, the outcomes of every PBE can be obtained as outcomes of a PBE with truth-telling, and there is no loss for the HQ in considering only truth-inducing contracts.

Step 3 - Optimal contracting with the production manager. Because of IT constraints, second-best production decisions and compensation are not attainable. We next determine the optimal truth-inducing contract in the modified problem. We now use $W_{1}\left(\theta_{1}, \Theta_{1}^{u}\right)$ to represent the expected utility of the production manager with private information $\theta_{1}$ who reports $\Theta_{1}^{u}, u \in\{1,2, \ldots, k\}$, and selects any $z_{1}\left(\Theta_{1}^{u}, \theta_{1}\right)$ that satisfies (A-3) (suppressing the dependence of $W_{1}(\cdot)$ on $\alpha_{1}(\cdot)$ and $\beta_{1}(\cdot)$ ):

$W_{1}\left(\theta_{1}, \Theta_{1}^{u}\right) \equiv \beta_{1}\left(\Theta_{1}^{u}\right)+E_{\Theta_{2}}\left[q\left(\Theta_{1}^{u}, \theta_{2}\right)\right]\left(\alpha_{1}\left(\Theta_{1}^{u}\right)\left[T\left(\Theta_{1}^{u}\right)-C\left(1, z_{1}\left(\Theta_{1}^{u}, \theta_{1}\right)\right)\right]-b_{1}\left(z_{1}\left(\Theta_{1}^{u}, \theta_{1}\right)\right) v_{1}\left(\theta_{1}\right)\right)$.

The firm's modified problem is then Program A1:

$$
\max _{\substack{z_{1}(\cdot), \alpha_{1}(\cdot), \beta_{1}(\cdot), T(\cdot),(\cdot)}} E_{\Theta_{2}} \sum_{u=1}^{k} E_{\Theta_{1}^{u}}\left[q\left(\Theta_{1}^{u}, \theta_{2}\right)\left\{\bar{R}\left(\theta_{2}\right)-C\left(1, z_{1}\left(\Theta_{1}^{u}, \theta_{1}\right)\right)+\alpha_{1}\left(\Theta_{1}^{u}\right)\left[T\left(\Theta_{1}^{u}\right)-C\left(1, z_{1}\left(\Theta_{1}^{u}, \theta_{1}\right)\right)\right]\right\}+\beta_{1}\left(\Theta_{1}^{u}\right)\right],
$$

subject to: for all $u \in\{1,2, \ldots, k\}, \theta_{1} \in \Theta_{1}^{u}$ :

$$
\begin{aligned}
& z_{1}\left(\Theta_{1}^{u}, \theta_{1}\right) \in \arg \min _{z_{1} \in Z_{1}}\left[\alpha_{1}\left(\Theta_{1}^{u}\right) C\left(q\left(\Theta_{1}^{u}, \theta_{2}\right), z_{1}\right)+b_{1}\left(z_{1}\right) v_{1}\left(\theta_{1}\right)\right] \text { for all } \theta_{2} \in \Theta_{2} \\
& W_{1}\left(\theta_{1}, \Theta_{1}^{u}\right) \geq W_{1}\left(\theta_{1}, \Theta_{1}^{v}\right) \text { for all } v \in\{1,2, \ldots, k\} \\
& W_{1}\left(\theta_{1}, \Theta_{1}^{u}\right) \geq 0 .
\end{aligned}
$$

(A-8) is the production manager's sequential rationality constraint; (A-9) guarantees that the manager truthfully reports the interval containing $\theta_{1}$; and (A-10) is the standard participation, or individual 
rationality, constraint, which assures that the manager does not quit.

For every $\theta_{1} \in \Theta_{1}^{u}$, HQ needs to guarantee that the manager prefers reporting $\Theta_{1}^{u}$ to $\Theta_{1}^{u+1}$, i.e. $W_{1}\left(\theta_{1}, \Theta_{1}^{u}\right) \geq W_{1}\left(\theta_{1}, \Theta_{1}^{u+1}\right)$. For every $\hat{\theta}_{1} \in \Theta_{1}^{u+1}$, HQ needs to guarantee that the manager prefers reporting $\Theta_{1}^{u+1}$ to $\Theta_{1}^{u}$, i.e. $W_{1}\left(\hat{\theta}_{1}, \Theta_{1}^{u+1}\right) \geq W_{1}\left(\hat{\theta}_{1}, \Theta_{1}^{u}\right)$. By continuity of $W_{1}\left(\theta_{1}, \Theta_{1}^{u}\right)$ in $\theta_{1}$ for all $u \in\{1,2, \ldots, k\}$, this means that $W_{1}\left(\bar{\theta}_{1}^{u}, \Theta_{1}^{u}\right)=W_{1}\left(\bar{\theta}_{1}^{u}, \Theta_{1}^{u+1}\right)$, or, substituting (A-7):

$$
\begin{gathered}
E_{\Theta_{2}}\left[q\left(\Theta_{1}^{u+1}, \theta_{2}\right)\right]\left[\alpha_{1}\left(\Theta_{1}^{u+1}\right)\left(T\left(\Theta_{1}^{u+1}\right)-C\left(1, z_{1}\left(\Theta_{1}^{u+1}, \bar{\theta}_{1}^{u}\right)\right)\right)-b_{1}\left(z_{1}\left(\Theta_{1}^{u+1}, \bar{\theta}_{1}^{u}\right)\right) v_{1}\left(\bar{\theta}_{1}^{u}\right)\right]+\beta_{1}\left(\Theta_{1}^{u+1}\right) \\
=E_{\Theta_{2}}\left[q\left(\Theta_{1}^{u}, \theta_{2}\right)\right]\left[\alpha_{1}\left(\Theta_{1}^{u}\right)\left(T\left(\Theta_{1}^{u}\right)-C\left(1, z_{1}\left(\Theta_{1}^{u}, \bar{\theta}_{1}^{u}\right)\right)\right)-b_{1}\left(z_{1}\left(\Theta_{1}^{u}, \bar{\theta}_{1}^{u}\right)\right) v_{1}\left(\bar{\theta}_{1}^{u}\right)\right]+\beta_{1}\left(\Theta_{1}^{u}\right)
\end{gathered}
$$

for all $u \in\{1,2, \ldots, k-1\}$. We then set the fixed salary for the "worst" report $\Theta_{1}^{k}$ as low as possible to satisfy the participation constraint (A-10) for every $\theta_{1} \in \Theta_{1}^{k}$ :

$\alpha_{1}\left(\Theta_{1}^{k}\right) E_{\Theta_{2}}\left[q\left(\Theta_{1}^{k}, \theta_{2}\right)\right]\left[T\left(\Theta_{1}^{k}\right)-C\left(1, z_{1}\left(\Theta_{1}^{k}, \bar{\theta}_{1}^{k}\right)\right)\right]+\beta_{1}\left(\Theta_{1}^{k}\right)=E_{\Theta_{2}}\left[q\left(\Theta_{1}^{k}, \theta_{2}\right)\right] b_{1}\left(z_{1}\left(\Theta_{1}^{k}, \bar{\theta}_{1}^{k}\right)\right) v_{1}\left(\bar{\theta}_{1}^{k}\right)$

By induction, (A-11) gives the following necessary condition on production manager's compensation:

$$
\begin{aligned}
& \alpha_{1}\left(\Theta_{1}^{u}\right) E_{\Theta_{2}}\left[q\left(\Theta_{1}^{u}, \theta_{2}\right)\right]\left[T\left(\Theta_{1}^{u}\right)-C\left(1, z_{1}\left(\Theta_{1}^{u}, \bar{\theta}_{1}^{u}\right)\right)\right]+\beta_{1}\left(\Theta_{1}^{u}\right) \\
& =E_{\Theta_{2}}\left[q\left(\Theta_{1}^{u}, \theta_{2}\right) b_{1}\left(z_{1}\left(\Theta_{1}^{u}, \bar{\theta}_{1}^{u}\right)\right) v_{1}\left(\bar{\theta}_{1}^{u}\right)+\sum_{j=u+1}^{k} q\left(\Theta_{1}^{j}, \theta_{2}\right) b_{1}\left(z_{1}\left(\Theta_{1}^{j}, \bar{\theta}_{1}^{j}\right)\right)\left(v_{1}\left(\bar{\theta}_{1}^{j}\right)-v_{1}\left(\bar{\theta}_{1}^{j-1}\right)\right)\right] .
\end{aligned}
$$

Taking expectation over each $\Theta_{1}^{u}, u \in\{1, \ldots, k\}$, and then summing over $u \in\{1, \ldots, k\}$ to find expected compensation over the entire set $\Theta_{1}$ gives

$$
\begin{aligned}
& \sum_{u=1}^{k} E_{\Theta_{1}^{u}} E_{\Theta_{2}}\left[q\left(\Theta_{1}^{u}, \theta_{2}\right) b_{1}\left(z_{1}\left(\Theta_{1}^{u}, \bar{\theta}_{1}^{u}\right)\right) v_{1}\left(\bar{\theta}_{1}^{u}\right)+\sum_{j=u+1}^{k} q\left(\Theta_{1}^{j}, \theta_{2}\right) b_{1}\left(z_{1}\left(\Theta_{1}^{j}, \bar{\theta}_{1}^{j}\right)\right)\left(v_{1}\left(\bar{\theta}_{1}^{j}\right)-v_{1}\left(\bar{\theta}_{1}^{j-1}\right)\right)\right] \\
& =\sum_{u=1}^{k} E_{\Theta_{1}^{u}} E_{\Theta_{2}}\left[q\left(\Theta_{1}^{u}, \theta_{2}\right) b_{1}\left(z_{1}\left(\Theta_{1}^{u}, \bar{\theta}_{1}^{u}\right)\right) h_{1}\left(\theta_{1}^{u}\right)\right] .
\end{aligned}
$$

Substitute (A-12) and (A-13) into the objective of program A1 and rearrange to obtain Program A2:

$$
\begin{gathered}
\max _{\alpha_{1}(\cdot), q(\cdot)} \sum_{u=1}^{k} E_{\Theta_{1}^{u}} E_{\Theta_{2}} q\left(\Theta_{1}^{u}, \theta_{2}\right)\left[\bar{R}\left(\theta_{2}\right)-\left(1-\alpha_{1}\left(\Theta_{1}^{u}\right)\right) C\left(1, z_{1}\left(\Theta_{1}^{u}, \theta_{1}\right)\right)-b_{1}\left(z_{1}\left(\Theta_{1}^{u}, \theta_{1}\right)\right) v_{1}\left(\theta_{1}\right) \frac{v_{1}^{\prime}\left(\theta_{1}^{u}\right)}{v_{1}\left(\theta_{1}^{u}\right)} \frac{F_{1}\left(\theta_{1}^{u}\right)}{f_{1}\left(\theta_{1}^{u}\right)}\right. \\
\left.-\alpha_{1}\left(\Theta_{1}^{u}\right) C\left(1, z_{1}\left(\Theta_{1}^{u}, \bar{\theta}_{1}^{u}\right)\right)-b_{1}\left(z_{1}\left(\Theta_{1}^{u}, \bar{\theta}_{1}^{u}\right)\right) v_{1}\left(\bar{\theta}_{1}^{u}\right)\right]
\end{gathered}
$$

subject to $z_{1}\left(\Theta_{1}^{u}, \theta_{1}\right) \in \arg \min _{z_{1} \in Z_{1}}\left[\alpha_{1}\left(\Theta_{1}^{u}\right) C\left(q\left(\Theta_{1}^{u}, \theta_{2}\right), z_{1}\right)+b_{1}\left(z_{1}\right) v_{1}\left(\theta_{1}\right)\right] \forall u ; \theta_{1} \in \Theta_{1}^{u} ; \theta_{2} \in \Theta_{2}$.

From (A-14), $z_{1}\left(\Theta_{1}^{u}, \bar{\theta}_{1}^{u}\right) \in \arg \min _{z_{1} \in Z_{1}}\left[\alpha_{1}\left(\Theta_{1}^{u}\right) C\left(q\left(\Theta_{1}^{u}, \theta_{2}\right), z_{1}\right)+b_{1}\left(z_{1}\right) v_{1}\left(\bar{\theta}_{1}^{u}\right)\right]$. Program A2 is then just: 
$\max _{\alpha_{1}(\cdot), q(\cdot)} \sum_{u=1}^{k} E_{\Theta_{1}^{u}} E_{\Theta_{2}} q\left(\Theta_{1}^{u}, \theta_{2}\right)\left[\bar{R}\left(\theta_{2}\right)-\left(1-\alpha_{1}\left(\Theta_{1}^{u}\right)\right) C\left(1, z_{1}\left(\Theta_{1}^{u}, \theta_{1}\right)\right)-b_{1}\left(z_{1}\left(\Theta_{1}^{u}, \theta_{1}\right)\right) v_{1}\left(\theta_{1}\right) \frac{v_{1}^{\prime}\left(\theta_{1}^{u}\right)}{v_{1}\left(\theta_{1}^{u}\right)} \frac{F_{1}\left(\theta_{1}^{u}\right)}{f_{1}\left(\theta_{1}^{u}\right)}\right]$

subject to $z_{1}\left(\Theta_{1}^{u}, \theta_{1}\right) \in \arg \min _{z_{1} \in Z_{1}}\left[\alpha_{1}\left(\Theta_{1}^{u}\right) C\left(q\left(\Theta_{1}^{u}, \theta_{2}\right), z_{1}\right)+b_{1}\left(z_{1}\right) v_{1}\left(\theta_{1}\right)\right] \forall u ; \theta_{1} \in \Theta_{1}^{u} ; \theta_{2} \in \Theta_{2}$.

The first part of the solution is then to select, for every $u \in\{1,2, \ldots, k\}, \alpha_{1}\left(\Theta_{1}^{u}\right) \in(0,1)$ such that

$$
\frac{v_{1}^{\prime}\left(\theta_{1}^{u}\right)}{v_{1}\left(\theta_{1}^{u}\right)} \frac{F_{1}\left(\theta_{1}^{u}\right)}{f_{1}\left(\theta_{1}^{u}\right)} \frac{1}{1-\alpha_{1}\left(\Theta_{1}^{u}\right)}=\frac{1}{\alpha_{1}\left(\Theta_{1}^{u}\right)}
$$

This gives $\alpha_{1}\left(\Theta_{1}^{u}\right)=\frac{v_{1}\left(\theta_{1}^{u}\right)}{h_{1}\left(\theta_{1}^{u}\right)}$, which is equation (7). Efficient operations are then

$\hat{z}_{1}\left(\Theta_{1}^{u}, \theta_{1}\right) \equiv \arg \min _{z_{1} \in Z_{1}}\left[C\left(1, z_{1}\right)+b_{1}\left(z_{1}\right) h_{1}\left(\theta_{1}^{u}\right)\left(v_{1}\left(\theta_{1}\right) / v_{1}\left(\theta_{1}^{u}\right)\right)\right]$. The second part of the solution to the

relaxed program is to find the optimal internal-trade rule $\hat{q}()$. To do this, maximize pointwise over $q \in\{0,1\}$; substitute the optimal $\alpha_{1}\left(\Theta_{1}^{u}\right)$ and $z_{1}\left(\Theta_{1}^{u}, \theta_{1}\right)$; and use (A-1) to conclude:

$$
\hat{q}\left(\Theta_{1}^{u}, \theta_{2}\right)=1 \text { if and only if } E_{\Theta_{1}^{u}}\left[\Gamma\left(\Theta_{1}^{u}, \theta_{1}, \theta_{2}\right)\right] \geq 0 \text {. }
$$

HQ then sets $\beta_{1}\left(\Theta_{1}^{u}\right)$ to satisfy (A-12). The fact that the production manager reports truthfully when faced with the menus of contracts $\left\langle\alpha_{1}\left(\Theta_{1}^{u}\right), \beta_{1}\left(\Theta_{1}^{u}\right)\right\rangle$ can be verified using the Mirrlees (1986) technique in the same manner as (though more tediously than) for the marketing manager.

Step 4 - Firm's operations under the cost-based transfer-pricing contract. In step 3, we derived the optimal operations of the firm under a relaxed contract-design program. The final step is to show that the firm's expected profit with the additional constraint is the same as in the modified program.

For all $u \in\{1, \ldots, k\}, \theta_{1} \in \Theta_{1}^{u}, \theta_{2} \in \Theta_{2}$, the production manager's operating decision $z_{1}^{C B}\left(\Theta_{1}^{u}, \theta_{1}\right)$ is identical to $\hat{z}_{1}\left(\Theta_{1}^{u}, \theta_{1}\right)$ - the optimal one in the relaxed program. From (8) and (9), the marketing manager orders the product if and only if $E_{\Theta_{1}^{u}}\left[\Gamma\left(\Theta_{1}^{u}, \theta_{1}, \theta_{2}\right)\right] \geq 0$; thus, from (A-16), $q^{C B}\left(\Theta_{1}^{u}, \theta_{2}\right)=\hat{q}\left(\Theta_{1}^{u}, \theta_{2}\right)$. It is easy to verify that under either the firm's problem or the relaxed problem the production manager with the worst private information $\bar{\theta}_{1}$ does not receive any informational rents. The revenue equivalence theorem (Myerson, 1981, among others) then guarantees that the firm's expected profit is identical to the one under 
the relaxed program.

Theorem 2. $q^{N E G}: M_{1} \times \Theta_{1} \times \Theta_{2} \rightarrow\{0,1\}$ represents the internal-trade decisions with negotiated pricing. With truthful reporting, profit shares in (10) guarantee that the managers operate their divisions efficiently. HQ sets

$$
\begin{aligned}
& \beta_{1}\left(\Theta_{1}^{u}\right)=\delta E_{\Theta_{2}}\left[\sum_{j=u+1}^{k}\left[b_{1}\left(\dot{z}_{1}\left(\Theta_{1}^{j}, \theta_{2}\right)\right)\left(v_{1}\left(\bar{\theta}_{1}^{j}\right)-v_{1}\left(\bar{\theta}_{1}^{j-1}\right)\right)\right]-\alpha_{1}\left(\Theta_{1}^{u}\right) \int_{\bar{\theta}_{1}^{u-1}}^{\bar{\theta}_{1}^{u}} \hat{\Gamma}\left(\Theta_{1}^{u}, t, \theta_{2}\right) f_{1}(t) d t\right] \\
& \beta_{2}\left(m_{2}\right)=\delta \sum_{u=1}^{k}\left[\left(\int_{m_{2}}^{\bar{\theta}_{2}} b_{2}\left(\dot{z}_{2}\left(\Theta_{1}^{u}, t\right)\right) v_{2}^{\prime}(t) d t\right)\left(F_{1}\left(\bar{\theta}_{1}^{u}\right)-F_{1}\left(\bar{\theta}_{1}^{u-1}\right)\right)\right]
\end{aligned}
$$

where $\dot{z}_{1}\left(\Theta_{1}^{u}, \theta_{2}\right) \equiv \hat{z}_{1}\left(\Theta_{1}^{u}, \theta_{1}\right) ; \dot{z}_{2}\left(\Theta_{1}^{u}, \theta_{2}\right) \equiv \bar{z}_{2}\left(\theta_{2}\right)$ if $\Gamma\left(\Theta_{1}^{u}, \theta_{1}^{u}, \theta_{2}\right) \geq 0$; otherwise, $\dot{z}_{1}\left(\Theta_{1}^{u}, \theta_{2}\right)=\dot{z}_{2}\left(\Theta_{1}^{u}, \theta_{2}\right)=0$. HQ also sets a suitable intervention policy; one example is if, following $a^{0}=\left(\Theta_{1}^{u}, m_{2}\right)$, time period $\bar{n}$ is reached, HQ requires manager $i$ to implement the operating decisions $\dot{z}_{i}\left(\Theta_{1}^{u}, m_{2}\right)$, forces internal transfer if and only if $\Gamma\left(\Theta_{1}^{u}, \theta_{1}^{u}, \theta_{2}\right) \geq 0$, and pays the managers

$$
\begin{aligned}
& x_{1}=b_{1}\left(\dot{z}_{1}\left(\Theta_{1}^{u}, m_{2}\right)\right) v_{1}\left(\theta_{1}^{u}\right)+\sum_{j=u+1}^{k}\left[b_{1}\left(\dot{z}_{1}\left(\Theta_{1}^{j}, m_{2}\right)\right)\left(v_{1}\left(\bar{\theta}_{1}^{j}\right)-v_{1}\left(\bar{\theta}_{1}^{j-1}\right)\right)\right] ; \\
& x_{2}=b_{2}\left(\dot{z}_{2}\left(\Theta_{1}^{u}, m_{2}\right)\right) v_{2}\left(m_{2}\right)+\int_{m_{2}}^{\bar{\theta}_{2}} b_{2}\left(\dot{z}_{2}\left(\Theta_{1}^{u}, t\right)\right) v_{2}^{\prime}(t) d t .
\end{aligned}
$$

Now a straightforward adaptation of Vaysman (2005) guarantees that, when managers have private information $\theta_{1} \in \Theta_{1}^{u}, \theta_{2} \in \Theta_{2}$, every perfect Bayesian equilibrium of managers' interactions is a truthtelling one $\left(a^{0}=\left(\Theta_{1}^{u}, \theta_{2}\right)\right)$. Also, if $\Gamma\left(\Theta_{1}^{u}, \theta_{1}, \theta_{2}\right) \geq 0$, managers agree at $n=1$ to produce and transfer at the price in (28); if $\Gamma\left(\Theta_{1}^{u}, \theta_{1}, \theta_{2}\right)<0$, managers agree at $n=1$ not to produce.

We complete the proof of the theorem by showing that as long as the discount factor $\delta$ is strictly decreasing in the length of each bargaining period $\Delta$, the firm's expected profit is higher under negotiated transfer pricing than under cost-based transfer pricing. We prove this for the case where the discount factor represents continuous discounting at the rate $r$, or $\delta=e^{-r \Delta}$. The profit-sharing parameters under each method are equal. Divisional operations are then:

(i) if $q^{C B}\left(\Theta_{1}^{u}, \theta_{2}\right)=1$ and $q^{N E G}\left(\Theta_{1}^{u}, \theta_{1}, \theta_{2}\right)=1$, then

$$
z_{1}^{N E G}\left(\Theta_{1}^{u}, \theta_{1}\right)=z_{1}^{C B}\left(\Theta_{1}^{u}, \theta_{1}\right) \in \arg \min _{z_{1}}\left[C\left(1, z_{1}\right)+b_{1}\left(z_{1}\right)\left(v_{1}\left(\theta_{1}\right) / v_{1}\left(\theta_{1}^{u}\right)\right) h_{1}\left(\theta_{1}^{u}\right)\right], \text { and }
$$




$$
z_{2}^{N E G}\left(\theta_{2}, \theta_{2}\right)=z_{2}^{C B}\left(\theta_{2}, \theta_{2}\right)=\bar{z}_{2}\left(\theta_{2}\right)
$$

(ii) if $q^{C B}\left(\Theta_{1}^{u}, \theta_{2}\right)=0$ and $q^{N E G}\left(\Theta_{1}^{u}, \theta_{1}, \theta_{2}\right)=0$, then each manager sets the productivity parameter to zero under either transfer-pricing system.

With the optimal cost-based system of Theorem 1, the firm's expected profit is

$$
\Pi^{C B} \equiv E_{\Theta_{2}}\left[\sum_{u=1}^{k} q^{C B}\left(\Theta_{1}^{u}, \theta_{2}\right) E_{\theta_{1} \in \Theta_{1}^{u}}\left[\Gamma\left(\Theta_{1}^{u}, \theta_{1}, \theta_{2}\right)\right]\right] .
$$

With $\Pi^{N E G} \equiv E_{\Theta_{2}}\left[\sum_{u=1}^{k} E_{\Theta_{1}^{u}}\left[q^{N E G}\left(\Theta_{1}^{u}, \theta_{1}, \theta_{2}\right) \Gamma\left(\Theta_{1}^{u}, \theta_{1}, \theta_{2}\right)\right]\right]$, the firm's expected profit under these negotiated transfer-pricing equilibria is $\delta \Pi^{N E G}$. Let $\varepsilon=\ln \left[\frac{1}{2}\left(\frac{\Pi^{C B}}{\Pi^{N E G}}+1\right)\right]^{-\frac{1}{r}}$. For every $\theta_{2} \in \Theta_{2}$ and every $u \in\{1,2, \ldots, k\}$, partition the interval $\Theta_{1}^{u}$ into the following four sets:

- $S_{0}^{u}\left(\Theta_{1}^{u}, \theta_{2}\right) \equiv\left\{\theta_{1} \in \Theta_{1}^{u}\right.$ such that $q^{C B}\left(\Theta_{1}^{u}, \theta_{2}\right)=0$ and $\left.q^{N E G}\left(\Theta_{1}^{u}, \theta_{1}, \theta_{2}\right)=0\right\}$;

- $S_{1}^{u}\left(\Theta_{1}^{u}, \theta_{2}\right) \equiv\left\{\theta_{1} \in \Theta_{1}^{u}\right.$ such that $q^{C B}\left(\Theta_{1}^{u}, \theta_{2}\right)=1$ and $\left.q^{N E G}\left(\Theta_{1}^{u}, \theta_{1}, \theta_{2}\right)=1\right\}$;

- $S_{2}^{u}\left(\Theta_{1}^{u}, \theta_{2}\right) \equiv\left\{\theta_{1} \in \Theta_{1}^{u}\right.$ such that $q^{C B}\left(\Theta_{1}^{u}, \theta_{2}\right)=1$ and $\left.q^{N E G}\left(\Theta_{1}^{u}, \theta_{1}, \theta_{2}\right)=0\right\}$;

- $S_{3}^{u}\left(\Theta_{1}^{u}, \theta_{2}\right) \equiv\left\{\theta_{1} \in \Theta_{1}^{u}\right.$ such that $q^{C B}\left(\Theta_{1}^{u}, \theta_{2}\right)=0$ and $\left.q^{N E G}\left(\Theta_{1}^{u}, \theta_{1}, \theta_{2}\right)=1\right\}$.

For every $\theta_{2} \in \Theta_{2}$ and every $u \in\{1,2, \ldots, k\}$, at least two and at most three of the sets $S_{j}^{u}\left(\Theta_{1}^{u}, \theta_{2}\right)$ are nonempty. For at least some $\theta_{2} \in \Theta_{2}$ and $u \in\{1,2, \ldots, k\}$, the sets $S_{2}^{u}\left(\Theta_{1}^{u}, \theta_{2}\right)$ and $S_{3}^{u}\left(\Theta_{1}^{u}, \theta_{2}\right)$ are non-empty. For every $\theta_{2} \in \Theta_{2}$ and every $u \in\{1,2, \ldots, k\}$, we use (A-17) and (A-18) to derive the following:

$$
\begin{gathered}
\int_{\theta_{1} \in S_{0}^{u}\left(\Theta_{1}^{u}, \theta_{2}\right)}\left[q^{N E G}\left(\Theta_{1}^{u}, \theta_{1}, \theta_{2}\right) \Gamma\left(\Theta_{1}^{u}, \theta_{1}, \theta_{2}\right) f_{1}\left(\theta_{1}\right) d \theta_{1}\right]=q^{C B}\left(\Theta_{1}^{u}, \theta_{2}\right) \int_{\theta_{1} \in S_{0}^{u}\left(\Theta_{1}^{u}, \theta_{2}\right)} \Gamma\left(\Theta_{1}^{u}, \theta_{1}, \theta_{2}\right) f_{1}\left(\theta_{1}\right) d \theta_{1} ; \\
\int_{\theta_{1} \in S_{1}^{u}\left(\theta_{1}^{u}, \theta_{2}\right)}\left[q^{N E G}\left(\Theta_{1}^{u}, \theta_{1}, \theta_{2}\right) \Gamma\left(\Theta_{1}^{u}, \theta_{1}, \theta_{2}\right) f_{1}\left(\theta_{1}\right) d \theta_{1}\right]=q^{C B}\left(\Theta_{1}^{u}, \theta_{2}\right) \int_{\theta_{1} \in S_{1}^{u}\left(\Theta_{1}^{u}, \theta_{2}\right)} \Gamma\left(\Theta_{1}^{u}, \theta_{1}, \theta_{2}\right) f_{1}\left(\theta_{1}\right) d \theta_{1} .
\end{gathered}
$$

When $\theta_{1} \in S_{2}^{u}\left(\Theta_{1}^{u}, \theta_{2}\right), q^{N E G}\left(\Theta_{1}^{u}, \theta_{1}, \theta_{2}\right)=0$ and, thus, $\Gamma\left(\Theta_{1}^{u}, \theta_{1}, \theta_{2}\right)<0$. Hence,

$$
\int_{\theta_{1} \in S_{2}^{u}\left(\Theta_{1}^{u}, \theta_{2}\right)}\left[q^{N E G}\left(\Theta_{1}^{u}, \theta_{2}, \theta_{1}\right) \Gamma\left(\Theta_{1}^{u}, \theta_{2}, \theta_{1}\right) f_{1}\left(\theta_{1}\right) d \theta_{1}\right]>\int_{\theta_{1} \in S_{2}^{u}\left(\Theta_{1}^{u}, \theta_{2}\right)}\left[q^{C B}\left(\Theta_{1}^{u}, \theta_{2}, \theta_{2}\right) \Gamma\left(\Theta_{1}^{u}, \theta_{2}, \theta_{1}\right) f_{1}\left(\theta_{1}\right) d \theta_{1}\right] .
$$

When $\theta_{1} \in S_{3}^{u}\left(\Theta_{1}^{u}, \theta_{2}\right), q^{N E G}\left(\Theta_{1}^{u}, \theta_{1}, \theta_{2}\right)=1$ and, thus, $\Gamma\left(\Theta_{1}^{u}, \theta_{1}, \theta_{2}\right) \geq 0$. Hence, 
$\int_{\theta_{1} \in S_{3}^{u}\left(\Theta_{1}^{u}, \theta_{2}\right)}\left[q^{N E G}\left(\Theta_{1}^{u}, \theta_{1}, \theta_{2}\right) \Gamma\left(\Theta_{1}^{u}, \theta_{1}, \theta_{2}\right) f_{1}\left(\theta_{1}\right) d \theta_{1}\right] \geq \int_{\theta_{1} \in S_{3}^{u}\left(\Theta_{1}^{u}, \theta_{2}\right)}\left[q^{C B}\left(\Theta_{1}^{u}, \theta_{2}\right) \Gamma\left(\Theta_{1}^{u}, \theta_{1}, \theta_{2}\right) f_{1}\left(\theta_{1}\right) d \theta_{1}\right]$.

Combining the above four results, summing over $u \in\{1,2, \ldots, k\}$, and taking expectation over $\Theta_{2}$ :

$E_{\Theta_{2}}\left[\sum_{u=1}^{k} E_{\Theta_{1}^{u}}\left[q^{N E G}\left(\Theta_{1}^{u}, \theta_{1}, \theta_{2}\right) \Gamma\left(\Theta_{1}^{u}, \theta_{1}, \theta_{2}\right)\right]\right]>E_{\Theta_{2}}\left[\sum_{u=1}^{k} q^{C B}\left(\Theta_{1}^{u}, \theta_{2}\right) E_{\Theta_{1}^{u}}\left[\Gamma\left(\Theta_{1}^{u}, \theta_{1}, \theta_{2}\right)\right]\right]$,

or $\Pi^{N E G}>\Pi^{C B}$. From (A-19), we thus have $\left[\frac{1}{2}\left(\frac{\Pi^{C B}}{\Pi^{N E G}}+1\right)\right]<1$ and $\varepsilon>0$. With $0<\Delta<\varepsilon$,

$e^{-r \Delta}>\left[\frac{1}{2}\left(\frac{\Pi^{C B}}{\Pi^{N E G}}+1\right)\right]$, and $\delta \Pi^{N E G}=e^{-r \Delta} \Pi^{N E G}>\Pi^{N E G}\left[\frac{1}{2}\left(\frac{\Pi^{C B}}{\Pi^{N E G}}+1\right)\right]>\Pi^{C B}$.

Theorem 3. Begin with an information system with $k$ reporting intervals. Let $K \equiv\{k, 2 k, 4 k, \ldots\}$ represent the set indexing the sequence of improved information systems. We use $M_{1, j}, j \in K$, to refer to the production manager's message space under the system with $j$ reporting partitions. A generic reporting interval in this system is $\Theta_{1, j}^{u}, u \in\{1,2, \ldots, j\}$. The private information with average pre-transfer costs in the interval $\Theta_{1, j}^{u}$ is $\theta_{1, j}^{u}$. We continue to use $\Theta_{1, j}^{u}$ to represent production manager's report that private information is in the interval $\Theta_{1, j}^{u}$. We use

$$
G\left(\theta_{1}, \theta_{2}\right) \equiv\left[R\left(q^{S B}\left(\theta_{1}, \theta_{2}\right), \bar{z}_{2}\left(\theta_{2}\right)\right)-C\left(q^{S B}\left(\theta_{1}, \theta_{2}\right), \bar{z}_{1}\left(\theta_{1}\right)\right)-\sum_{i=1}^{2} b_{i}\left(\bar{z}_{i}\left(\theta_{i}\right)\right) h_{i}\left(\theta_{i}\right)\right]
$$

to represent the firm's gains from trade in the absence of IT constraints. Let $\Pi^{S B} \equiv E_{\left(\Theta_{1}, \Theta_{2}\right)}\left[G\left(\theta_{1}, \theta_{2}\right)\right]$. $\Pi_{j}^{N E G}$ represents expected profit for the optimal negotiated transfer-pricing scheme with an IT system with $j \in K$ intervals. For any bargaining-period length $\Delta$, with discount factor $\delta$, for all $j \in K$,

$$
\Pi_{j}^{N E G} \leq \delta \Pi^{S B} .
$$

For optimal cost-based pricing from Theorem 1, with an IT system with $j \in K$ intervals, we use the following notation: $\Pi_{j}^{C B}$ is the firm's expected profit; $q_{j}^{C B}: M_{1, j} \times \Theta_{2} \rightarrow\{0,1\}$ is the marketing manager's internal-ordering decision; $z_{1, j}^{C B}\left(\Theta_{1, j}^{u}, \theta_{1}\right)$ is the production manager's operating decision:

$$
z_{1, j}^{C B}\left(\Theta_{1, j}^{u}, \theta_{1}\right) \in \arg \min _{z_{1} \in Z_{1}}\left[C\left(1, z_{1}\right)+b_{1}\left(z_{1}\right) h_{1}\left(\theta_{1, j}^{u}\right)\left(v_{1}\left(\theta_{1}\right) / v_{1}\left(\theta_{1, j}^{u}\right)\right)\right] .
$$

The gains from trade with an IT system with $j$ intervals are 


$$
\begin{aligned}
\Gamma_{j}\left(\Theta_{1, j}^{u}, \theta_{1}, \theta_{2}\right) \equiv & {\left[R\left(1, \bar{z}_{2}\left(\theta_{2}\right)\right)-b_{2}\left(\bar{z}_{2}\left(\theta_{2}\right)\right) h_{2}\left(\theta_{2}\right)\right] } \\
& -\left[C\left(1, z_{1, j}^{C B}\left(\Theta_{1, j}^{u}, \theta_{1}\right)\right)+b_{1}\left(z_{1, j}^{C B}\left(\Theta_{1, j}^{u}, \theta_{1}\right)\right)\left(v_{1}\left(\theta_{1}\right) / v_{1}\left(\theta_{1, j}^{u}\right)\right) h_{1}\left(\theta_{1, j}^{u}\right)\right] .
\end{aligned}
$$

For each information system $j \in K$, for every $\theta_{2} \in \Theta_{2}$, and for every $u \in\{1,2, \ldots, j\}$, partition the reporting interval $\Theta_{1, j}^{u}$ into the following four sets:

- $S_{0, j}^{u}\left(\Theta_{1, j}^{u}, \theta_{2}\right) \equiv\left\{\theta_{1} \in \Theta_{1, j}^{u}\right.$ such that $q_{j}^{C B}\left(\Theta_{1, j}^{u}, \theta_{2}\right)=0$ and $\left.q^{S B}\left(\theta_{1}, \theta_{2}\right)=0\right\}$;

- $S_{1, j}^{u}\left(\Theta_{1, j}^{u}, \theta_{2}\right) \equiv\left\{\theta_{1} \in \Theta_{1, j}^{u}\right.$ such that $q_{j}^{C B}\left(\Theta_{1, j}^{u}, \theta_{2}\right)=1$ and $\left.q^{S B}\left(\theta_{1}, \theta_{2}\right)=0\right\}$;

- $S_{2, j}^{u}\left(\Theta_{1, j}^{u}, \theta_{2}\right) \equiv\left\{\theta_{1} \in \Theta_{1, j}^{u}\right.$ such that $q_{j}^{C B}\left(\Theta_{1, j}^{u}, \theta_{2}\right)=1$ and $\left.q^{S B}\left(\theta_{1}, \theta_{2}\right)=1\right\}$;

- $S_{3, j}^{u}\left(\Theta_{1, j}^{u}, \theta_{2}\right) \equiv\left\{\theta_{1} \in \Theta_{1, j}^{u}\right.$ such that $q_{j}^{C B}\left(\Theta_{1, j}^{u}, \theta_{2}\right)=0$ and $\left.q^{S B}\left(\theta_{1}, \theta_{2}\right)=1\right\}$.

With $q_{j}^{C B}\left(\Theta_{1, j}^{u}, \theta_{2}\right)=1$ if and only if $\Gamma_{j}\left(\Theta_{1, j}^{u}, \theta_{1}, \theta_{2}\right) \geq 0$, and $q^{S B}\left(\theta_{1}, \theta_{2}\right)=1$ if and only if $G\left(\theta_{1}, \theta_{2}\right) \geq 0$,

$$
\begin{aligned}
& \Pi_{j}^{C B}=E_{\Theta_{2}}\left[\sum_{u=1}^{j}\left(\sum_{m=1}^{2} E_{S_{m, j}^{u}\left(\Theta_{1, j}^{u}, \theta_{2}\right)}\left[\Gamma_{j}\left(\Theta_{1, j}^{u}, \theta_{1}, \theta_{2}\right)\right]\right)\right], \\
& \Pi^{S B}=E_{\Theta_{2}}\left[\sum_{u=1}^{j}\left(\sum_{m=2}^{3} E_{S_{m, j}^{u}\left(\Theta_{1, j}^{u}, \theta_{2}\right)}\left[G\left(\theta_{1}, \theta_{2}\right)\right]\right)\right] .
\end{aligned}
$$

For every $\theta_{1} \in \Theta_{1}$, for every $\varepsilon>0$, there is a $j \in K$ such that if $l \in K, l>j$, and $\theta_{1} \in \Theta_{1, l}^{u}$, then $\left|\theta_{1}-\theta_{1, l}^{u}\right|<\varepsilon$ for all $u \in\{1,2, \ldots, l\}$. For all $j$, for all $u \in\{1,2, \ldots, j\}:$ (i) (A-26) and (3) imply that $z_{1, j}^{C B}\left(\Theta_{1, j}^{u}, \theta_{1, j}^{u}\right)=\bar{z}_{1}\left(\theta_{1, j}^{u}\right)$; and (ii) (A-27) and (A-1) imply that $\Gamma_{j}\left(\Theta_{1, j}^{u}, \theta_{1}, \theta_{2, j}^{u}\right)=G\left(\theta_{1, j}^{u}, \theta_{2}\right)$ for every $\theta_{2} \in \Theta_{2} . z_{1, j}^{C B}\left(\Theta_{1, j}^{u}, \theta_{1}\right)$ and $\Gamma_{j}\left(\Theta_{1, j}^{u}, \theta_{1}, \theta_{2}\right)$ are monotone in $\theta_{1}$; thus, for every $\theta_{1} \in \Theta_{1}$, for every $\varepsilon>0$, there is a $j \in K$ such that if $l \in K, l>j$, and $\theta_{1} \in \Theta_{1, l}^{u}$, then $\left|z_{1, l}^{C B}\left(\Theta_{1, l}^{u}, \theta_{1}\right)-\bar{z}_{1}\left(\theta_{1}\right)\right|<\varepsilon$ and

$$
\left|\Gamma_{l}\left(\Theta_{1, l}^{u}, \theta_{1}, \theta_{2}\right)-G\left(\theta_{1}, \theta_{2}\right)\right|<\varepsilon \text { for all } u \in\{1,2, \ldots, l\}, \theta_{2} \in \Theta_{2} .
$$

This uniform convergence of $\Gamma_{j}\left(\Theta_{1, j}^{u}, \theta_{2}, \theta_{2}\right)$ to $G\left(\theta_{1}, \theta_{2}\right)$ in turn implies that there is a $j \in K$ such that for all $l \in K, l>j$, and $\theta_{2} \in \Theta_{2}$ :

$$
\begin{aligned}
& \sum_{u=1}^{l}\left[\int_{\theta_{1} \in S_{1, l}^{u}\left(\Theta_{1, l}^{u}, \theta_{2}\right)} f_{1}\left(\theta_{1}\right)\right] \leq \sum_{u=1}^{j}\left[\int_{\theta_{1} \in S_{1, j}^{u}\left(\Theta_{1, j}^{u}, \theta_{2}\right)} f_{1}\left(\theta_{1}\right)\right] ; \text { and } \\
& \sum_{u=1}^{l}\left[\int_{\theta_{1} \in S_{3, l}^{u}\left(\Theta_{1, l}^{u}, \theta_{2}\right)} f_{1}\left(\theta_{1}\right)\right] \leq \sum_{u=1}^{j}\left[\int_{\theta_{1} \in S_{3, j}^{u}\left(\Theta_{1, j}^{u}, \theta_{2}\right)} f_{1}\left(\theta_{1}\right)\right] .
\end{aligned}
$$

Since $\delta>0$, (A-34) and (A-35) imply that for some $j^{\prime} \in K$, if $l \in K$ and $l>j^{\prime}$, then for all $\theta_{2} \in \Theta_{2}$, 


$$
\begin{aligned}
& \sum_{u=1}^{l}\left[\int_{\theta_{1} \in S_{1, l}^{u}\left(\Theta_{1, l}^{u}, \theta_{2}\right)}\left|\Gamma_{l}\left(\Theta_{1, l}^{u}, \theta_{1}, \theta_{2}\right)-G\left(\theta_{1}, \theta_{2}\right)\right| f_{1}\left(\theta_{1}\right)\right] \leq \frac{\delta}{4}, \text { and, thus } \\
& E_{\Theta_{2}} \sum_{u=1}^{l}\left[E_{S_{1, l}^{u}\left(\Theta_{1, l}^{u}, \theta_{2}\right)}\left|\Gamma_{l}\left(\Theta_{1, l}^{u}, \theta_{1}, \theta_{2}\right)-G\left(\theta_{1}, \theta_{2}\right)\right|\right] \leq \frac{\delta}{4} .
\end{aligned}
$$

From (A-34) and (A-36), for some $j^{\prime \prime} \in K$, if $l \in K$ and $l>j^{\prime \prime}$, then for all $\theta_{2} \in \Theta_{2}$,

$$
\begin{aligned}
& \sum_{u=1}^{l}\left[\int_{\theta_{1} \in S_{3, l}^{u}\left(\Theta_{1, l}^{u}, \theta_{2}\right)}\left|\Gamma_{l}\left(\Theta_{1, l}^{u}, \theta_{1}, \theta_{2}\right)-G\left(\theta_{1}, \theta_{2}\right)\right| f_{1}\left(\theta_{1}\right)\right] \leq \frac{\delta}{4}, \text { and, thus } \\
& E_{\Theta_{2}} \sum_{u=1}^{l}\left[E_{S_{3, l}^{u}\left(\Theta_{1, l}^{u}, \theta_{2}\right)}\left|\Gamma_{l}\left(\Theta_{1, l}^{u}, \theta_{1}, \theta_{2}\right)-G\left(\theta_{1}, \theta_{2}\right)\right|\right] \leq \frac{\delta}{4} .
\end{aligned}
$$

For some $\hat{j} \in K$, if $l \in K$ and $l>\hat{j}$, then $\left|\Gamma_{l}\left(\Theta_{1, l}^{u}, \theta_{1}, \theta_{2}\right)-G\left(\theta_{1}, \theta_{2}\right)\right|<\frac{\delta}{4}$ for all $\theta_{2} \in \Theta_{2}$, $u \in\{1,2, \ldots, l\}, \theta_{1} \in \Theta_{1}^{u}$. Now if $l \in K$ and $l>\max \left\{j^{\prime}, j^{\prime \prime}, \hat{j}\right\}$, then, by (A-37) and (A-38),

$$
\left|\Pi_{l}^{C B}-\Pi^{S B}\right|=E_{\Theta_{2}}\left[\sum_{u=1}^{l}\left(\sum_{m=1}^{3} E_{S_{m, l}^{u}\left(\Theta_{1, l}^{u}, \theta_{2}\right)}\left|\Gamma_{l}\left(\Theta_{1, l}^{u}, \theta_{1}, \theta_{2}\right)-G\left(\theta_{1}, \theta_{2}\right)\right|\right)\right]<\frac{3}{4} \delta .
$$

This, along with (A-25), gives $\Pi_{l}^{C B}>\Pi_{l}^{N E G}$, completing the proof.

Theorem 4. The marketing manager's reporting set $M_{2}=\left\{\Theta_{2}^{1}, \Theta_{2}^{2}, \ldots, \Theta_{2}^{k}\right\}$ is a partition of $\Theta_{2}$ into $k$ intervals numbered in order of increasing $\theta_{2}$ (the results are not affected if the managers' reporting sets are of different sizes). We use $\bar{\theta}_{2}^{v}$ to refer to the upper bound of $\Theta_{2}^{v}$; the "typical" private-information realization $\theta_{2}^{v}$ in $\Theta_{2}^{v}$ is implicitly defined by $h_{2}\left(\theta_{2}^{v}\right)=E_{\Theta_{2}^{v}}\left[h_{2}\left(\theta_{2}\right)\right]$. For completeness, set $\bar{\theta}_{2}^{0} \equiv \underline{\theta}_{2}$. We prove the theorem in three steps: (i) we document the firm's operations with optimal cost-based transfer pricing; (ii) we show how HQ uses menus of managerial compensation contracts and intervention rules to guide the managers toward a truth-telling perfect Bayesian bargaining equilibrium under negotiated pricing; (iii) we show that, for a large enough discount factor $\delta$, the firm earns strictly higher expected profit under negotiated pricing.

Step 1. To document the firm's operations under optimal cost-based transfer pricing, we adjust the contract from Theorem 1 to incorporate marketing's IT constraints. First, note that, similar to Step 2 of Theorem 1 proof, there is no loss for the HQ in considering only truth-inducing contracts with each manager. HQ then uses: (i) $\alpha_{1}\left(\Theta_{1}^{u}\right)$ and $\alpha_{2}\left(\Theta_{2}^{v}\right)$ to provide incentives for the managers to operate efficiently; (ii) the transfer-pricing rule to manage internal trade given efficient divisional operations; and (iii) $\beta_{1}\left(\Theta_{1}^{u}\right)$ and $\beta_{2}\left(\Theta_{2}^{v}\right)$ to guarantee truthful reporting given the other contracting components. 
Along the lines of Step 3 of Theorem 1 proof, efficient divisional operations when $q^{C B}=1$ satisfy

$$
\begin{aligned}
& z_{1}^{*}\left(\Theta_{1}^{u}, \theta_{1}\right) \in \arg \min _{z_{1} \in Z_{1}}\left[C\left(1, z_{1}\right)+b_{1}\left(z_{1}\right) h_{1}\left(\theta_{1}^{u}\right)\left(v_{1}\left(\theta_{1}\right) / v_{1}\left(\theta_{1}^{u}\right)\right)\right] \text { and } \\
& z_{2}^{*}\left(\Theta_{2}^{v}, \theta_{2}\right) \in \arg \max _{z_{2} \in Z_{2}}\left[R\left(1, z_{2}\right)-b_{2}\left(z_{2}\right) h_{2}\left(\theta_{2}^{v}\right)\left(v_{2}\left(\theta_{2}\right) / v_{2}\left(\theta_{2}^{v}\right)\right)\right] .
\end{aligned}
$$

To provide incentives for the managers to operate their divisions efficiently, HQ sets profit shares ${ }^{28}$

$$
\alpha_{1}\left(\Theta_{1}^{u}\right)=\frac{v_{1}\left(\theta_{1}^{u}\right)}{h_{1}\left(\theta_{1}^{u}\right)} ; \quad \alpha_{2}\left(\Theta_{2}^{v}\right)=\frac{v_{2}\left(\theta_{2}^{v}\right)}{h_{2}\left(\theta_{2}^{v}\right)} \text {. }
$$

We use the following notation to represent each division's efficient cash flow (including the divisional manager's expected compensation) and the firm's gains from trade:

$$
\begin{aligned}
& R^{*}\left(\Theta_{2}^{v}, \theta_{2}\right) \equiv R\left(1, z_{2}^{*}\left(\Theta_{2}^{v}, \theta_{2}\right)\right)-b_{2}\left(z_{2}^{*}\left(\Theta_{2}^{v}, \theta_{2}\right)\right) h_{2}\left(\theta_{2}^{v}\right) \frac{v_{2}\left(\theta_{2}\right)}{v_{2}\left(\theta_{2}^{v}\right)} \\
& C^{*}\left(\Theta_{1}^{u}, \theta_{1}\right) \equiv C\left(1, z_{1}^{*}\left(\Theta_{1}^{u}, \theta_{1}\right)\right)+b_{1}\left(z_{1}^{*}\left(\Theta_{1}^{u}, \theta_{1}\right)\right) h_{1}\left(\theta_{1}^{u}\right) \frac{v_{1}\left(\theta_{1}\right)}{v_{1}\left(\theta_{1}^{u}\right)} \\
& \Gamma\left(\theta_{1}, \theta_{2}, \Theta_{1}^{u}, \Theta_{2}^{v}\right) \equiv R^{*}\left(\Theta_{2}^{v}, \theta_{2}\right)-C^{*}\left(\Theta_{1}^{u}, \theta_{1}\right) .
\end{aligned}
$$

Anticipating $\beta_{1}\left(\Theta_{1}^{u}\right)$ and $\beta_{2}\left(\Theta_{2}^{v}\right)$ specified below, along the lines of Steps 3 and 4 of Theorem 1 proof, the firm's optimal internal trade decision is

$$
q^{C B}\left(\Theta_{1}^{u}, \Theta_{2}^{v}, \theta_{2}\right)=1 \text { if and only if } E_{\Theta_{1}^{u}}\left[\Gamma\left(\theta_{1}, \theta_{2}, \Theta_{1}^{u}, \Theta_{2}^{v}\right)\right] \geq 0
$$

The cost-based transfer-pricing rule $T\left(\Theta_{1}^{u}\right)$ that implements this decision is identical to (9).

HQ guarantees truthful reporting at a minimum cost with the following fixed-salary components of managers' compensation (this can be checked using the Mirrlees, 1986 technique):

$$
\begin{aligned}
\beta_{1}\left(\Theta_{1}^{u}\right)= & \sum_{v=1}^{k} E_{\Theta_{2}^{v}}\left[q^{C B}\left(\Theta_{1}^{u}, \Theta_{2}^{v}, \theta_{2}\right)\left(b_{1}\left(z_{1}^{*}\left(\Theta_{1}^{u}, \bar{\theta}_{1}^{u}\right)\right) v_{1}\left(\bar{\theta}_{1}^{u}\right)-\alpha_{1}\left(\Theta_{1}^{u}\right)\left(T\left(\Theta_{1}^{u}\right)-C\left(1, z_{1}^{*}\left(\Theta_{1}^{u}, \bar{\theta}_{1}^{u}\right)\right)\right)\right)\right] \\
& +\sum_{v=1}^{k} E_{\Theta_{2}^{v}}\left[\sum_{j=u+1}^{k} q^{C B}\left(\Theta_{1}^{j}, \Theta_{2}^{v}, \theta_{2}\right) b_{1}\left(z_{1}^{*}\left(\Theta_{1}^{j}, \bar{\theta}_{1}^{j}\right)\right)\left(v_{1}\left(\bar{\theta}_{1}^{j}\right)-v_{1}\left(\bar{\theta}_{1}^{j-1}\right)\right)\right] \\
\beta_{2}\left(\Theta_{2}^{v}\right)= & \sum_{u=1}^{k} E_{\Theta_{1}^{u}}\left[q^{C B}\left(\Theta_{1}^{u}, \Theta_{2}^{v}, \bar{\theta}_{2}\right)\left(b_{2}\left(z_{2}^{*}\left(\Theta_{2}^{v}, \bar{\theta}_{2}^{v}\right)\right) v_{2}\left(\bar{\theta}_{2}^{v}\right)-\alpha_{2}\left(\Theta_{2}^{v}\right) \Gamma\left(\theta_{1}, \bar{\theta}_{2}, \Theta_{1}^{u}, \Theta_{2}^{v}\right)\right)\right] \\
& +\sum_{u=1}^{k} E_{\Theta_{1}^{u}}\left[\sum_{j=1}^{k} q^{C B}\left(\Theta_{1}^{u}, \Theta_{2}^{v}, \bar{\theta}_{2}\right) b_{2}\left(z_{2}^{*}\left(\Theta_{2}^{j}, \bar{\theta}_{2}^{j}\right)\right)\left(v_{2}\left(\bar{\theta}_{2}^{j}\right)-v_{2}\left(\bar{\theta}_{2}^{j-1}\right)\right)\right] .
\end{aligned}
$$

\footnotetext{
${ }^{28}$ As expected, the production manager's profit share is the same as in (7).
} 
Step 2. We now show how negotiated transfer pricing allows the firm to diminish the cost-based-pricing method's inefficiencies. Initially, we maintain the assumption that HQ can use $\beta_{1}\left(\Theta_{1}^{u}\right)$ and $\beta_{2}\left(\Theta_{2}^{v}\right)$ to support period-0 truthful reporting in a perfect Bayesian equilibrium (we will call such an equilibrium a truthful PBE) with the following HQ-mandated instruments: (i) profit shares identical to the ones in (A-41) ; (ii) $\bar{n}=2$; (iii) HQ's intervention threat to impose the optimal cost-based transfer price and let the marketing manager make the ordering decision.

Consider any game history $\Upsilon^{2}$ with $a^{0}=\left(\Theta_{1}^{u}, \Theta_{2}^{v}\right)$. Define $\hat{\theta}_{2}\left(\Theta_{1}^{u}, \Theta_{2}^{v}\right)$ as follows:

- If $R^{*}\left(\Theta_{2}^{v}, \bar{\theta}_{2}^{v}\right)>E_{\Theta_{1}^{u}}\left[C^{*}\left(\Theta_{1}^{u}, \theta_{1}\right)\right]$, let $\hat{\theta}_{2}\left(\Theta_{1}^{u}, \Theta_{2}^{v}\right)=\bar{\theta}_{2}^{v}$

- If $R^{*}\left(\Theta_{2}^{v}, \bar{\theta}_{2}^{v-1}\right)<E_{\Theta_{1}^{u}}\left[C^{*}\left(\Theta_{1}^{u}, \theta_{1}\right)\right]$, let $\hat{\theta}_{2}\left(\Theta_{1}^{u}, \Theta_{2}^{v}\right)=\bar{\theta}_{2}^{v-1}$

- Otherwise, implicitly define $\hat{\theta}_{2}\left(\Theta_{1}^{u}, \Theta_{2}^{v}\right)$ by $R^{*}\left(\Theta_{2}^{v}, \hat{\theta}_{2}\left(\Theta_{1}^{u}, \Theta_{2}^{v}\right)\right)=E_{\Theta_{1}^{u}}\left[C^{*}\left(\Theta_{1}^{u}, \theta_{1}\right)\right]$.

We use $U_{i}^{I}(\cdot)$ to represent the intervention-stage utility change of manager $i \in\{1,2\}$. By sequential rationality, if $\theta_{2}>\hat{\theta}_{2}\left(\Theta_{1}^{u}, \Theta_{2}^{v}\right), U_{1}^{I}\left(\Theta_{1}^{u}, \Theta_{2}^{v}, \theta_{1}, \theta_{2}\right)=U_{2}^{I}\left(\Theta_{1}^{u}, \Theta_{2}^{v}, \theta_{2}\right)=0$; if $\theta_{2} \leq \hat{\theta}_{2}\left(\Theta_{1}^{u}, \Theta_{2}^{v}\right)$ :

$$
\begin{aligned}
U_{1}^{I}\left(\Theta_{1}^{u}, \Theta_{2}^{v}, \theta_{1}, \theta_{2}\right) & =\alpha_{1}\left(\Theta_{1}^{u}\right)\left(E_{\Theta_{1}^{u}}\left[C^{*}\left(\Theta_{1}^{u}, \theta_{1}\right)\right]-C\left(1, z_{1}^{*}\left(\Theta_{1}^{u}, \theta_{1}\right)\right)\right)-b_{1}\left(z_{1}^{*}\left(\Theta_{1}^{u}, \theta_{1}\right)\right) v_{1}\left(\theta_{1}\right) \\
& =\alpha_{1}\left(\Theta_{1}^{u}\right)\left(E_{\Theta_{1}^{u}}\left[C^{*}\left(\Theta_{1}^{u}, \theta_{1}\right)\right]-C^{*}\left(\Theta_{1}^{u}, \theta_{1}\right)\right) \\
U_{2}^{I}\left(\Theta_{1}^{u}, \Theta_{2}^{v}, \theta_{2}\right)= & \alpha_{2}\left(\Theta_{2}^{v}\right)\left(R\left(1, z_{2}^{*}\left(\Theta_{2}^{v}, \theta_{2}\right)\right)-E_{\Theta_{1}^{u}}\left[C^{*}\left(\Theta_{1}^{u}, \theta_{1}\right)\right]\right)-b_{2}\left(z_{2}^{*}\left(\Theta_{2}^{v}, \theta_{2}\right)\right) v_{2}\left(\theta_{2}\right) \\
= & \alpha_{2}\left(\Theta_{2}^{v}\right)\left(R^{*}\left(\Theta_{2}^{v}, \theta_{2}\right)-E_{\Theta_{1}^{u}}\left[C^{*}\left(\Theta_{1}^{u}, \theta_{1}\right)\right]\right) .
\end{aligned}
$$

In any truthful PBE where marketing's period-1 price offer $p^{1}$ reveals whether $\theta_{2}$ is (weakly) less than or greater than $\hat{\theta}_{2}\left(\Theta_{1}^{u}, \Theta_{2}^{v}\right)$, production's acceptance strategy takes the form of two cut-off rules:

1. If $\int_{\underline{\theta}_{2}}^{\hat{\theta}_{2}\left(\Theta_{1}^{u}, \Theta_{2}^{v}\right)} \mu_{1}\left(\theta_{2} \mid \theta_{1}, \Upsilon^{1}\right) d \theta_{2}=1$, production accepts price offer $p^{1}$ if and only if $\alpha_{1}\left(\Theta_{1}^{u}\right)\left(p^{1}-C^{*}\left(\Theta_{1}^{u}, \theta_{1}\right)\right) \geq \delta U_{1}^{I}\left(\Theta_{1}^{u}, \Theta_{2}^{v}, \theta_{1}, \theta_{2}\right)$, or, equivalently (because $C^{*}\left(\Theta_{1}^{u}, \theta_{1}\right)$ is increasing in $\left.\theta_{1}\right)$ if and only if $\theta_{1} \leq \hat{\theta}_{1}\left(\Theta_{1}^{u}, p^{1}\right)$, with $\hat{\theta}_{1}\left(\Theta_{1}^{u}, p^{1}\right)$ defined as follows:

- If $p^{1}>\delta E_{\Theta_{1}^{u}}\left[C^{*}\left(\Theta_{1}^{u}, \theta_{1}\right)\right]+(1-\delta) C^{*}\left(\Theta_{1}^{u}, \bar{\theta}_{1}^{u}\right)$, then $\hat{\theta}_{1}\left(\Theta_{1}^{u}, p^{1}\right)=\bar{\theta}_{1}^{u}$;

- If $p^{1}<\delta E_{\Theta_{1}^{u}}\left[C^{*}\left(\Theta_{1}^{u}, \theta_{1}\right)\right]+(1-\delta) C^{*}\left(\Theta_{1}^{u}, \bar{\theta}_{1}^{u-1}\right)$, then $\hat{\theta}_{1}\left(\Theta_{1}^{u}, p^{1}\right)=\bar{\theta}_{1}^{u-1}$ 
- Otherwise, implicitly define $\hat{\theta}_{1}\left(\Theta_{1}^{u}, p^{1}\right)$ by $p^{1}=\delta E_{\Theta_{1}^{u}}\left[C^{*}\left(\Theta_{1}^{u}, \theta_{1}\right)\right]+(1-\delta) C^{*}\left(\Theta_{1}^{u}, \hat{\theta}_{1}\left(\Theta_{1}^{u}, p^{1}\right)\right)$.

2. If $\int_{\underline{\theta}_{2}}^{\hat{\theta}_{2}\left(\Theta_{1}^{u}, \Theta_{2}^{v}\right)} \mu_{1}\left(\theta_{2} \mid \theta_{1}, \Upsilon^{1}\right) d \theta_{2}=0$, production accepts price offer $p^{1}$ if and only if $p^{1} \geq C^{*}\left(\Theta_{1}^{u}, \theta_{1}\right)$, or, equivalently, if $\theta_{1} \leq \dot{\theta}_{1}\left(\Theta_{1}^{u}, p^{1}\right)$, with $\dot{\theta}_{1}\left(\Theta_{1}^{u}, p^{1}\right)$ defined as follows:

- If $p^{1}>C^{*}\left(\Theta_{1}^{u}, \bar{\theta}_{1}^{u}\right)$, then $\dot{\theta}_{1}\left(\Theta_{1}^{u}, p^{1}\right)=\bar{\theta}_{1}^{u}$;

- If $p^{1}<C^{*}\left(\Theta_{1}^{u}, \bar{\theta}_{1}^{u-1}\right)$, then $\dot{\theta}_{1}\left(\Theta_{1}^{u}, p^{1}\right)=\bar{\theta}_{1}^{u-1}$;

- $\quad$ Otherwise, implicitly define $\dot{\theta}_{1}\left(\Theta_{1}^{u}, p^{1}\right)$ by $p^{1}=C^{*}\left(\Theta_{1}^{u}, \dot{\theta}_{1}\left(\Theta_{1}^{u}, p^{1}\right)\right)$.

Now consider the following pure strategies by the marketing manager after $a^{0}=\left(\Theta_{1}^{u}, \Theta_{2}^{v}\right)$ :

Case 1: If $\theta_{2} \leq \hat{\theta}_{2}\left(\Theta_{1}^{u}, \Theta_{2}^{v}\right)$, marketing offers price $p^{1}\left(\Theta_{1}^{u}, \Theta_{2}^{v}, \theta_{2}\right)$ that solves

$$
\max _{p_{1} \geq 0}\left\{\left(F_{1}\left(\hat{\theta}_{1}\left(\Theta_{1}^{u}, p^{1}\right)\right)-F_{1}\left(\bar{\theta}_{1}^{u-1}\right)\right)\left(R^{*}\left(\Theta_{2}^{v}, \theta_{2}\right)(1-\delta)+\delta E_{\Theta_{1}^{u}}\left[C^{*}\left(\Theta_{1}^{u}, \theta_{1}\right)\right]-p^{1}\right)\right\} .
$$

Case 2: If $\theta_{2}>\hat{\theta}_{2}\left(\Theta_{1}^{u}, \Theta_{2}^{v}\right)$ and $R^{*}\left(\Theta_{2}^{v}, \theta_{2}\right)>C^{*}\left(\Theta_{1}^{u}, \bar{\theta}_{1}^{u-1}\right)$, marketing offers $p^{1}\left(\Theta_{1}^{u}, \Theta_{2}^{v}, \theta_{2}\right)$ that solves

$$
\max _{p_{1} \geq 0}\left\{\left(F_{1}\left(\dot{\theta}_{1}\left(\Theta_{1}^{u}, p^{1}\right)\right)-F_{1}\left(\bar{\theta}_{1}^{u-1}\right)\right)\left(R^{*}\left(\Theta_{2}^{v}, \theta_{2}\right)-p^{1}\right)\right\} .
$$

Case 3: If $R^{*}\left(\Theta_{2}^{v}, \theta_{2}\right)<C^{*}\left(\Theta_{1}^{u}, \bar{\theta}_{1}^{u-1}\right)$, marketing manager offers "No Production".

We next show that these offers and the production manager's strategy to accept marketing's "No Production" offer and the cut-off price-acceptance rules $\hat{\theta}_{1}\left(\Theta_{1}^{u}, p^{1}\right)$ and $\dot{\theta}_{1}\left(\Theta_{1}^{u}, p^{1}\right)$ specified above are in equilibrium for the continuation game starting at period 1, given a high enough $\delta$. In a truthful PBE, following $a^{0}=\left(\Theta_{1}^{u}, \Theta_{2}^{v}\right)$, the managers update their beliefs as follows:

$\mu_{1}\left(\theta_{2} \mid \theta_{1},\left(\Theta_{1}^{u}, \Theta_{2}^{v}\right)\right)=f_{2}\left(\theta_{2}\right)\left(F_{2}\left(\bar{\theta}_{2}^{v}\right)-F_{2}\left(\bar{\theta}_{2}^{v-1}\right)\right)^{-1}$ if $\theta_{2} \in \Theta_{2}^{v} ; \mu_{1}\left(\theta_{2} \mid \theta_{1},\left(\Theta_{1}^{u}, \Theta_{2}^{v}\right)\right)=0$ otherwise; (A-55) $\mu_{2}\left(\theta_{1} \mid \theta_{2},\left(\Theta_{1}^{u}, \Theta_{2}^{v}\right)\right)=f_{1}\left(\theta_{1}\right)\left(F_{1}\left(\bar{\theta}_{1}^{u}\right)-F_{1}\left(\bar{\theta}_{1}^{u-1}\right)\right)^{-1}$ if $\theta_{1} \in \Theta_{1}^{u} ; \mu_{2}\left(\theta_{1} \mid \theta_{2},\left(\Theta_{1}^{u}, \Theta_{2}^{v}\right)\right)=0$ otherwise. (A-56)

Given these beliefs and the production manager's strategy, if $R^{*}\left(\Theta_{2}^{v}, \theta_{2}\right)<C^{*}\left(\Theta_{1}^{u}, \bar{\theta}_{1}^{u-1}\right)$, any price offer by the marketing manager that has a strictly positive probability of being accepted must satisfy $p^{1}>C^{*}\left(\Theta_{1}^{u}, \bar{\theta}_{1}^{u-1}\right)$, which, since this implies $p^{1}>R^{*}\left(\Theta_{2}^{v}, \theta_{2}\right)$, results in strictly negative utility for the marketing manager. With $R^{*}\left(\Theta_{2}^{v}, \theta_{2}\right)<C^{*}\left(\Theta_{1}^{u}, \bar{\theta}_{1}^{u-1}\right)<E_{\Theta_{1}^{u}}\left[C^{*}\left(\Theta_{1}^{u}, \theta_{1}\right)\right]$, intervention-stage trade also 
strictly lowers the marketing manager's utility. The marketing manager thus offers "No Production."

We turn to Case 1. With $\theta_{2} \leq \hat{\theta}_{2}\left(\Theta_{1}^{u}, \Theta_{2}^{v}\right)$, if production rejects marketing's offer $p^{1}$, there will be internal trade at $n=2$. Given production's cut-off strategy, marketing's assessment of the probability that a price $p^{1}$ is accepted equals $\int_{\theta_{1}}^{\hat{\theta}_{1}\left(\Theta_{1}^{u}, p^{1}\right)} \mu_{2}\left(\theta_{1} \mid \theta_{2},\left(\Theta_{1}^{u}, \Theta_{2}^{v}\right)\right) d \theta_{1}$; marketing's utility change when this price is accepted is $\left[\alpha_{2}\left(\Theta_{2}^{v}\right)\left(R^{*}\left(\Theta_{2}^{v}, \theta_{2}\right)-p^{1}\right)\right]$. If the price is rejected, marketing earns the utility $U_{2}^{I}\left(\Theta_{1}^{u}, \Theta_{2}^{v}, \theta_{2}\right)$ one period later. Substituting (A-49) and (A-56), marketing picks $p^{1}$ to maximize

$$
\begin{aligned}
& \frac{F_{1}\left(\hat{\theta}_{1}\left(\Theta_{1}^{u}, p^{1}\right)\right)-F_{1}\left(\bar{\theta}_{1}^{u-1}\right)}{F_{1}\left(\bar{\theta}_{1}^{u}\right)-F_{1}\left(\bar{\theta}_{1}^{u-1}\right)} \alpha_{2}\left(\Theta_{2}^{v}\right)\left[R^{*}\left(\Theta_{2}^{v}, \theta_{2}\right)-p^{1}\right] \\
& +\left(1-\frac{F_{1}\left(\hat{\theta}_{1}\left(\Theta_{1}^{u}, p^{1}\right)\right)-F_{1}\left(\bar{\theta}_{1}^{u-1}\right)}{F_{1}\left(\bar{\theta}_{1}^{u}\right)-F_{1}\left(\bar{\theta}_{1}^{u-1}\right)}\right) \delta \alpha_{2}\left(\Theta_{2}^{v}\right)\left[R^{*}\left(\Theta_{2}^{v}, \theta_{2}\right)-E_{\Theta_{1}^{u}}\left[C^{*}\left(\Theta_{1}^{u}, \theta_{1}\right)\right]\right],
\end{aligned}
$$

which, after rearranging and dividing by $\alpha_{2}\left(\Theta_{2}^{v}\right)\left(F_{1}\left(\bar{\theta}_{1}^{u}\right)-F_{1}\left(\bar{\theta}_{1}^{u-1}\right)\right)^{-1}>0$, yields (A-52).

In Case 2, with $\theta_{2}>\hat{\theta}_{2}\left(\Theta_{1}^{u}, \Theta_{2}^{v}\right)$, marketing's assessment of the probability that $p^{1}$ is accepted equals $\int_{\underline{\theta}_{1}}^{\dot{\theta}_{1}\left(\Theta_{1}^{u}, p^{1}\right)} \mu_{2}\left(\theta_{1} \mid \theta_{2},\left(\Theta_{1}^{u}, \Theta_{2}^{v}\right)\right) d \theta_{1}$; with no intervention-stage trade, marketing picks $p^{1}$ to maximize $\frac{F_{1}\left(\dot{\theta}_{1}\left(\Theta_{1}^{u}, p^{1}\right)\right)-F_{1}\left(\bar{\theta}_{1}^{u-1}\right)}{F_{1}\left(\bar{\theta}_{1}^{u}\right)-F_{1}\left(\bar{\theta}_{1}^{u-1}\right)} \alpha_{2}\left(\Theta_{2}^{v}\right)\left[R^{*}\left(\Theta_{2}^{v}, \theta_{2}\right)-p^{1}\right]$, which is equivalent to (A-53).

Next, we show that, for a large enough $\delta, p^{1}\left(\Theta_{1}^{u}, \Theta_{2}^{v}, \theta_{2}\right)$ reveals whether $\theta_{2} \leq \hat{\theta}_{2}\left(\Theta_{1}^{u}, \Theta_{2}^{v}\right)$. We do this by contradiction: suppose for some $\theta_{2} \leq \hat{\theta}_{2}\left(\Theta_{1}^{u}, \Theta_{2}^{v}\right)<\theta_{2}^{\prime}, p^{1}\left(\Theta_{1}^{u}, \Theta_{2}^{v}, \theta_{2}\right)=p^{1}\left(\Theta_{1}^{u}, \Theta_{2}^{v}, \theta_{2}^{\prime}\right)$.

Differentiating (A-52) and rearranging, $p^{1}\left(\Theta_{1}^{u}, \Theta_{2}^{v}, \theta_{2}\right)$ satisfies

$$
\begin{aligned}
p^{1}\left(\Theta_{1}^{u}, \Theta_{2}^{v}, \theta_{2}\right)= & R^{*}\left(\Theta_{2}^{v}, \theta_{2}\right)(1-\delta)+\delta E_{\Theta_{1}^{u}}\left[C^{*}\left(\Theta_{1}^{u}, \theta_{1}\right)\right] \\
& -\frac{F_{1}\left(\hat{\theta}_{1}\left(\Theta_{1}^{u}, p^{1}\left(\Theta_{1}^{u}, \Theta_{2}^{v}, \theta_{2}^{\prime}\right)\right)\right)-F_{1}\left(\bar{\theta}_{1}^{u-1}\right)}{f_{1}\left(\hat{\theta}_{1}\left(\Theta_{1}^{u}, p^{1}\left(\Theta_{1}^{u}, \Theta_{2}^{v}, \theta_{2}^{\prime}\right)\right)\right) \frac{\partial}{\partial p_{1}} \hat{\theta}_{1}\left(\Theta_{1}^{u}, p^{1}\left(\Theta_{1}^{u}, \Theta_{2}^{v}, \theta_{2}^{\prime}\right)\right)} .
\end{aligned}
$$

From (A-53), $p^{1}\left(\Theta_{1}^{u}, \Theta_{2}^{v}, \theta_{2}^{\prime}\right)$ satisfies

$$
p^{1}\left(\Theta_{1}^{u}, \Theta_{2}^{v}, \theta_{2}^{\prime}\right)=R^{*}\left(\Theta_{2}^{v}, \theta_{2}^{\prime}\right)-\frac{F_{1}\left(\dot{\theta}_{1}\left(\Theta_{1}^{u}, p^{1}\left(\Theta_{1}^{u}, \Theta_{2}^{v}, \theta_{2}^{\prime}\right)\right)\right)-F_{1}\left(\bar{\theta}_{1}^{u-1}\right)}{f_{1}\left(\dot{\theta}_{1}\left(\Theta_{1}^{u}, p^{1}\left(\Theta_{1}^{u}, \Theta_{2}^{v}, \theta_{2}^{\prime}\right)\right)\right) \frac{\partial}{\partial p_{1}} \dot{\theta}_{1}\left(\Theta_{1}^{u}, p^{1}\left(\Theta_{1}^{u}, \Theta_{2}^{v}, \theta_{2}^{\prime}\right)\right)} .
$$

Since $\theta_{2} \leq \hat{\theta}_{2}\left(\Theta_{1}^{u}, \Theta_{2}^{v}\right)<\theta_{2}^{\prime}$, 


$$
R^{*}\left(\Theta_{2}^{v}, \theta_{2}\right)(1-\delta)+\delta E_{\Theta_{1}^{u}}\left[C^{*}\left(\Theta_{1}^{u}, \theta_{1}\right)\right] \geq E_{\Theta_{1}^{u}}\left[C^{*}\left(\Theta_{1}^{u}, \theta_{1}\right)\right]>R^{*}\left(\Theta_{2}^{v}, \theta_{2}^{\prime}\right) .
$$

From (A-50) and (A-51), for some $\delta^{\prime} \in(0,1)$, when $\delta^{\prime}<\delta<1$, we have, for all $p^{1}>0$,

$$
\frac{\partial}{\partial p_{1}} \hat{\theta}_{1}\left(\Theta_{1}^{u}, p^{1}\right)=\frac{1}{(1-\delta) \frac{\partial}{\partial \theta_{1}} C^{*}\left(\Theta_{1}^{u}, \hat{\theta}_{1}\left(\Theta_{1}^{u}, p^{1}\right)\right)}>\frac{1}{\frac{\partial}{\partial \theta_{1}} C^{*}\left(\Theta_{1}^{u}, \dot{\theta}_{1}\left(\Theta_{1}^{u}, p^{1}\right)\right)}=\frac{\partial}{\partial p_{1}} \dot{\theta}_{1}\left(\Theta_{1}^{u}, p^{1}\right) .
$$

Since $\theta_{2}^{\prime}>\hat{\theta}_{2}\left(\Theta_{1}^{u}, \Theta_{2}^{v}\right), p^{1}\left(\Theta_{1}^{u}, \Theta_{2}^{v}, \theta_{2}^{\prime}\right)<E_{\Theta_{1}^{u}}\left[C^{*}\left(\Theta_{1}^{u}, \theta_{1}\right)\right]$, and thus

$$
p^{1}\left(\Theta_{1}^{u}, \Theta_{2}^{v}, \theta_{2}^{\prime}\right)-\delta p^{1}\left(\Theta_{1}^{u}, \Theta_{2}^{v}, \theta_{2}^{\prime}\right)>p^{1}\left(\Theta_{1}^{u}, \Theta_{2}^{v}, \theta_{2}^{\prime}\right)-\delta E_{\Theta_{1}^{u}}\left[C^{*}\left(\Theta_{1}^{u}, \theta_{1}\right)\right] \text {. }
$$

Using the definition of $\hat{\theta}_{1}\left(\Theta_{1}^{u}, p^{1}\right)$ in (A-50), of $\dot{\theta}_{1}\left(\Theta_{1}^{u}, p^{1}\right)$ in (A-51) along with (A-61) gives $\hat{\theta}_{1}\left(\Theta_{1}^{u}, p^{1}\left(\Theta_{1}^{u}, \Theta_{2}^{v}, \theta_{2}^{\prime}\right)\right)<\dot{\theta}_{1}\left(\Theta_{1}^{u}, p^{1}\left(\Theta_{1}^{u}, \Theta_{2}^{v}, \theta_{2}^{\prime}\right)\right)$ and, thus, using the monotone risk ratio condition,

$$
\frac{F_{1}\left(\hat{\theta}_{1}\left(\Theta_{1}^{u}, p^{1}\left(\Theta_{1}^{u}, \Theta_{2}^{v}, \theta_{2}^{\prime}\right)\right)\right)-F_{1}\left(\bar{\theta}_{1}^{u-1}\right)}{f_{1}\left(\hat{\theta}_{1}\left(\Theta_{1}^{u}, p^{1}\left(\Theta_{1}^{u}, \Theta_{2}^{v}, \theta_{2}^{\prime}\right)\right)\right)}<\frac{F_{1}\left(\dot{\theta}_{1}\left(\Theta_{1}^{u}, p^{1}\left(\Theta_{1}^{u}, \Theta_{2}^{v}, \theta_{2}^{\prime}\right)\right)\right)-F_{1}\left(\bar{\theta}_{1}^{u-1}\right)}{f_{1}\left(\dot{\theta}_{1}\left(\Theta_{1}^{u}, p^{1}\left(\Theta_{1}^{u}, \Theta_{2}^{v}, \theta_{2}^{\prime}\right)\right)\right)} .
$$

Combining (A-59), (A-60), and (A-62) gives $p^{1}\left(\Theta_{1}^{u}, \Theta_{2}^{v}, \theta_{2}\right)>p^{1}\left(\Theta_{1}^{u}, \Theta_{2}^{v}, \theta_{2}^{\prime}\right)$, providing the contradiction. Using similar logic, for some $\delta^{\prime \prime} \in(0,1)$, as long as $\delta^{\prime \prime}<\delta<1$, if $\theta_{2} \leq \hat{\theta}_{2}\left(\Theta_{1}^{u}, \Theta_{2}^{v}\right)<\theta_{2}^{\prime}$, it is not possible that $p^{1}\left(\Theta_{1}^{u}, \Theta_{2}^{v}, \theta_{2}^{\prime}\right)$ solves

$$
\max _{p_{1} \geq 0}\left\{\left(F_{1}\left(\dot{\theta}_{1}\left(\Theta_{1}^{u}, p^{1}\right)\right)-F_{1}\left(\bar{\theta}_{1}^{u-1}\right)\right)\left(R^{*}\left(\Theta_{2}^{v}, \theta_{2}\right)(1-\delta)+\delta E_{\Theta_{1}^{u}}\left[C^{*}\left(\Theta_{1}^{u}, \theta_{1}\right)\right]-p^{1}\right)\right\} .
$$

Thus, when the marketing manager's private information is $\theta_{2} \leq \hat{\theta}_{2}\left(\Theta_{1}^{u}, \Theta_{2}^{v}\right)$, the manager does not mimic the pricing strategy used when private information is $\theta_{2}^{\prime}>\hat{\theta}_{2}\left(\Theta_{1}^{u}, \Theta_{2}^{v}\right)$. And when the marketing manager's private information is $\theta_{2}^{\prime}>\hat{\theta}_{2}\left(\Theta_{1}^{u}, \Theta_{2}^{v}\right)$, the manager does not mimic by offering $p^{1}\left(\Theta_{1}^{u}, \Theta_{2}^{v}, \theta_{2}\right)$ for some $\theta_{2} \leq \hat{\theta}_{2}\left(\Theta_{1}^{u}, \Theta_{2}^{v}\right)$, since $\hat{\theta}_{1}\left(\Theta_{1}^{u}, p^{1}\right)<\dot{\theta}_{1}\left(\Theta_{1}^{u}, p^{1}\right)$ and (A-53) imply

$$
\begin{aligned}
& \left(F_{1}\left(\hat{\theta}_{1}\left(\Theta_{1}^{u}, p^{1}\left(\Theta_{1}^{u}, \Theta_{2}^{v}, \theta_{2}\right)\right)\right)-F_{1}\left(\bar{\theta}_{1}^{u-1}\right)\right)\left(R^{*}\left(\Theta_{2}^{v}, \theta_{2}^{\prime}\right)-p^{1}\left(\Theta_{1}^{u}, \Theta_{2}^{v}, \theta_{2}\right)\right) \\
& \quad<\left(F_{1}\left(\dot{\theta}_{1}\left(\Theta_{1}^{u}, p^{1}\left(\Theta_{1}^{u}, \Theta_{2}^{v}, \theta_{2}\right)\right)\right)-F_{1}\left(\bar{\theta}_{1}^{u-1}\right)\right)\left(R^{*}\left(\Theta_{2}^{v}, \theta_{2}^{\prime}\right)-p^{1}\left(\Theta_{1}^{u}, \Theta_{2}^{v}, \theta_{2}\right)\right) \\
& \quad \leq\left(F_{1}\left(\dot{\theta}_{1}\left(\Theta_{1}^{u}, p^{1}\left(\Theta_{1}^{u}, \Theta_{2}^{v}, \theta_{2}^{\prime}\right)\right)\right)-F_{1}\left(\bar{\theta}_{1}^{u-1}\right)\right)\left(R^{*}\left(\Theta_{2}^{v}, \theta_{2}^{\prime}\right)-p^{1}\left(\Theta_{1}^{u}, \Theta_{2}^{v}, \theta_{2}^{\prime}\right)\right) .
\end{aligned}
$$

Off the equilibrium path, following a detectable deviation, beliefs are updated as follows: the marketing manager does not revise prior beliefs; the production manager updates beliefs to $\mu_{1}\left(\underline{\theta}_{2} \mid \theta_{1}, \Upsilon^{1}\right)=1$. Marketing's strategy following a production deviation is to order the product if and only 
if $\theta_{2} \leq \hat{\theta}_{2}\left(\Theta_{1}^{u}, \Theta_{2}^{v}\right)$. Production's strategy following a marketing-manager deviation is: (i) to accept a "No Production" offer, and (ii) accept a price offer $p^{1}$ if and only if $p^{1}>\max \left\{C^{*}\left(\Theta_{1}^{u}, \theta_{1}\right), R^{*}\left(\Theta_{2}^{v}, \underline{\theta}_{2}\right)\right\}$.

Now, with $\max \left\{\delta^{\prime}, \delta^{\prime \prime}\right\}<\delta<1$, given marketing's strategy, if offered "No Production," the production manager always accepts. Otherwise, the cut-off strategies $\hat{\theta}_{1}\left(\Theta_{1}^{u}, p^{1}\right)$ and $\dot{\theta}_{1}\left(\Theta_{1}^{u}, p^{1}\right)$ are optimal. And marketing's strategies in (A-52)-(A-54) are an optimal response for the continuation game starting at period lof a truthful PBE. We use $q^{N E G}\left(\Theta_{1}^{u}, \Theta_{2}^{v}, \theta_{1}, \theta_{2}\right) \in\{0,1\}$ to represent the internal-order outcome in this PBE, when $a^{0}=\left(\Theta_{1}^{u}, \Theta_{2}^{v}\right)$, and the managers' private-information realizations are $\theta_{1}$ and $\theta_{2}$. $\hat{q}^{N E G}\left(\Theta_{1}^{u}, \Theta_{2}^{v}, \theta_{1}, \theta_{2}\right)$ represents the present value, at time 0 , of $q^{N E G}\left(\Theta_{1}^{u}, \Theta_{2}^{v}, \theta_{1}, \theta_{2}\right)$ : $\hat{q}^{N E G}\left(\Theta_{1}^{u}, \Theta_{2}^{v}, \theta_{1}, \theta_{2}\right)=\delta^{n} q^{N E G}\left(\Theta_{1}^{u}, \Theta_{2}^{v}, \theta_{1}, \theta_{2}\right)$ if there is internal trade at time $n$; if there is no internal trade $\hat{q}^{N E G}\left(\Theta_{1}^{u}, \Theta_{2}^{v}, \theta_{1}, \theta_{2}\right)=0$. HQ sets $\beta_{i}(\cdot)$ 's as follows:

$$
\begin{aligned}
\beta_{1}\left(\Theta_{1}^{u}\right)= & \sum_{v=1}^{k} E_{\Theta_{2}^{v}}\left[\hat{q}^{N E G}\left(\Theta_{1}^{j}, \Theta_{2}^{v}, \bar{\theta}_{1}^{u}, \theta_{2}\right)\left(b_{1}\left(z_{1}^{*}\left(\Theta_{1}^{u}, \bar{\theta}_{1}^{u}\right)\right) v_{1}\left(\bar{\theta}_{1}^{u}\right)-\alpha_{1}\left(\Theta_{1}^{u}\right)\left(p^{1}\left(\Theta_{1}^{u}, \Theta_{2}^{v}, \theta_{2}\right)-C\left(1, z_{1}^{*}\left(\Theta_{1}^{u}, \bar{\theta}_{1}^{u}\right)\right)\right)\right)\right] \\
& +\sum_{v=1}^{k} E_{\Theta_{2}^{v}}\left[\sum_{j=u+1}^{k} \hat{q}^{N E G}\left(\Theta_{1}^{j}, \Theta_{2}^{v}, \bar{\theta}_{1}^{j}, \theta_{2}\right) b_{1}\left(z_{1}^{*}\left(\Theta_{1}^{j}, \bar{\theta}_{1}^{j}\right)\right)\left(v_{1}\left(\bar{\theta}_{1}^{j}\right)-v_{1}\left(\bar{\theta}_{1}^{j-1}\right)\right)\right] ; \\
\beta_{2}\left(\Theta_{2}^{v}\right)= & \sum_{u=1}^{k} E_{\Theta_{1}^{u}}\left[\hat{q}^{N E G}\left(\Theta_{1}^{j}, \Theta_{2}^{v}, \theta_{1}, \bar{\theta}_{2}^{v}\right)\left(b_{2}\left(z_{2}^{*}\left(\Theta_{2}^{v}, \bar{\theta}_{2}^{v}\right)\right) v_{2}\left(\bar{\theta}_{2}^{v}\right)-\alpha_{2}\left(\Theta_{2}^{v}\right)\left(R\left(1, z_{2}^{*}\left(\Theta_{2}^{v}, \bar{\theta}_{2}^{v}\right)\right)-p^{1}\left(\Theta_{1}^{u}, \Theta_{2}^{v}, \bar{\theta}_{2}^{v}\right)\right)\right)\right] \\
& +\sum_{u=1}^{k} E_{\Theta_{1}^{u}}\left[\sum_{j=1}^{k} \hat{q}^{N E G}\left(\Theta_{1}^{j}, \Theta_{2}^{v}, \theta_{1}, \bar{\theta}_{2}^{v}\right) b_{2}\left(z_{2}^{*}\left(\Theta_{2}^{j}, \bar{\theta}_{2}^{j}\right)\right)\left(v_{2}\left(\bar{\theta}_{2}^{j}\right)-v_{2}\left(\bar{\theta}_{2}^{j-1}\right)\right)\right] .
\end{aligned}
$$

With the off-equilibrium beliefs and strategies specified above, these fixed-salary components of managers' compensation contracts support period-0 truthful reporting in the equilibrium specified above (as before, the Mirrlees, 1986 technique implies this as long as $z_{1}^{*}\left(\Theta_{1}^{u}, \theta\right)$ is decreasing in $u$ and $z_{2}^{*}\left(\Theta_{2}^{v}, \bar{\theta}_{2}^{v}\right)$ is decreasing in $v$, which in turn holds by (A-39) and (A-40)).

Step 3. The analysis proceeds closely along the lines of Theorem 2 proof above (though, of course, here it is no longer that case that negotiated transfer pricing leads to internal trade if and only if there are gains from trade). The key steps in the analysis are as follows. From Step 1 and Step 2 above, note that if $q^{C B}\left(\Theta_{1}^{u}, \Theta_{2}^{v}, \theta_{2}\right)=1$, then $R^{*}\left(\Theta_{2}^{v}, \theta_{2}\right)>E_{\Theta_{1}^{u}}\left[C^{*}\left(\Theta_{1}^{u}, \theta_{1}\right)\right]$; thus, $U_{2}^{I}\left(\Theta_{1}^{u}, \Theta_{2}^{v}, \theta_{2}\right)>0$; and, thus, $q^{N E G}\left(\Theta_{1}^{u}, \Theta_{2}^{v}, \theta_{1}, \theta_{2}\right)=1$ for all $\theta_{1} \in \Theta_{1}^{u}$. Thus, whenever there is internal trade under optimal cost-based 
transfer pricing, there is internal trade under negotiated pricing of Step 2 (delayed at most two periods).

Consider the regions $\Theta_{1}^{u} \times \Theta_{2}^{v}$ where $\Gamma\left(\bar{\theta}_{1}^{u-1}, \bar{\theta}_{2}^{v-1}, \Theta_{1}^{u}, \Theta_{2}^{v}\right)>0$ and $\Gamma\left(\bar{\theta}_{1}^{u}, \bar{\theta}_{2}^{v}, \Theta_{1}^{u}, \Theta_{2}^{v}\right)<0$ (the existence of these regions is guaranteed because the firm's internal-trade decision is non-trivial). Under cost-based transfer pricing, the "no-trade" inefficiency is the subset of $\Theta_{1}^{u} \times \Theta_{2}^{v}$ where $\Gamma\left(\theta_{1}, \theta_{2}, \Theta_{1}^{u}, \Theta_{2}^{v}\right)>0$ yet $E_{\Theta_{1}^{u}}\left[\Gamma\left(\theta_{1}, \theta_{2}, \Theta_{1}^{u}, \Theta_{2}^{v}\right)\right]<0$. The set $S\left(\Theta_{1}^{u}, \Theta_{2}^{v}\right) \equiv\left\{\theta_{2} \in \Theta_{2}^{v}\right.$ such that $\left.\Gamma\left(\bar{\theta}_{1}^{u-1}, \theta_{2}, \Theta_{1}^{u}, \Theta_{2}^{v}\right)>0\right\}$ is non-empty and continuous. When $\theta_{2} \in S\left(\Theta_{1}^{u}, \Theta_{2}^{v}\right)$, the marketing manager offers the price $p^{1}\left(\Theta_{1}^{u}, \Theta_{2}^{v}, \theta_{2}\right)$ that solves (A-53). The production manager revises beliefs to $\mu_{1}\left(\theta_{2} \mid \theta_{1},\left(\Theta_{1}^{u}, \Theta_{2}^{v}\right)\right)=f_{2}\left(\theta_{2}\right)\left(\int_{t \in S\left(\Theta_{1}^{u}, \Theta_{2}^{v}\right)} f_{2}(t) d t\right)^{-1}$ and accepts the price offer if and only if $\theta_{1} \leq \dot{\theta}_{1}\left(\Theta_{1}^{u}, p^{1}\left(\Theta_{1}^{u}, \Theta_{2}^{v}, \theta_{2}\right)\right)$. Using (A-51), there will be internal trade if $p^{1}\left(\Theta_{1}^{u}, \Theta_{2}^{v}, \theta_{2}\right) \geq C^{*}\left(\Theta_{1}^{u}, \theta_{1}\right)$. Consider (A-53), reproduced below:

$$
\max _{p_{1} \geq 0}\left\{\left(F_{1}\left(\dot{\theta}_{1}\left(\Theta_{1}^{u}, p^{1}\right)\right)-F_{1}\left(\bar{\theta}_{1}^{u-1}\right)\right)\left(R^{*}\left(\Theta_{2}^{v}, \theta_{2}\right)-p^{1}\right)\right\} .
$$

Since $S\left(\Theta_{1}^{u}, \Theta_{2}^{v}\right)$ is non-empty, for a non-empty subset of $\theta_{1} \in \Theta_{1}^{u}, R^{*}\left(\Theta_{2}^{v}, \theta_{2}\right)>C^{*}\left(\Theta_{1}^{u}, \theta_{1}\right)$. Thus, for a non-empty subset of $\theta_{1} \in \Theta_{1}^{u}, C^{*}\left(\Theta_{1}^{u}, \theta_{1}\right) \leq p^{1}\left(\Theta_{1}^{u}, \Theta_{2}^{v}, \theta_{2}\right)<R^{*}\left(\Theta_{2}^{v}, \theta_{2}\right)$ (this gives a strictly positive value of the objective in (A-53); setting the price outside these boundaries gives a zero-value objective). Thus, with strictly positive probability, there is internal trade under the PBE of negotiated transfer pricing in the "no-trade" inefficiency region.

The subset of the set with trade under negotiated pricing in the cost-based "no-trade" inefficiency region is independent of $\delta$ (because, at $n=2$, there is no trade at intervention stage). Thus, for a high enough $\delta \in\left[\max \left\{\delta^{\prime}, \delta^{\prime \prime}\right\},<1\right)$, the value of this trade to the firm strictly exceeds the opportunity cost from delay. 


\section{References}

Arya, A., Fellingham, J., Glover, J. and Sivaramakrishnan, K., 2000. Capital budgeting, the hold-up problem, and information system design. Management Science 46, 205-216.

Atkinson, A. A. 1987. Intra-firm cost and resource allocations: Theory and practice. Toronto: Canadian Academic Accounting Association.

Baldenius, T., 2000. Intrafirm trade, bargaining power and specific investments. Review of Accounting Studies 5, 27-56.

Baldenius, T., Melumad, N. D. and Reichelstein, S., 2003. Integrating managerial and tax objectives in transfer pricing. Working Paper, Columbia University.

Baldenius, T., Reichelstein, S. and Sahay, S. A., 1999. Negotiated versus cost-based transfer pricing. Review of Accounting Studies 4, 67-91.

Brickley, J. A., Smith, C. W. and Zimmerman, J. L. 2004. Managerial economics and organizational architecture. (3rd ed.). New York, NY.: McGraw-Hill Irwin.

Cairncross, F., 2000. A survey of e-management. The Economist November 11, 2000, S1-S40.

Christie, A. A., Joye, M. P. and Watts, R. L., 2003. Decentralization of the firm: Theory and evidence. Journal of Corporate Finance 9, 3-36.

Copithorne, L. W., 1971. International corporate transfer prices and government policy. Canadian Journal of Economics 4, 324-341.

Demsetz, H., 1988. The theory of the firm revisited. Journal of Law, Economics, and Organization 4, 141161.

Demski, J. S. and Sappington, D., 1984. Optimal incentive contracts with multiple agents. Journal of Economic Theory 33, 152.

Edlin, A. and Reichelstein, S., 1995. Specific investment under negotiated transfer pricing: An efficiency result. The Accounting Review 70, 275-291.

Ernst \& Young. 1999. Transfer pricing global survey: Practices, perceptions and trends in 19 countries for 2000 and beyond. New York, NY.: Ernst \& Young International, Ltd.

Fudenberg, D. and Tirole, J. 1991. Game theory. Cambridge, Massachusetts: MIT Press.

Guesnerie, R. and Laffont, J.-J., 1984. A complete solution to a class of principal-agent problems with an application to the control of a self-managed firm. Journal of Public Economics 25, 329.

Halperin, R. and Srinidhi, B., 1987. The effects of the united-states income-tax regulations transfer pricing rules on allocative efficiency. Accounting Review 62, 686-706.

Harris, D. G. and Sansing, R. C., 1998. Distortions caused by the use of arm's-length transfer prices. Journal of the American Taxation Association 20, 40.

Hirshleifer, J., 1956. On the economics of transfer pricing. Journal of Business 29, 172-184.

Horst, T., 1971. The theory of the multinational firm: Optimal behavior under different tariff and tax rates. Journal of Political Economy 79, 1059.

Jensen, M. C. and Meckling, W. 1992. Specific and general knowledge and organizational structure. In Werin, L. and Wijkander, H. (Eds.), Main currents in contract economics. Oxford, UK: Basil Blackwell Press.

Kaplan, R. S. and Atkinson, A. A. 1998. Advanced management accounting. (Vol. Third Edition). Englewood Cliffs, NJ: Prentice-Hall. 
Kirby, A. J., Reichelstein, S., Sen, P. K. and Paik, T.-Y., 1991. Participation, slack, and budget-based performance evaluation. Journal of Accounting Research 29, 109-128.

Melumad, N., Mookherjee, D. and Reichelstein, S., 1992. A theory of responsibility centers. Journal of Accounting and Economics 15, 445-484.

Mirrlees, J. 1986. The theory of optimal taxation. In Arrow, K. J. and Intriligator, M. D. (Eds.), Handbook of public economics, Vol. III: 1197-1249. Amsterdam: North-Holland.

Mishra, B. and Vaysman, I., 2001. Delegating investment decisions. Working Paper, INSEAD and University of Texas at Dallas.

Myerson, R. B., 1981. Optimal auction design. Mathematics of Operations Research 6, 58-73.

Narayanan, V. G. and Smith, M., 2000. Impact of competition and taxes on responsibility center organization and transfer prices. Contemporary Accounting Research 17, 497.

Price Waterhouse. 1984. Transfer pricing practices of American industry. New York: Price Waterhouse.

PR-Newswire, 2002. Information systems upgrade at Hershey foods powers business transformation. PR Newswire Association, Inc. August, 29.

Samuelson, L., 1982. The multinational firm with arm's length transfer price limits. Journal of International Economics 13, 365.

Sansing, R., 1999. Relationship specific investments and the transfer pricing paradox. Review of Accounting Studies 4, 119-134.

Sappington, D. E. M., 1986. Commitment to regulatory bureaucracy. Information Economics and Policy 2, 243-258.

Simons, R. 2000. Performance measurement \& control systems for implementing strategy. Upper Saddle River, NJ.: Prentice-Hall.

Sircar, S., Turnbow, J. L. and Bordoloi, B., 2000. A framework for assessing the relationship between information technology investments and firm performance. Journal of Management Information Systems 16, 69-97.

Smith, M. J., 2002. Ex ante and ex post discretion over arm's length transfer prices. Accounting Review 77,161 .

Springsteel, I., 1999. Separate but unequal. CFO Magazine August, 89-91.

Tang, R. Y. W. 1993. Transfer pricing in the 1990s: Tax and management perspectives.: Quorum Books, Westport, Conn.

Vancil, R. F. 1978. Decentralization: Managerial ambiguity by design. Homewood, IL.: Dow Jones-Irwin.

Vaysman, I., 1996. A model of cost-based transfer pricing. Review of Accounting Studies 1, 73-108.

Vaysman, I., 1998. A model of negotiated transfer pricing. Journal of Accounting and Economics 25, 349384.

Vaysman, I., 2005. Bargaining in firms. Working Paper, INSEAD, France. 